San Jose State University

SJSU ScholarWorks

Master's Theses

Master's Theses and Graduate Research

Spring 2013

\title{
System Level Modeling and Circuit Design for Low Voltage CMOS Equalizer for Coaxial Cable for Video Application
}

Han Zhang

San Jose State University

Follow this and additional works at: https://scholarworks.sjsu.edu/etd_theses

\section{Recommended Citation}

Zhang, Han, "System Level Modeling and Circuit Design for Low Voltage CMOS Equalizer for Coaxial Cable for Video Application" (2013). Master's Theses. 4325.

DOI: https://doi.org/10.31979/etd.bd7q-3bja

https://scholarworks.sjsu.edu/etd_theses/4325

This Thesis is brought to you for free and open access by the Master's Theses and Graduate Research at SJSU ScholarWorks. It has been accepted for inclusion in Master's Theses by an authorized administrator of SJSU ScholarWorks. For more information, please contact scholarworks@sjsu.edu. 


\title{
SYSTEM-LEVEL MODELING AND CIRCUIT DESIGN FOR LOW VOLTAGE CMOS EQUALIZER FOR COAXIAL CABLE FOR VIDEO APPLICATION
}

\author{
A Thesis \\ Presented to \\ The Faculty of the Department of Electrical Engineering \\ San José State University \\ In Partial Fulfillment \\ of the Requirements for the Degree \\ Master of Science
}

by

Han Zhang

May 2013 
(C) 2013

Han Zhang

ALL RIGHT RESERVED 


\title{
SYSTEM-LEVEL MODELING AND CIRCUIT DESIGN FOR LOW VOLTAGE CMOS EQUALIZER FOR COAXIAL CABLE FOR VIDEO APPLICATION
}

\author{
by \\ Han Zhang \\ APPROVED FOR THE DEPARTMENT OF ELECTRICAL ENGINEERING \\ SAN JOSÉ STATE UNIVERSITY
}

May 2013

Dr. Shahab Ardalan

Department of Electrical Engineering

Dr. Sotoudeh Hamedi-Hagh

Department of Electrical Engineering

Prof. Morris Jones

Department of Electrical Engineering 
ABSTRACT

\title{
SYSTEM-LEVEL MODELING AND CIRCUIT DESIGN FOR LOW VOLTAGE CMOS EQUALIZER FOR COAXIAL CABLE FOR VIDEO APPLICATION
}

\author{
by Han Zhang
}

A new method of modeling coaxial cable frequency response with genetic algorithm was introduced. A system-level multi-stages adaptive equalizer model with QFB block was generated and tested with multiple cable models, pathological PRBS-23 data with data rate $1.5 \mathrm{GHz}$ was used. This thesis also provided analysis of influences on output by using different parameters in simulations. Two adaptive equalizer circuits with different pre-amplifiers were implemented in GPDK $45 \mathrm{~nm}$ CMOS technology. Related simulations about adaptive ability, single stage compensation ability, and cascade stages compensation ability were completed. A tradeoff between output eye height and peak-to-peak jitter was discussed based on different simulations. Future work will be digital control circuit implementation, entire circuit fabrication, and testing. 


\section{ACKNOWLEDGEMENTS}

I would like to express my deepest gratitude to my advisor Dr. Shahab Ardalan for his patient guidance and fully support throughout the entire work. Thank you for opening the door of mix signal design and being the constant source of inspiration for me during my master study.

I would also like to thank other members on my thesis committee, Dr. Sotoudeh Hamedi-Hagh and Prof. Morris Jones. Their participation has provided me valuable advises in my research.

Great thanks to my lab mates, Yu Feng, Zain and Alfred. Thanks for all your help. It has been fun working with you guys.

Finally, I am grateful for the support from my parents, my wife Yue Zhao, and my son Kyle Zhang. Thank you for standing beside me all these years and I love you all. 


\section{Table of Contents}

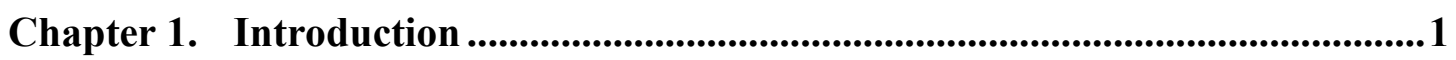

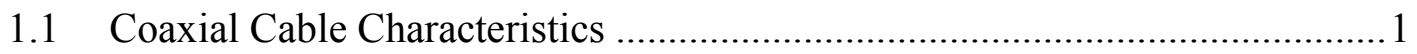

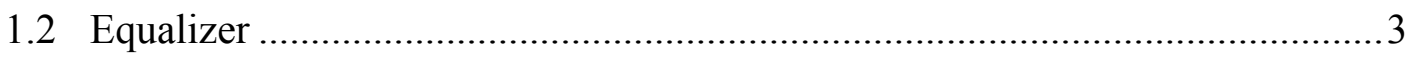

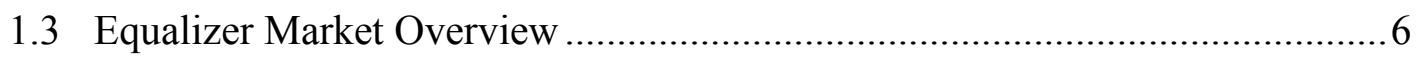

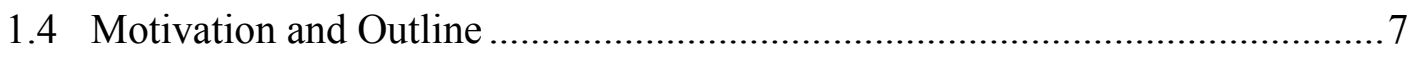

Chapter 2. Equalizer System-level Modeling.........................................................8

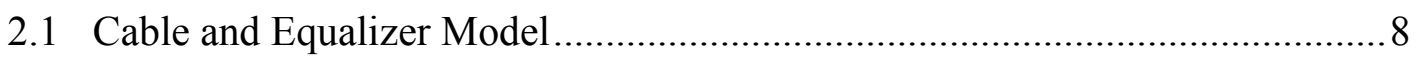

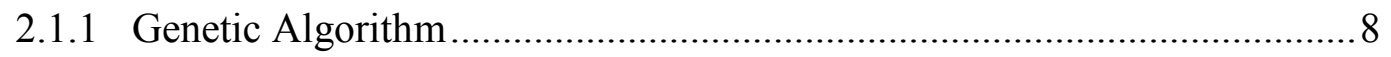

2.1.2 Cable Model Optimization using Genetic Algorithm ............................. 11

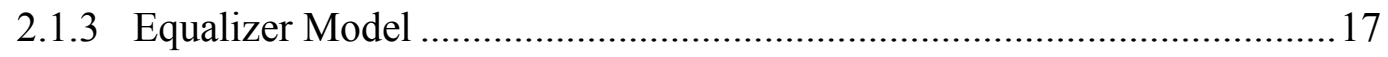

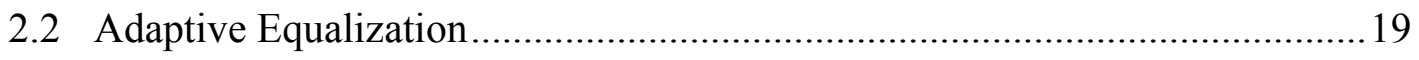

2.3 Quantization Feedback (QFB) Block .......................................................24

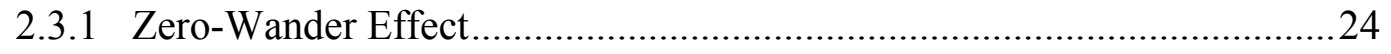

2.3.2 Quantization Feedback Modeling …...................................................26

2.4 Adaptive Equalizer Model with QFB Block ...............................................29

Chapter 3. Circuit Implementation ..................................................................................37

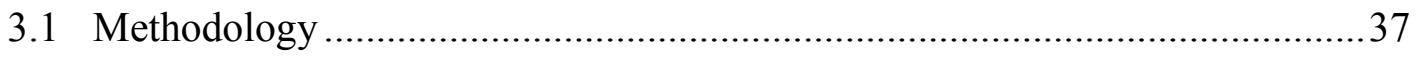

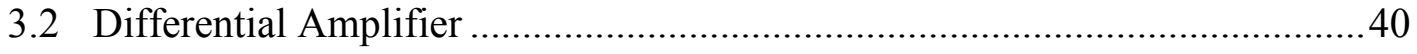

3.3 Wide Swing Current Mirror and Folded Cascode ......................................... 43

3.4 Gilbert Cell and Folded Gilbert Cell ........................................................... 49

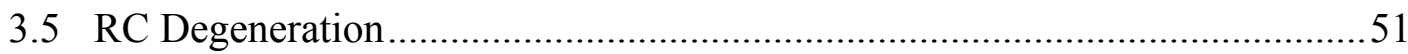

3.6 Folded Cascode Amplifier Type Equalizer Stage ...........................................53

3.7 Differential Amplifier Type Equalizer Stage ….............................................55

3.8 Adaptive Simulation Results and Cascade Simulation Results ......................57

Chapter 4. Conclusion and Future Work.......................................................63 


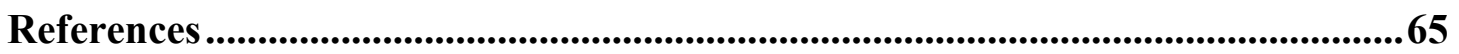

Appendix ...............................................................................................................................67

1. Model of A Single Adaptive Equalizer Stage ...................................................67

2. CMOS Folded Cascode Amplifier in GPDK $45 \mathrm{~nm}$ Technology ........................6 68

3. Folded Cascode Amplifier Type Equalizer Stage ................................................69

4. Differential Amplifier Type Equalizer Stage ................................................. 70 


\section{List of Figures}

Figure 1.1 : A Common Coaxial Cable .....................................................................

Figure 1.2 : Belden 1694A Coaxial Cable Attenuation for Different Cable Lengths....2

Figure 1.3 : Coaxial Cable Output Eye-diagram and Expected Equalized Output.........3

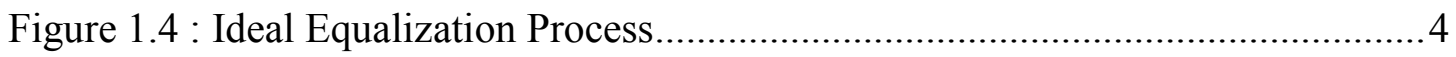

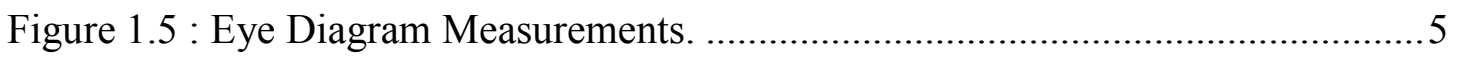

Figure 2.1 : Evolution Process in Genetic Algorithm................................................ 10

Figure 2.2 : Initialization Process of Zero-Pole Vector .............................................. 13

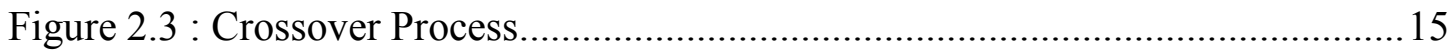

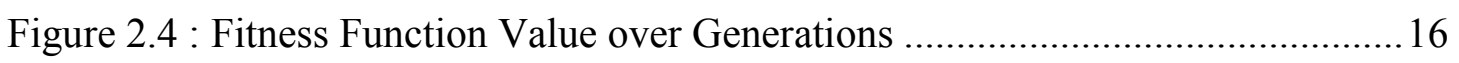

Figure 2.5 : 60 m Belden 1694A Coaxial Cable Model Results................................. 17

Figure 2.6 : 60 m Belden 1694A Coaxial Cable Equalizer Model .............................. 18

Figure 2.7 : Adaptive Equalizer Model with Different Alpha Values........................20

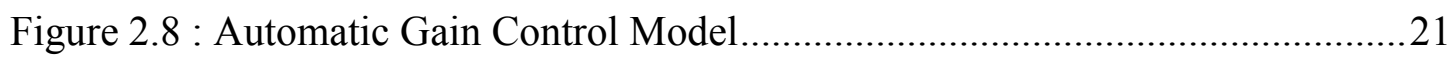

Figure 2.9 : Model of A Single Adaptive Equalizer Stage …...................................22

Figure 2.10 : Input and Output of Adaptive Equalizer Model ....................................24

Figure 2.11 : Pathological Data Combined with PRBS-23 Data Zero-Wander Effect 25

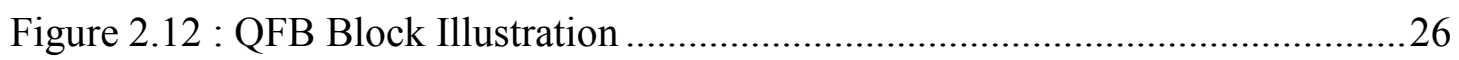

Figure 2.13 : Typical QFB Simulink Model............................................................2

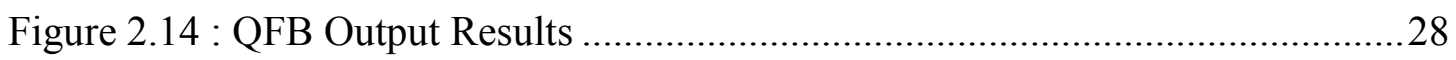

Figure 2.15 : Complete Equalizer System Model .....................................................22

Figure 2.16 : 120 m Belden 1694A Coaxial Cable Equalization Results.....................31

Figure 2.17 : 40 m Belden 1694A Coaxial Cable Equalization Results .......................33

Figure 2.18 : 200 m Belden 1694A Coaxial Cable Equalization Results..................... 34

Figure 2.19 : 240 m Belden 1694A Coaxial Cable Equalization Results.....................36

Figure 2.20 : 20 m Belden 1694A Coaxial Cable Equalization Results ....................... 37

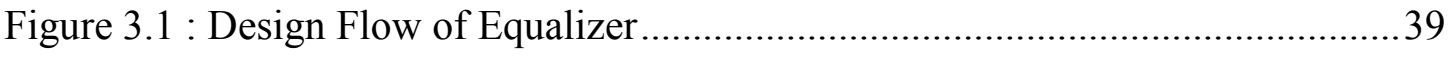


Figure 3.2 : CMOS Differential Amplifier in GPDK $45 \mathrm{~nm}$ Technology 41

Figure 3.3 : Frequency Response of the Differential Amplifier ..................................4 43

Figure 3.4 : Wide Swing Current Mirror .................................................................... 44

Figure 3.5 : Folded Cascode Amplifier.................................................................... 45

Figure 3.6 : CMOS Folded Cascode Amplifier in GPDK 45 nm Technology .............47

Figure 3.7 : Frequency Response of the Folded Cascode Amplifier ...........................48

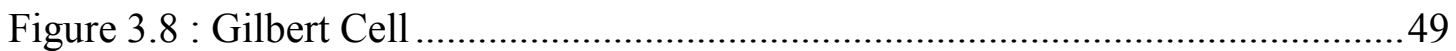

Figure 3.9 : CMOS Folded Gilbert Cell in GPDK 45 nm Technology ........................50

Figure 3.10 : Folded Gilbert Tuning Results ...............................................................51

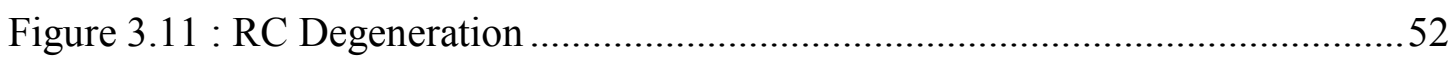

Figure 3.12 : Folded Cascode Amplifier Type Equalizer Stage ..................................54

Figure 3.13 : Differential Amplifier Type Equalizer Stage ........................................56

Figure 3.14 : Differential Amplifier Type Equalizer Stage Adaptive Output .............58

Figure 3.15 : Differential Amplifier Type Equalizer Stage Cascade Results ..............60

Figure 3.16 : Folded Cascode Amplifier Type Equalizer Stage Cascade Results .......62 


\section{List of Tables}

Table 1. Specifications of Equalizers from Different Companies................................6

Table 2. Transistor Sizes and Devices Parameters of $45 \mathrm{~nm}$ Differential Amplifier....42

Table 3. Transistor Sizes in Folded Cascode and Wide Swing Current Mirror............47

Table 4. Target Frequency Response for $80 \mathrm{~m}$ Belden 1694A Coaxial Cable...............53

Table 5. Targeting Frequency Response and Circuit Frequency Response of Differential

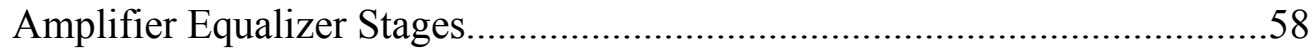

Table 6. Targeting Frequency Response and Circuit Frequency Response of Folded Cascode Amplifier Equalizer Stages............................................................61 


\section{Chapter 1. Introduction}

\subsection{Coaxial Cable Characteristics}

Coaxial cables are normally composed of four layers, from inside to outside, there is an inner conductor core, an inner dielectric insulator layer, a conducting shield layer, and an insulating outer jacket.

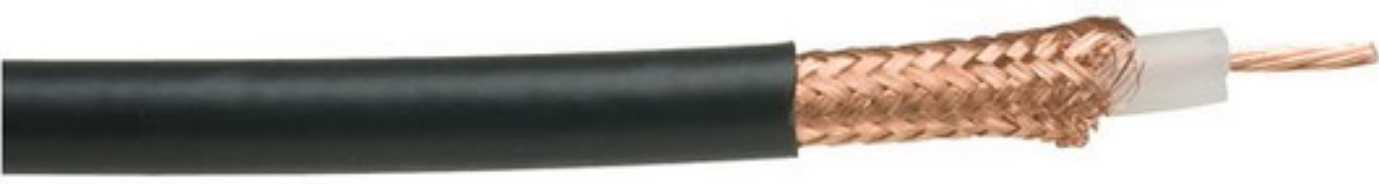

Figure 1.1: A Common Coaxial Cable

Coaxial cables are commonly used as transmission lines for radio, video, measurement, and data signals. Due to the DC resistance of the center conductor and dissipation factor of the dielectric material [1], one typical characteristic of the coaxial cables is cable loss. This can be modeled as a function of signal frequency and cable length [2]:

$$
C(f, l)=e^{-k_{s} l(1+j) \sqrt{f}-k_{d} l f}
$$

where $k_{s}$ and $k_{d}$ are the cable constants, $f$ is signal frequency, and $l$ is the cable 
length. According to Eq. (1.1), cable loss increases while cable length increases or signal frequency increases. A Belden 1694A coaxial cable was used to generate the relationship between cable loss, signal frequency, and cable length. This relationship is shown in Figure 1.2.

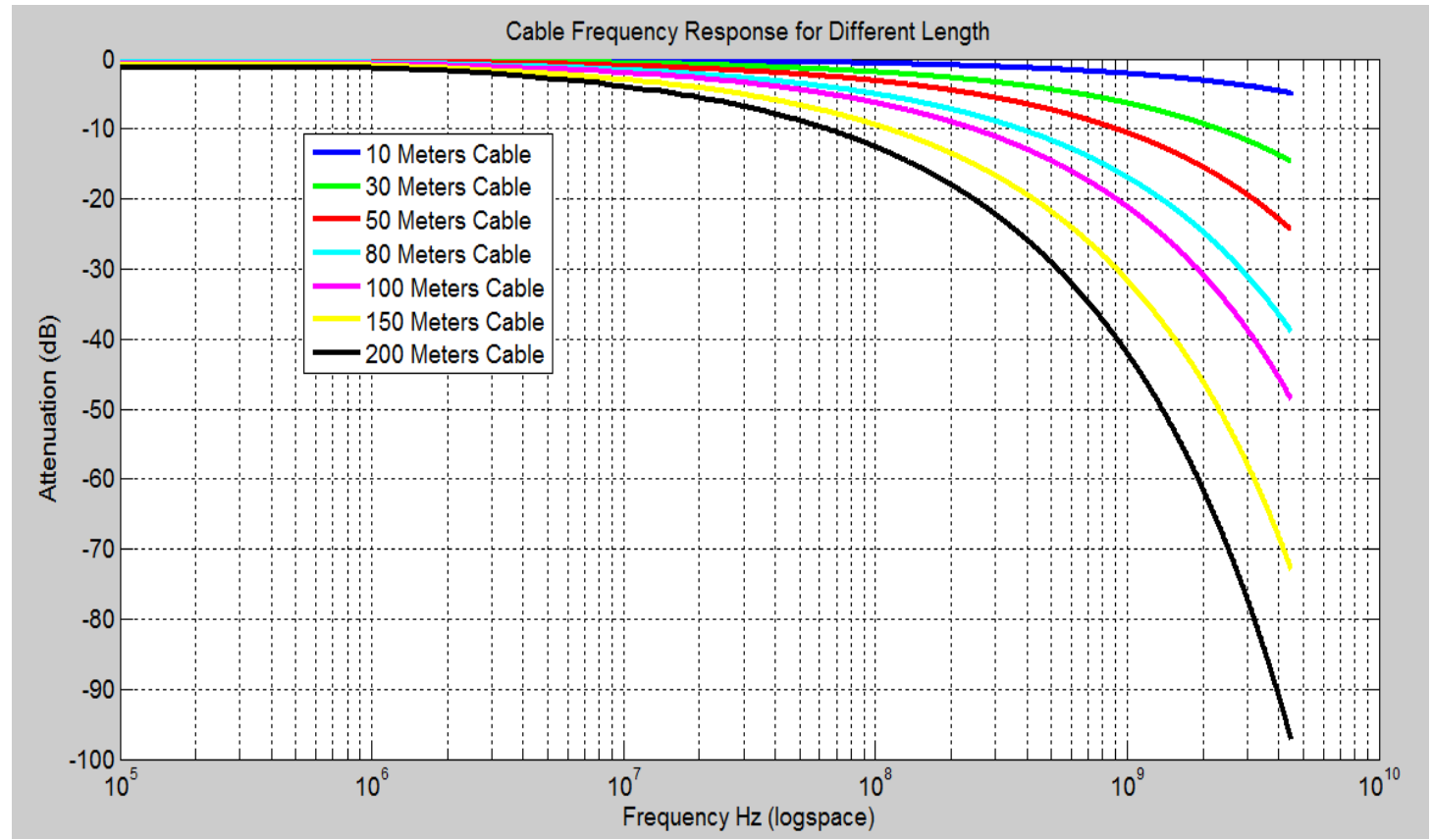

Figure 1.2: Belden 1694A Coaxial Cable Attenuation for Different Cable Lengths

If an $80 \mathrm{~m}$ 1694A coaxial cable were used to transmit a 1080P full HD video signal with a data rate $1.5 \mathrm{Gbps}$, the cable loss will be $20 \mathrm{~dB}$. This loss greatly limits the use of the coaxial cable. 


\subsection{Equalizer}

Cable loss directly causes vertical distortion in the eye diagram and horizontal distortion in the form of jitter [3]. A direct view of these effects and the necessity for equalizers are shown in Figure 1.3 below.

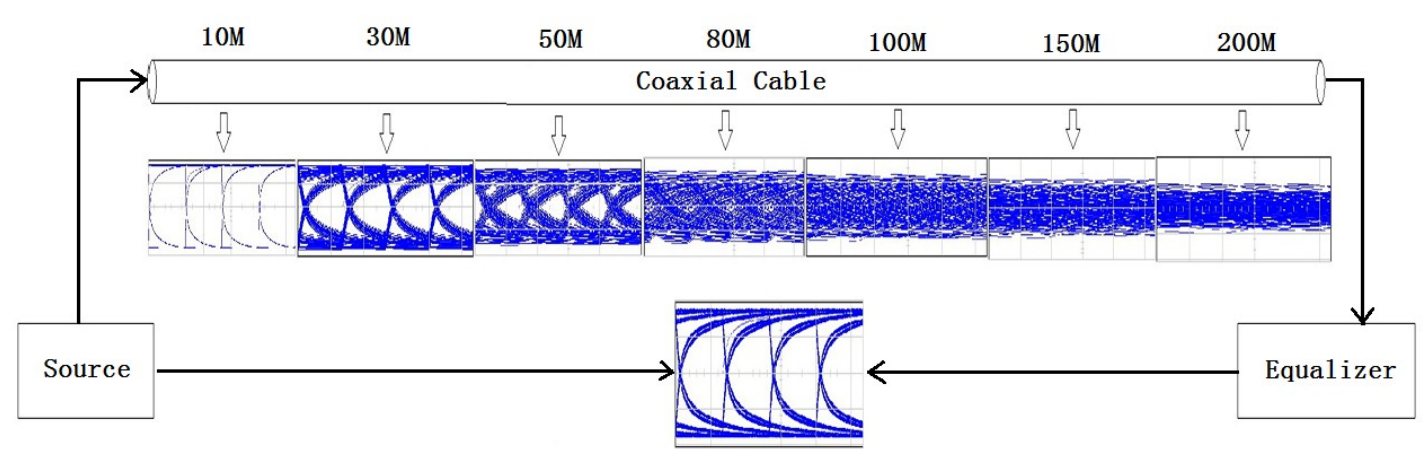

Figure 1.3: Coaxial Cable Output Eye-diagram and Expected Equalized Output

In order to compensate for the cable loss, an equalizer is used. Due to the low-pass characteristics of the cable in frequency domain, an ideal equalizer should have the opposite frequency response, allowing the combined frequency response to be an all-pass [4].

The theoretical transfer function of an equalizer is given by:

$$
E(f, l)=\frac{1}{C(f, l)}
$$

where $C(f, l)$ is the cable loss in terms of frequency and length.

In practice, analog equalizers are designed with a transfer function $E(f, l)$ in the frequency range from $0 \mathrm{~Hz}$ to the signal frequency. High frequency components in the 
signal are amplified whereas low frequency components remain the same. Frequency components higher than the signal frequency should be attenuated to limit high frequency noise.

An ideal equalization process for a $1 \mathrm{GHz}$ signal is shown in Figure 1.4. After equalization, the frequency response from $0 \mathrm{~Hz}$ to $1 \mathrm{GHz}$ has an all-pass characteristic, and displays a low-pass response after $1 \mathrm{GHz}$.

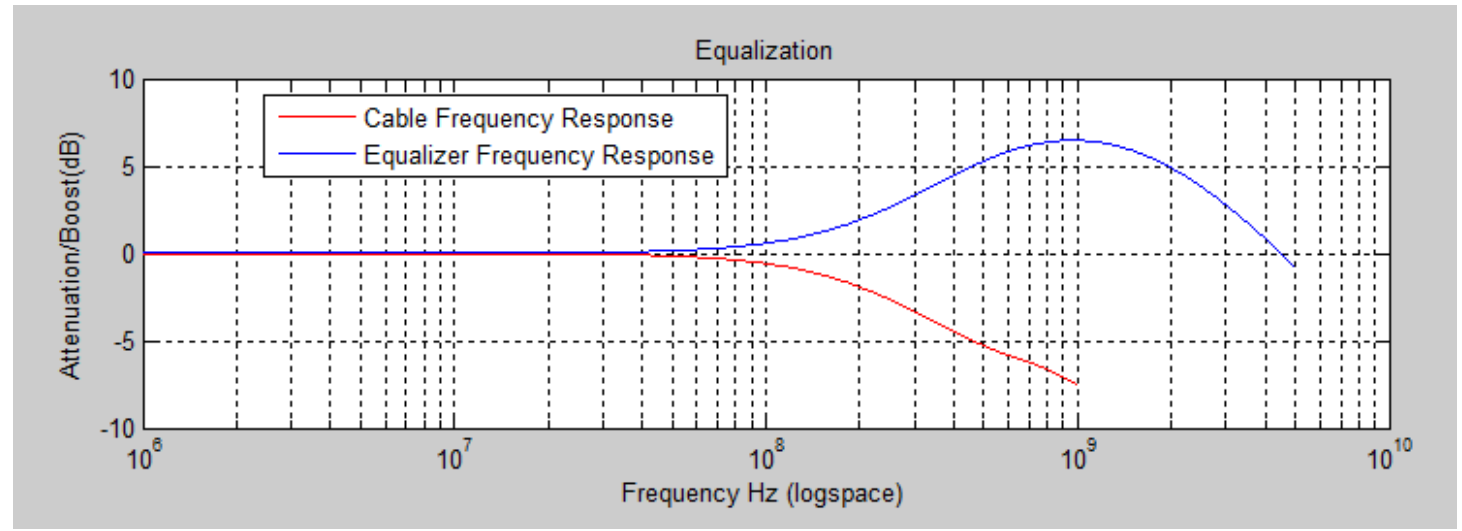

(a)

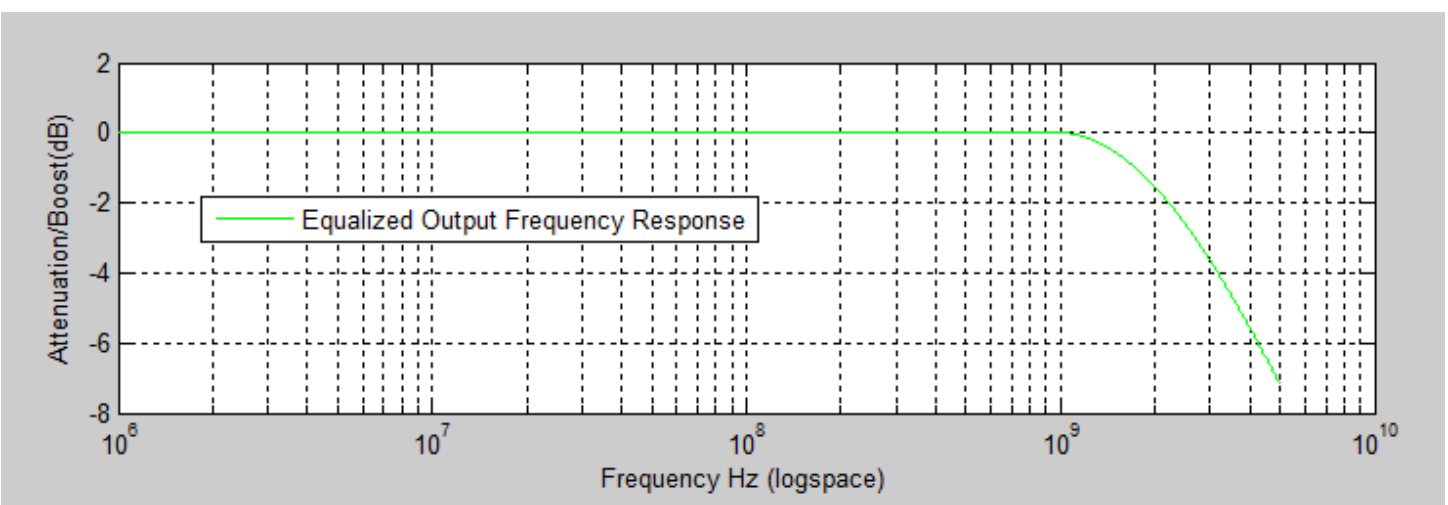

(b)

Figure 1.4: Ideal Equalization Process (a) Cable and Equalizer Frequency Response (b) Combined Frequency Response. 
In the output eye diagram, peak-to-peak jitter and eye height are commonly used as metrics to determine equalizer functionality and performance. Maximum eye height and minimum peak-to-peak jitter is the goal of equalizer design. Eye height is measured in volts. Peak-to-peak jitter is usually represented by a proportion of an unit interval (UI), which quantifies the jitter in terms of a fraction of the ideal bit period [5]. The eye height, peak-to-peak jitter, and UI are shown in Figure 1.5.

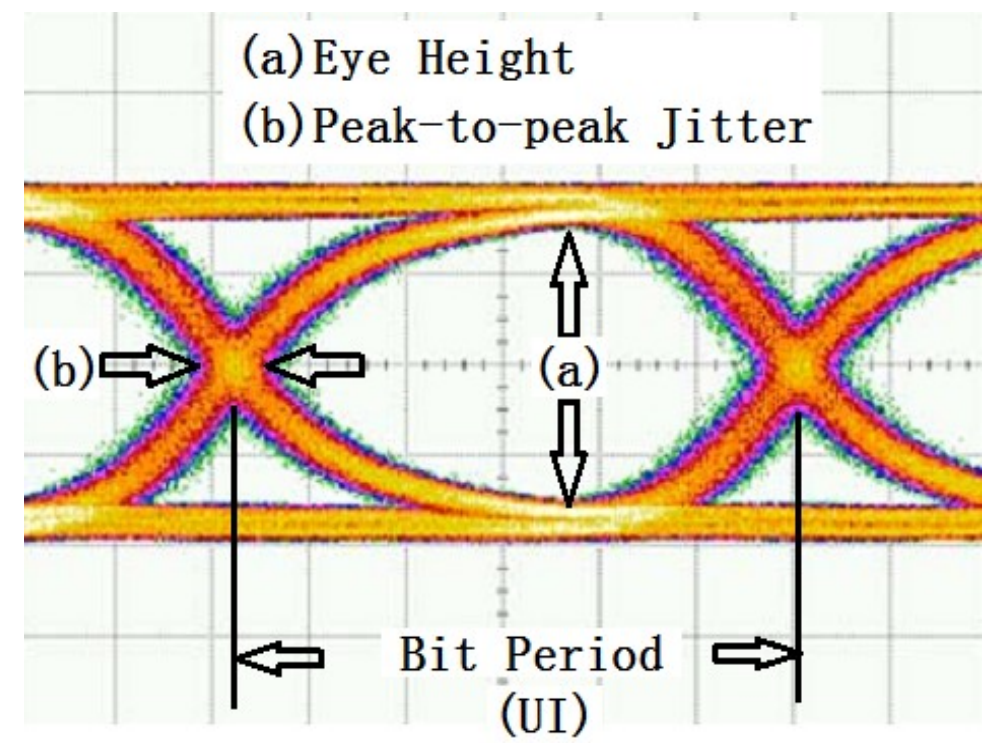

Figure 1.5: Eye Diagram Measurements.

Output eye diagrams from well-designed equalizers should have eye heights close to the original signal, and the peak-to-peak jitter should be less than 0.2 UI. The jitter requirement is strict because a clock and data recovery circuit will be used after the equalizer. 


\subsection{Equalizer Market Overview}

In today's market, most of the coaxial cable equalizers are implemented with Bipolar Junction Transistors (BJT). Table 1 compares six recent products from three major companies.

Table 1. Specifications of Equalizers from Different Companies

\begin{tabular}{|c|c|c|c|c|c|}
\hline Products & Data Rates & $\begin{array}{l}\text { Supply } \\
\text { Voltage }\end{array}$ & Power & Jitter & $\begin{array}{l}\text { Latest } \\
\text { Update }\end{array}$ \\
\hline $\begin{array}{c}\text { DS15EA101 } \\
\text { (National Semi) }\end{array}$ & $\begin{array}{c}150 \mathrm{Mbps} \\
\text { To } \\
1.5+\mathrm{Gbps}\end{array}$ & $\begin{array}{l}\text { Single } \\
3.3 \mathrm{~V}\end{array}$ & $\begin{array}{c}210 \mathrm{~mW} \\
\text { at } 1.5 \\
\text { Gbps }\end{array}$ & $\begin{array}{c}0.25 \mathrm{UI} \\
\text { to } \\
0.4 \mathrm{UI}\end{array}$ & Jan. 2012 \\
\hline $\begin{array}{c}\text { DS30EA101 } \\
\text { (National Semi) }\end{array}$ & $\begin{array}{c}150 \mathrm{Mbps} \\
\text { To } \\
3.125 \mathrm{Gbps}\end{array}$ & $\begin{array}{l}\text { Single } \\
2.5 \mathrm{~V}\end{array}$ & $\begin{array}{r}115 \mathrm{~mW} \\
\text { Typical }\end{array}$ & $\begin{array}{l}0.2 \mathrm{UI} \\
\text { to } \\
0.35 \mathrm{UI}\end{array}$ & Feb. 2012 \\
\hline $\begin{array}{c}\text { M21424 } \\
\text { (Mindspeed) }\end{array}$ & $\begin{array}{c}143 \mathrm{Mbps} \\
\text { to } \\
2970 \mathrm{Mbps}\end{array}$ & $\begin{array}{l}2.5 \mathrm{~V} \\
\text { or } \\
3.3 \mathrm{~V}\end{array}$ & $\begin{array}{c}175 \mathrm{~mW} \\
\text { to } \\
312 \mathrm{~mW}\end{array}$ & $\begin{array}{l}0.2 \mathrm{UI} \\
\text { to } \\
0.35 \mathrm{UI}\end{array}$ & Mar. 2010 \\
\hline $\begin{array}{l}\text { GS3441 } \\
\text { (Semtech) }\end{array}$ & $\begin{array}{c}270 \mathrm{Mbps} \\
\text { to } \\
2.97 \mathrm{Gbps}\end{array}$ & $\begin{array}{c}\text { Single } \\
3.3 \mathrm{~V}\end{array}$ & $\begin{array}{r}237 \mathrm{~mW} \\
\text { Typical }\end{array}$ & $\mathrm{n} / \mathrm{a}$ & Jan. 2010 \\
\hline $\begin{array}{l}\text { GS3440 } \\
\text { (Semtech) }\end{array}$ & $\begin{array}{c}270 \mathrm{Mbps} \\
\text { to } \\
2.97 \mathrm{Gbps}\end{array}$ & $\begin{array}{l}\text { Single } \\
3.3 \mathrm{~V}\end{array}$ & $\begin{array}{r}175 \mathrm{~mW} \\
\text { Typical }\end{array}$ & $\mathrm{n} / \mathrm{a}$ & $\begin{array}{l}\text { Aug. } \\
2011\end{array}$ \\
\hline $\begin{array}{l}\text { GS2984 } \\
\text { (Semtech) }\end{array}$ & $\begin{array}{c}270 \mathrm{Mbps} \\
\text { to } \\
2.97 \mathrm{Gbps}\end{array}$ & $\begin{array}{l}\text { Single } \\
3.3 \mathrm{~V}\end{array}$ & $\begin{array}{r}195 \mathrm{~mW} \\
\text { Typical }\end{array}$ & $\begin{array}{l}0.2 \mathrm{UI} \\
\text { to } \\
0.3 \mathrm{UI}\end{array}$ & Mar. 2010 \\
\hline
\end{tabular}


All of these coaxial cable equalizers are implemented with BJTs, and their supply voltage varies from $2.5 \mathrm{~V}$ to $3.3 \mathrm{~V}$. All designs are adaptive to different data rates and cable lengths.

\subsection{Motivation and Outline}

Present-day supply voltages of digital circuits are scaling with reductions in transistor channel lengths. The supply voltage for a $45 \mathrm{~nm}$ complementary metal-oxide semiconductor (CMOS) process is $1 \mathrm{~V}$. The equalizer interfaces between the analog transmission line and the digital circuit, so implementing designs in CMOS is advantageous. When the supply voltages of the equalizer and digital circuits are compatible, the receiver system does not require separate power supplies. CMOS design also allows for better portability across processes.

In this thesis, a system-level adaptive coaxial cable equalizer with automatic gain control (AGC) function and quantization feedback (QFB) block was modeled in Simulink. Using a Belden 1694A coaxial cable as the transmission line, the equalizer model was able to adaptively compensate for the cable loss for different cable lengths. The maximum cable length it can compensate for was $240 \mathrm{~m}$. Circuits were then designed and simulated using GPDK $45 \mathrm{~nm}$ CMOS technology. This work aimed for applications with a full HD 1080P video signal, so a 1.5 GHz PRBS-23 data with pathologic patterns stream was used in both modeling and circuit design. 


\section{Chapter 2. Equalizer System-level Modeling}

\subsection{Cable and Equalizer Model}

The genetic algorithm is an evolutionary algorithm in inartificial intelligence filed and commonly used for optimization problems. It is used for problems without clear mathematic expressions. It is usually used in a continuous system or at least in a system with continuous-like performance.

\subsubsection{Genetic Algorithm}

Several concepts need to be introduced before starting the algorithm. A candidate solution is referred to as a chromosome and a group of them is called a population or a generation. The number of chromosomes in a population should be selected based on the application. Larger population reduces the number of generations needed to finish the evolution while requiring an increase in calculation time for each generation. A fitness function is used to evaluate the optimization fitness of every chromosome in the population. Fitness functions should be well chosen since final solutions are selected through a fitness-based process. Evolution is defined as the process that generates a new population from the existing population.

A typical genetic algorithm starts with an initialization process, where the initial population is randomly generated in an area where optimal solutions are likely to be found based on a reasonable prediction. 
To end the evolution process, a termination condition should be defined such as finding a solution satisfying minimum criterion. In the case where no improvement is made after some number of generations, parameters can be modified and resume the evolution process to seek fitter solutions.

The evolution process, as the key process of the genetic algorithm, is illustrated in Figure 2.1. After evaluating all the chromosomes with the fitness function, if a terminal condition is not reached, the chromosomes are divided into three groups: fittest chromosome group, normal chromosome group, and least fit chromosome group. The fittest group and the least fit group should take up only a small proportion of the entire population. This division is the selection process.

The least fit chromosome group is removed from the population because it has the worst results. Crossover or recombination process is provided to the fittest chromosome group for generating new solutions, which helps to maintain a certain number of chromosomes in the population and raises the probability of generating fitter solutions. A pair of parent solutions is used to produce a child solution or a pair of children solutions. In the pair of children solutions, one child shares some components from each parent, and the other child has the remainder. The crossover process continues until a new population of appropriate size is generated. 


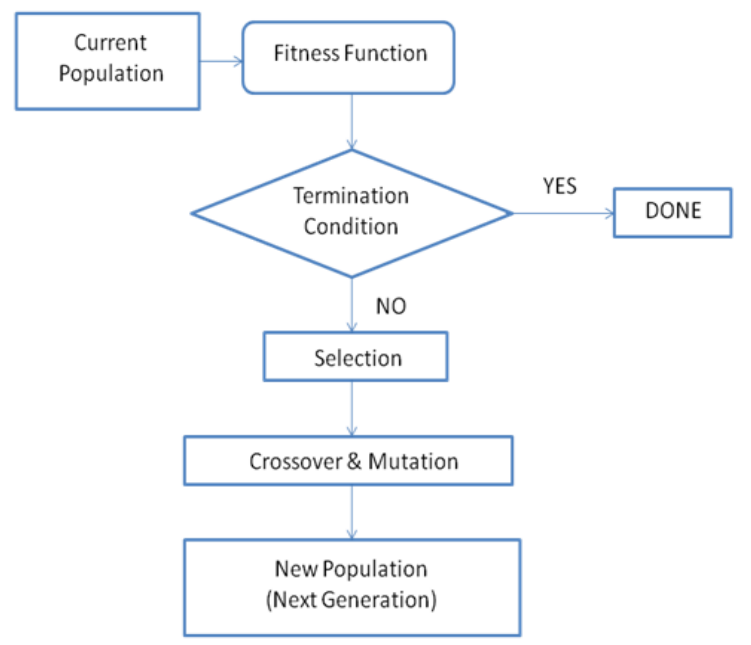

Figure 2.1: Evolution Process in Genetic Algorithm

A mutation process is provided to the normal chromosome group, since chromosomes in this group have potential to become either more or less fit. All characteristics of the chromosomes in the normal chromosome group mutate at a proper mutation rate based on a given mutation probability. Mutation process replaces a part of the chromosomes, but it does not change the population size. Mutation rate and mutation probability should be chosen carefully. A high mutation rate causes large variations between new and old chromosomes, which lower the probability of finding fitter solutions. However, low mutation rate slows down the overall speed of convergence to fitter solutions. Mutation probability value has less effect than mutation rate [6].

After the selection, crossover, and mutation processes, a new population is generated. Since the least fit group has been removed, the fittest group has been kept and enlarged by the crossover process, and normal group has been mutated, there is a 
higher probability for the new population to meet the termination condition. While progressing from generation to generation, the terminal condition will be met eventually or the evolution will stop at a certain level. Outside stimulus is required to continue the evolution after this point.

The genetic algorithm is commonly used for single object optimization. The complexity of the genetic algorithm facing multiple objects increases significantly with the number of objects, especially when the objects are dependent on each other. In this thesis, the genetic algorithm was used to optimize the cable system function.

\subsubsection{Cable Model Optimization using Genetic Algorithm}

Cable characteristics versus cable length and signal frequency can be obtained from the Belden 1694A coaxial cable data sheet. To model the cable, a transfer function was generated with similar frequency response characteristics in a proper frequency range using a genetic algorithm.

A transfer function can be represented by a vector of zeros and poles in units of $\mathrm{Hz}$ or $\mathrm{rad} / \mathrm{sec}$. For the initialization process, a zero-pole vector was generated following the steps illustrated in Figure 2.2. In Figure 2.2(a), sweeping the attenuation along the characteristic curve, the first pole was added to the vector when the attenuation reached a certain value. The transfer function with only one pole was plotted as shown in Figure 2.2(b). Sweeping the error between the target characteristics and the transfer 
function, a zero was then added to the vector after an error threshold was met and the new transfer function was plotted in Figure 2.2(c). Whether a zero or a pole was needed depended on the sign of the error between the target characteristics and the transfer function. By repeating this sweeping process, a transfer function with two poles and one zero was generated in Figure 2.2(d). Since a transfer function with only two poles and one zero was not able to adequately match the target characteristics, three extra zero-pole pairs were manually added as shown in Figure 2.2(d). An initial transfer function with multiple zeros and poles was finalized and represented by a zero-pole vector. Considering the vector as one chromosome, a new chromosome was generated by randomly increasing or decreasing each zero and pole value by no more than $5 \%$. Given $N$ total elements consisting of zeros and poles in one vector, then at least $2^{N}$ chromosome were needed to form the initial population. For a better represented initial population $2^{N+1}$ or $2^{N+2}$ can be used.

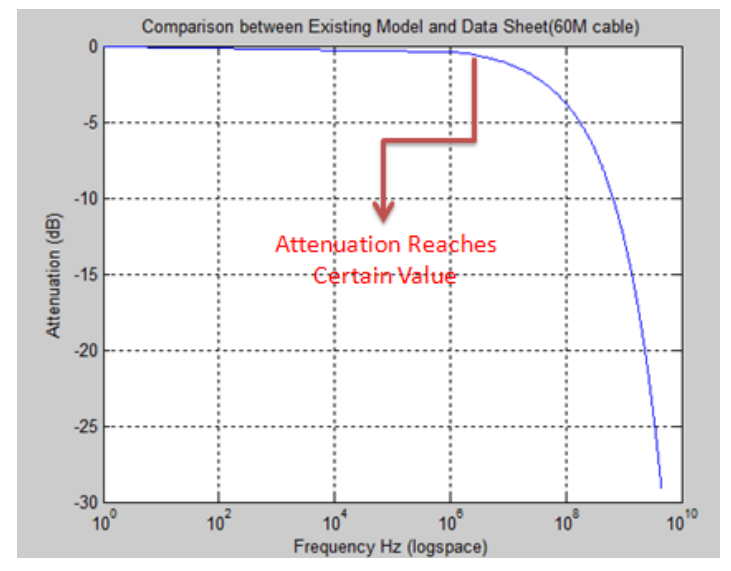

(a) 


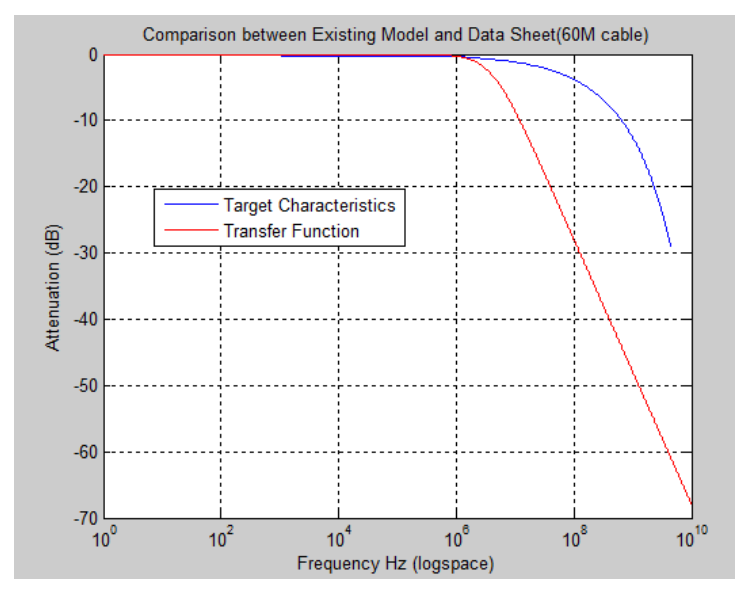

(b)

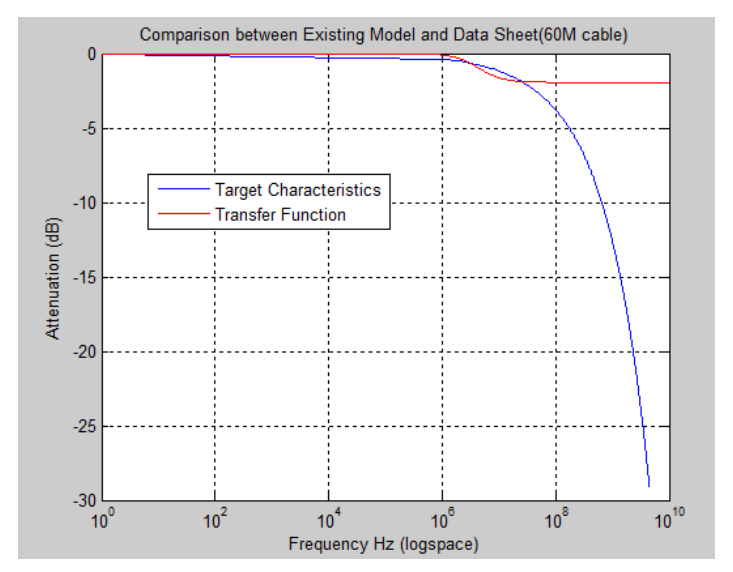

(c)

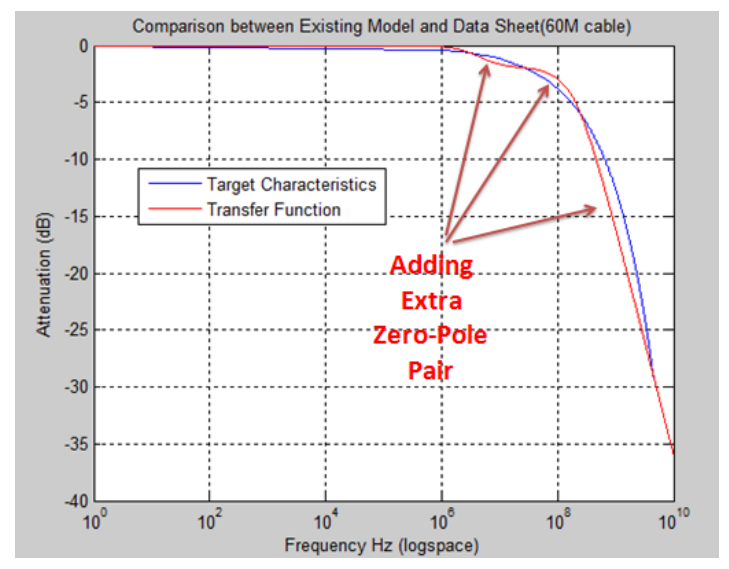

(d)

Figure 2.2: Initialization Process of Zero-Pole Vector (a) Target Characteristics (b) First Pole (c) Adding A Zero (d) Adding A Pole 
After initializing the original population with the initial vector, the fitness function was defined as the maximum absolute value of error between the target characteristic and the transfer function response in the range from $0 \mathrm{~Hz}$ to roughly $4.5 \mathrm{GHz}$. The lowest the fitness function value represented the most fit the transfer function. The termination condition was set to $0.25 \mathrm{~dB}$, implying that when the fitness function value of a vector among the population was smaller than $0.25 \mathrm{~dB}$, the evolution would be terminated and the transfer function represented by this vector was selected as the optimal solution.

According to the fitness function value, the population was divided into three groups: the top $15 \%$ vectors belong to the fittest group, the bottom $15 \%$ are the least fit and will be removed, and the remainder was the normal group.

The crossover process was then provided to the fittest group. Figure 2.3 illustrates how to generate two children vectors from two parent vectors. Elements with odd indices from one parent vector and elements with even indices from the other parent vector were combined to form a new child vector. The remaining elements from these two parent vectors were used to form the other child. Eventually the child vectors had the same number of elements as the parent vectors. Since the fittest chromosomes group used for crossover and the least fit group had same chromosomes amount, the population size remained the same after the crossover process. In this thesis, mutation was not provided to the fittest group since crossover also raised the probability of an optimal solution. In some applications, a smaller mutation rate and 
smaller mutation probability are used for the fittest group in order to increase the evolution speed.

\section{Parent Vectors}

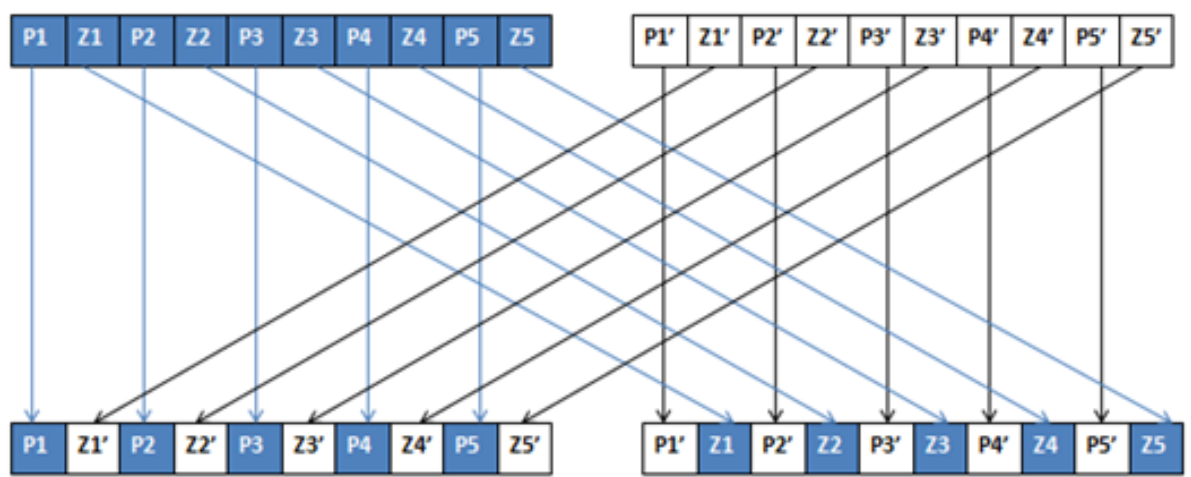

Child Vectors

Figure 2.3: Crossover Process

Mutation was only provided to normal chromosomes in this thesis. The mutation probability was set to 1 , which means every element in each chromosome needs to mutate. Mutation rate was $\pm 5 \%$, which means all zeros and poles values in every chromosomes were randomly increased or decreased by no more than $5 \%$ of their original values.

With all these genetic algorithm operators defined above, the entire genetic algorithm was set up for optimizing the transfer function. A fitness function value versus generation relationship was plotted in Figure 2.4. The fitness function value dropped quickly in the beginning 50 generations and reached a solid bottom in the next 50 generations. This situation suggested that there were not enough zeros and poles in 
a single chromosome.

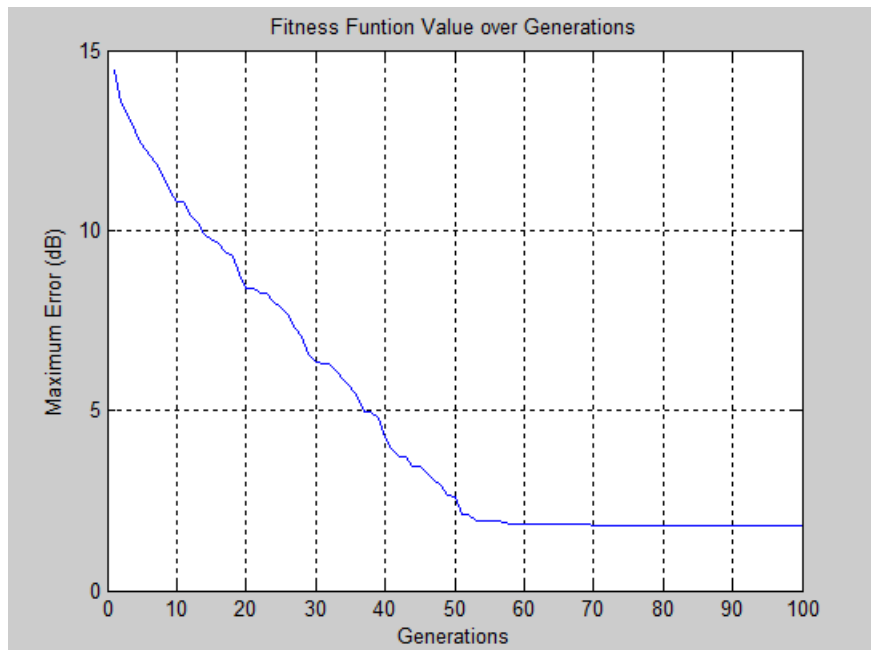

Figure 2.4: Fitness Function Value over Generations

A solution was implemented by checking if the fitness function value had not changed in a certain number of generations. An extra zero-pole pair then need to be added to every chromosome located around where the maximum error between the target process and the transfer function frequency response appears. After adding this pair, the new population was set as the initial population and the genetic algorithm restarted. This process was finished automatically by the program itself and it should be repeated when the fitness function value hit another bottom again.

Using the methods above, a 60 m Belden 1694A coaxial cable model transfer function was optimized to:

$$
\frac{3.03 e-44 s^{5}+1.92 e-34 s^{4}+3.618 e-25 s^{3}+2.368 e-16 s^{2}+5.207 e-08 s+1}{9.032 e-64 s^{7}+2.41 e-53 s^{6}+1.926 e-43 s^{5}+5.705 e-34 s^{4}+7.142 e-25 s^{3}+3.588 e-16 s^{2}+6.167 e-08 s+1}
$$


The frequency response of this transfer function was shown in Figure 2.5. The blue curve was the target characteristics to be modeled, the red curve was the transfer function frequency response generated by genetic algorithm, and the green curve was the error between the target characteristics and the transfer function frequency response. As shown in the Figure, the absolute value of the error was always smaller than $0.25 \mathrm{~dB}$ from $0 \mathrm{~Hz}$ to roughly $4.5 \mathrm{GHz}$.

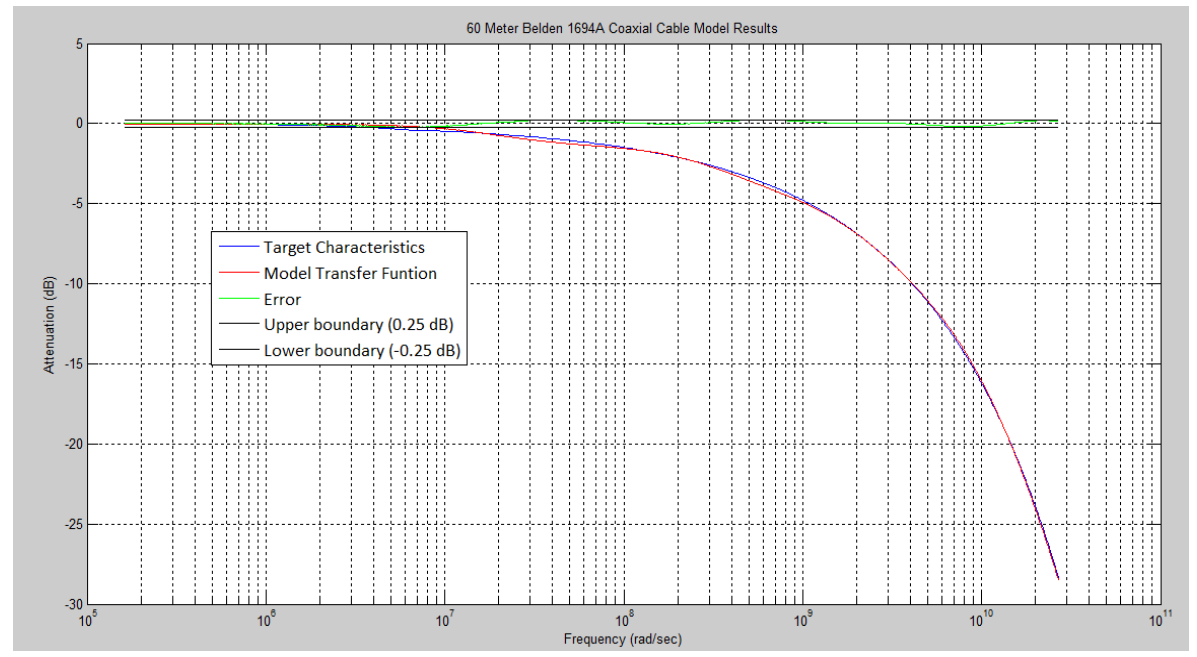

Figure 2.5: 60 m Belden 1694A Coaxial Cable Model Results

The optimal transfer function model for different cable lengths was obtained with same algorithm.

\subsubsection{Equalizer Model}

An equalizer is used to compensate cable loss. Since the cable model had already 
been optimized, the equalizer model was obtained simply by reversing the numerator and denominator in the cable model transfer function. In this case, the error between the cable-equalizer combined system and the all-pass system was also within \pm 0.25 dB. Results similar to the cable model were shown in Figure 2.6.

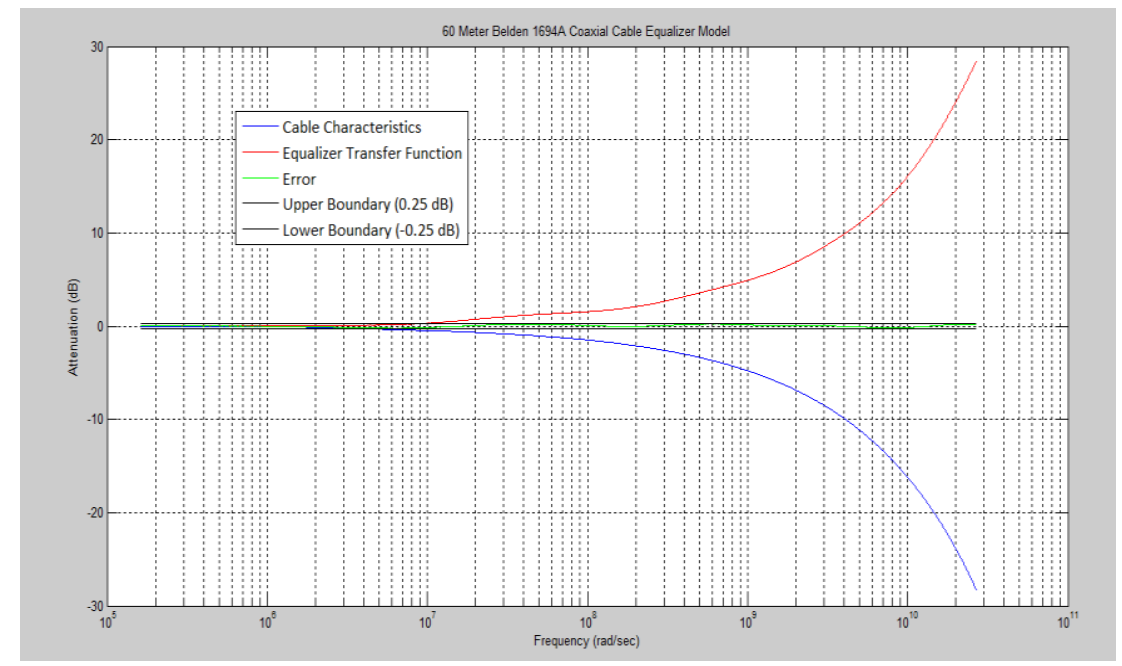

Figure 2.6: 60 m Belden 1694A Coaxial Cable Equalizer Model

Extra poles were needed for the equalizer transfer function at higher frequency in order to attenuate high frequency components after combining with cable system. This was achieved by adding extra poles at higher frequencies in the equalizer transfer function. 


\subsection{Adaptive Equalization}

Since the cable model transfer function generated above only fits an $80 \mathrm{~m}$ Belden 1694A coaxial cable, it is necessary to find an adaptive method for compensating the cable loss for lower cable lengths.

A curve-fitting method was used for adaptive equalization in this thesis. The general transfer function was written as:

$$
E_{q}(s)=1+\alpha H(s)
$$

and $H(s)$ was defined as:

$$
H(s)=\frac{1}{C_{\max }(s)}-1
$$

where $C_{\max }(s)$ was the optimal cable model transfer function for an $80 \mathrm{~m}$ Belden 1694A coaxial cable [7]. When $\alpha=0$, the cable length is 0 , then $E_{q}(s)=1$. This passes the original signal through since there is no cable loss. When $\alpha=1$, the cable length reaches maximum, resulting in $E_{q}(s)=\frac{1}{C_{\max }(s)}$. For any cable length between 0 and $80 \mathrm{~m}$, there is an unique $\alpha$ between 0 and 1 corresponding to it. By properly tuning the value of $\alpha, E_{q}(s)$ is now adaptive for any cable length smaller than the maximum. The equalizer model frequency response with different $\alpha$ values were illustrated in Figure 2.7. There is a nonlinearity in the $\alpha$ versus cable length characteristic. This is usually not an issue since the adaptive loop eventually settles at the optimal point [7]. 


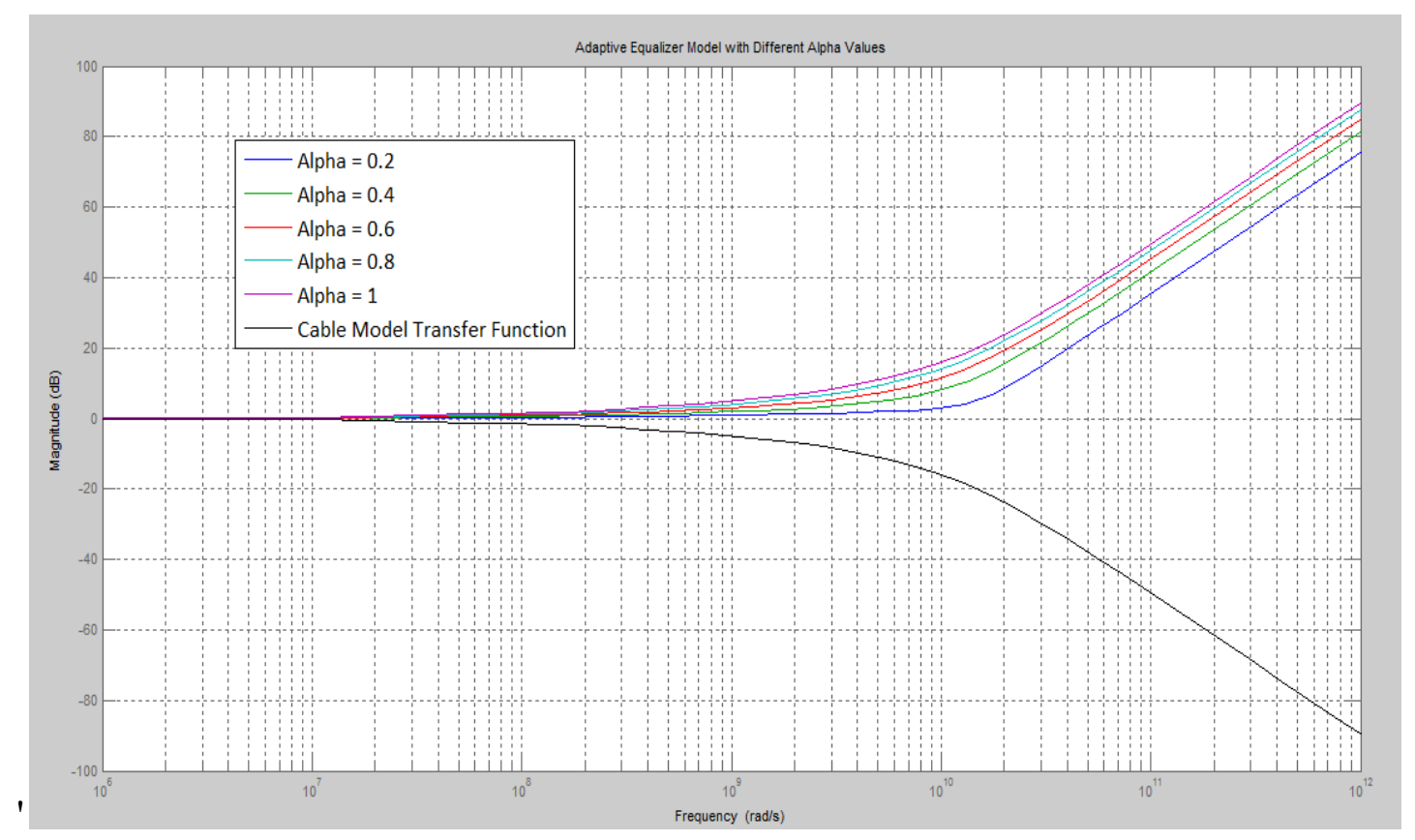

Figure 2.7: Adaptive Equalizer Model with Different Alpha Values

Based on the updated model in Eq. (2.2) and Eq. (2.3), an AGC mechanism was modeled as shown in Figure 2.8. Input signal from cable output was sent together with a sliced version to two equivalent band-pass filters. The lower cutoff frequency should be able to eliminate DC components without causing significant zero-wander effect and the higher cutoff frequency should be just above the signal frequency in order to reduce possible high frequency noise without affecting the signal. The two filtered signals were modified by full-wave rectifiers and then compared. If the power of the amplified signal was higher than the sliced version signal, it suggested that there was a strong overshoot in the amplified signal. The $\alpha$ was then too large for the current cable length and needed to be reduced. The $\alpha$ was set to 1 initially in the model and 
decreased as overshooting was observed. Then the amplified signal and the sliced signal were compared again. This adaptive loop stopped right after power of the amplified signal went lower than the sliced signal. If the power of the amplified signal was lower than the sliced signal when $\alpha$ was at 1 , then extra boosting stages were needed since one single stage can no longer compensate the cable loss completely. The comparison was achieved by an integrator with reset function.

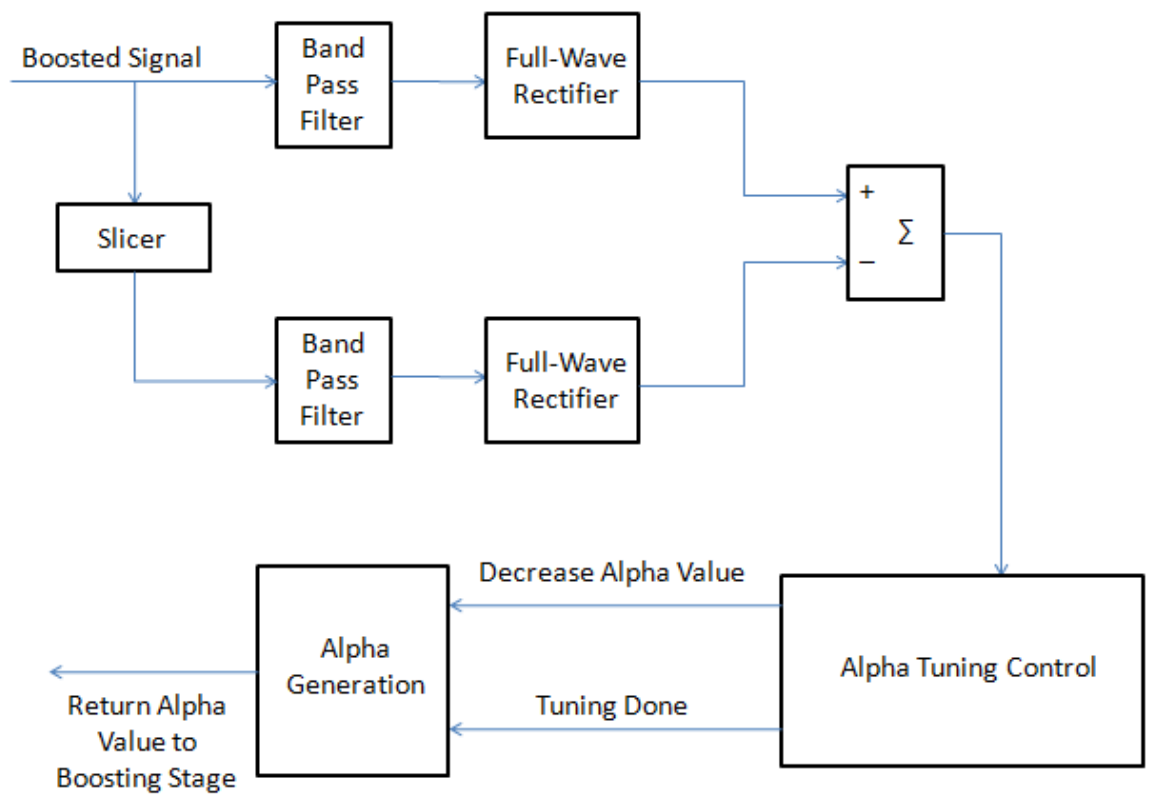

Figure 2.8: Automatic Gain Control Model [2]

A complete model of a single adaptive equalizer stage fit for a $60 \mathrm{~m}$ Belden 1694A coaxial cable was shown in Figure 2.9. A larger version of Figure 2.9(b) was attached in Appendix 1. 


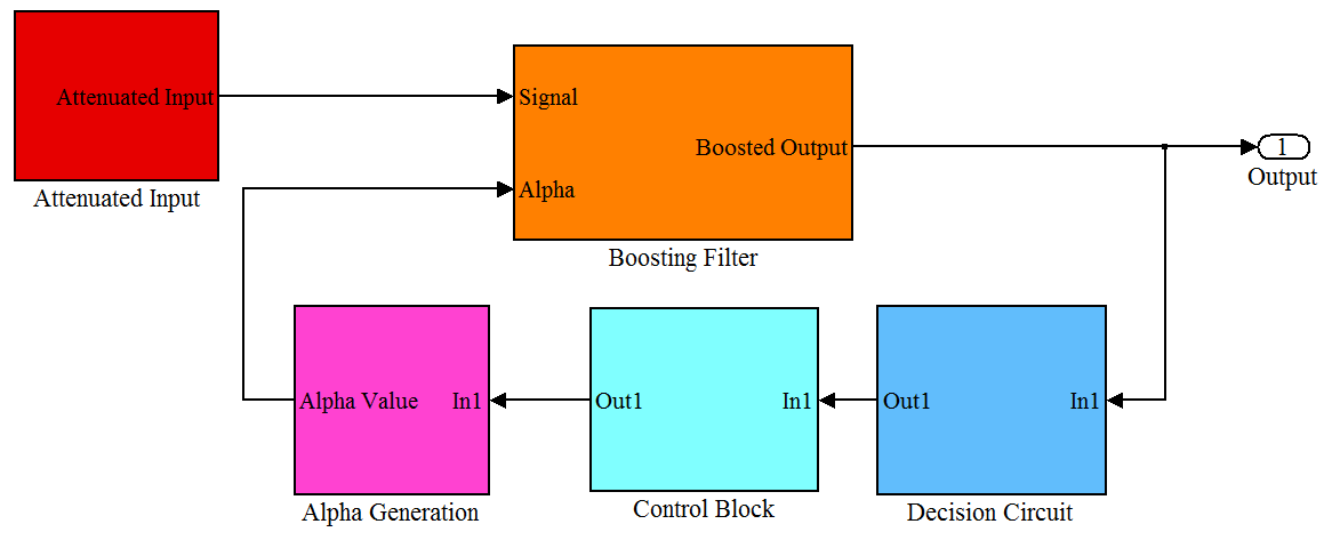

(a)

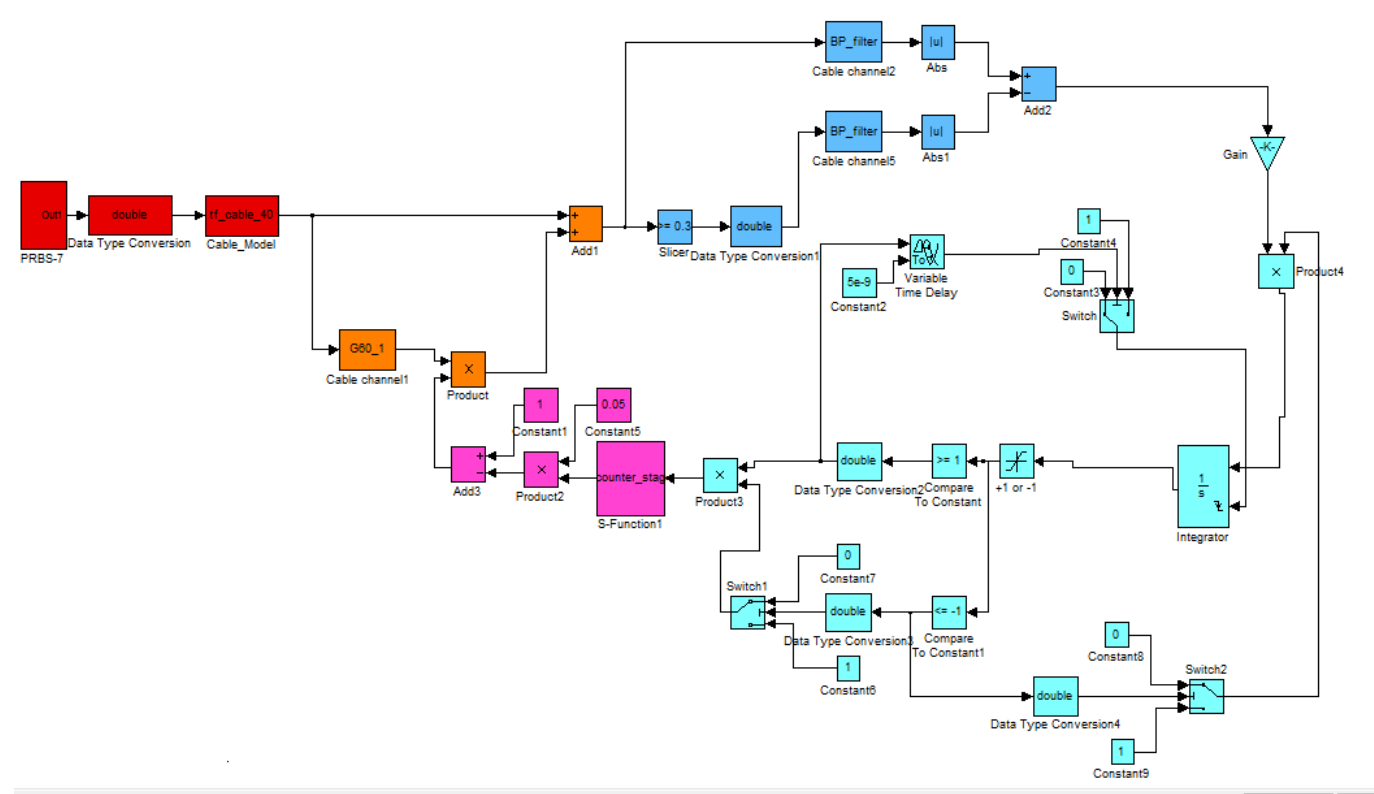

(b)

Figure 2.9: Model of A Single Adaptive Equalizer Stage (a) Block Diagram (b)Entire Model

The red blocks were the PRBS-7 input and the cable model transfer function.

The PRBS-7 data were sent through a $40 \mathrm{~m}$ cable model transfer function. The attenuated output, shown in Figure 2.10(a) and (b), were sent to the equalizer as the input. Orange blocks were the boosting stages, multiplying the value of $\alpha$ with a 
transfer function. The $\alpha$ values were generated by the purple blocks with initial values of $\alpha$ set to 1 . The blue blocks compared the power of the amplified signal and the sliced version. The result of the comparison was processed by the cyan blocks to decide whether to decrease $\alpha$ value or terminate the adaptive process. The eye diagram of the output from the adaptive equalizer model was shown in Figure 2.10(c). Although there was some overshoot, the power of the amplified signal was already lower than the sliced signal due to the rising and falling slope. Larger threshold values for the slicer could be used to reduce the overshoot.

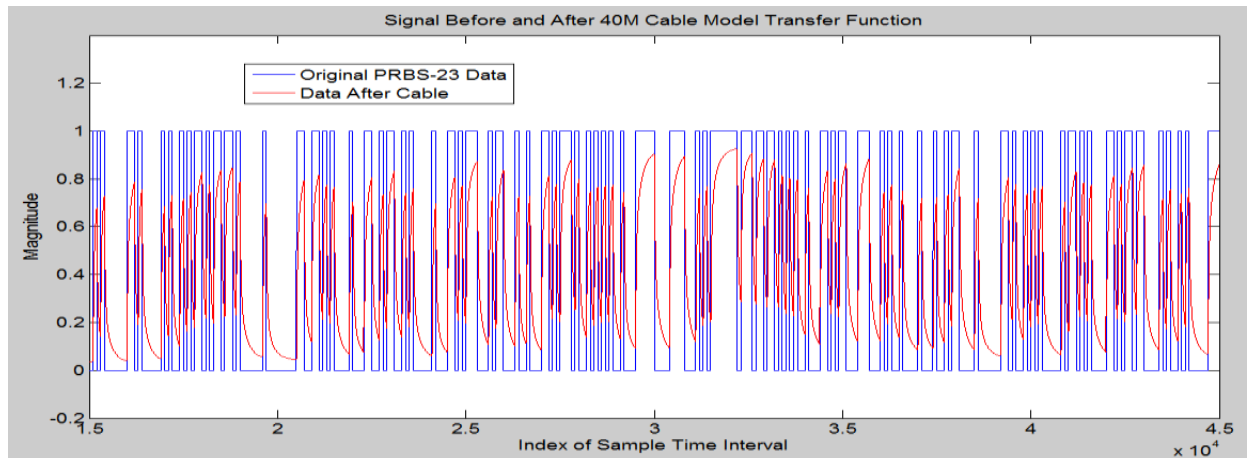

(a)

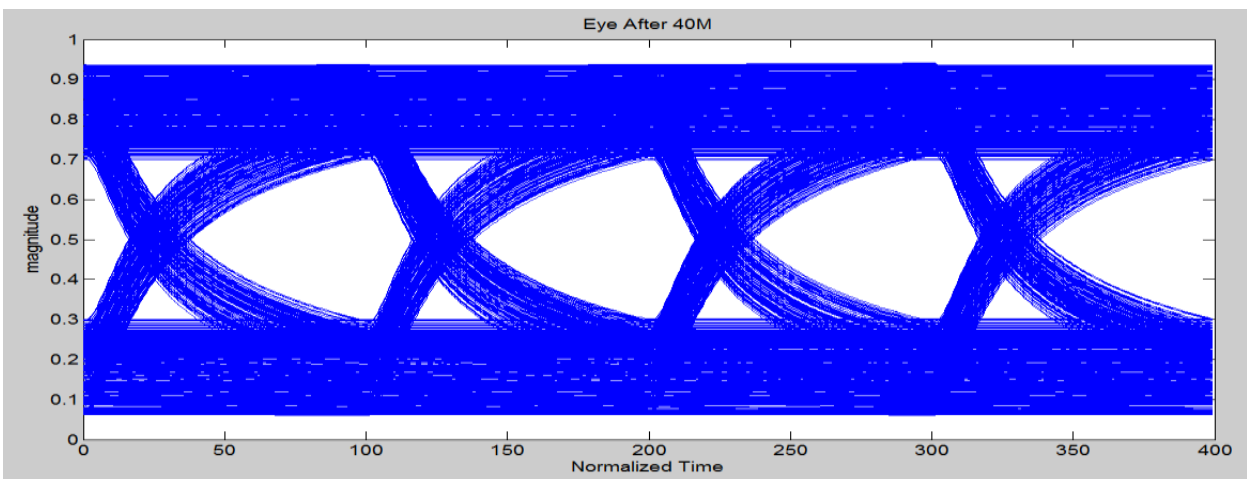

(b) 


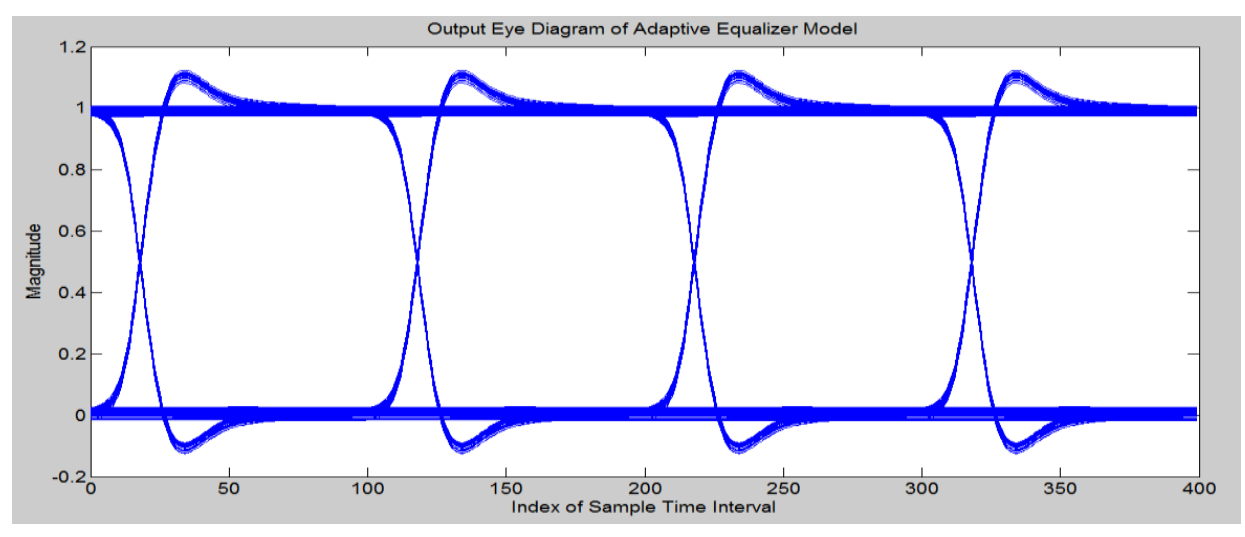

(c)

Figure 2.10: Input and Output of Adaptive Equalizer Model (a) PRBS-7 Input Signal and $40 \mathrm{~m}$ Cable Output Signal $\quad$ (b) Eye Diagram of $40 \mathrm{~m}$ Cable Output Signal $\quad$ (c) Eye Diagram of Equalized Signal

\subsection{Quantization Feedback (QFB) Block}

A quantization feedback block was used to eliminate a zero-wander effect in the equalizer system. The method was to reconstruct all the low frequency components blocked by AC coupling capacitors and the high-pass filter in itself.

\subsubsection{Zero-Wander Effect}

AC coupling method is commonly used to isolate the DC bias between two coupled circuits. It is achieved by using a coupling capacitor to connect two circuits so that the AC signal from the first circuit can pass through while the DC is blocked [8]. High-pass characteristic of the coupling capacitor causes the flat portions to decay towards the base line. The decay will be more obvious when pathological data with 
long sequence of 0 or 1 are passing through. This effect is called the zero-wander effect and is illustrated in Figure 2.11.

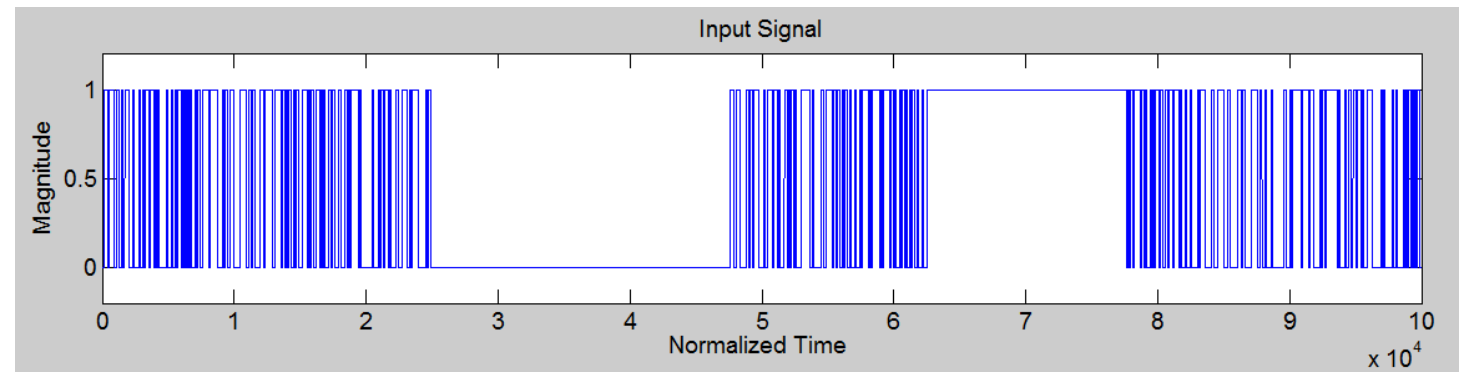

(a)

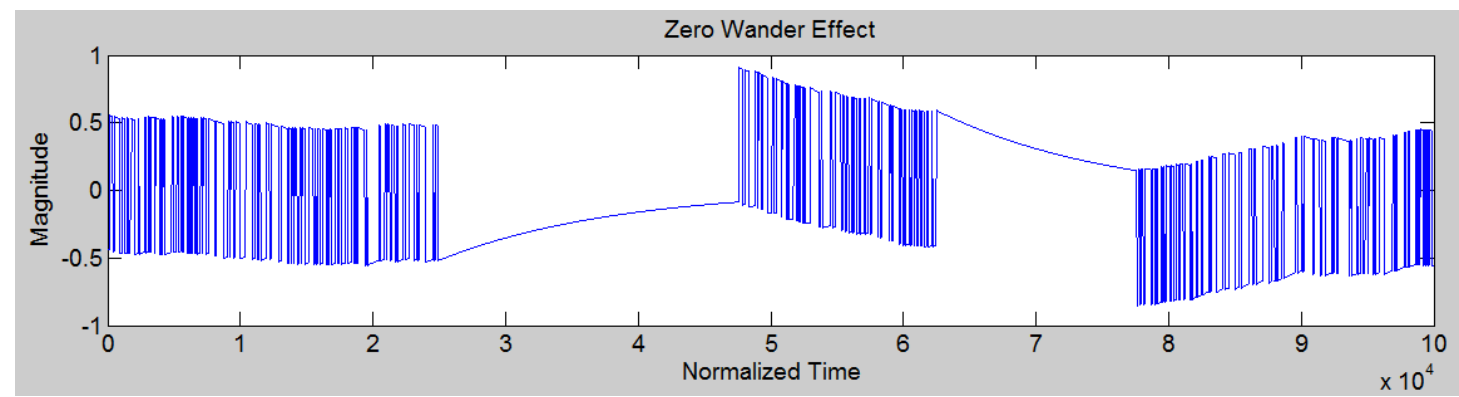

(b)

Figure 2.11: Pathological Data Combined with PRBS-23 Data Zero-Wander Effect (a) Original Pathological Combined with PRBS-23 Data $\quad$ (b) Zero-Wander Effect.

Since fast edges can pass through the coupling capacitor and only flat portions decays, a direct result of zero-wander effect is that the output eye diagram height reduces. A less obvious effect is that peak-to-peak jitter will increase due to fast-edge slope loss after the equalization process and base line shifting of the signal [7]. 


\subsubsection{Quantization Feedback Modeling}

An effective method to eliminate the zero-wander effect is the quantization feedback (QFB) method. A QFB block is formed by a high-pass filter, a low-pass filter, and a slicer, as shown in Figure 2.12.

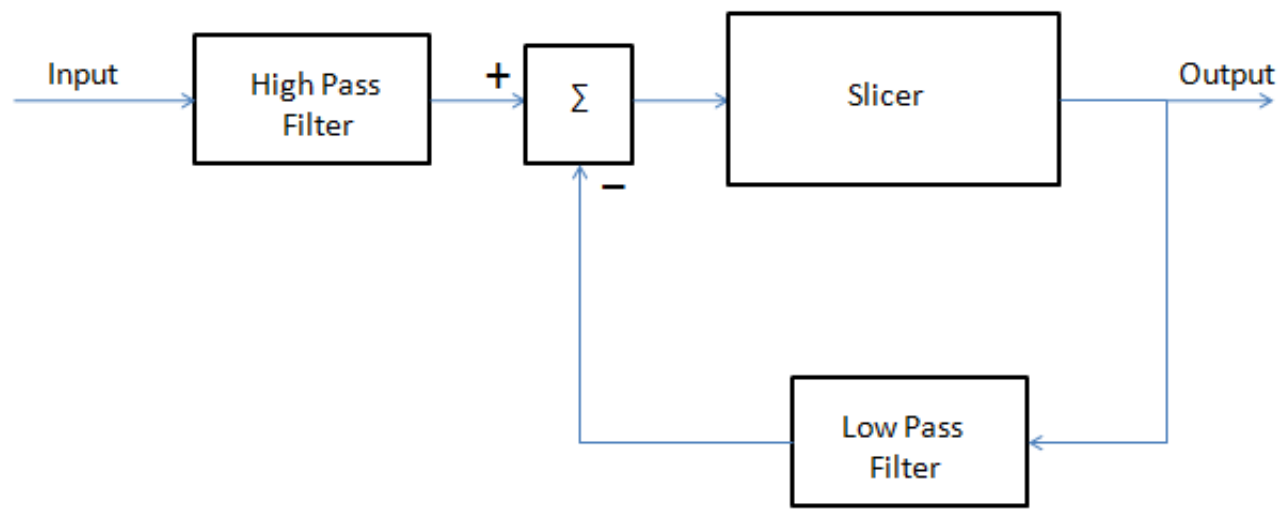

Figure 2.12: QFB Block Illustration

The high-pass filter and low-pass filter should have the same cutoff frequency.

This cutoff frequency should be higher than the cutoff frequencies of any AC coupling filters. The threshold of the slicer should be set at the middle between 0 and 1 levels [7].

The high-pass filter removes all the low frequency components from the input signal. The slicer then generates a new DC level for the high-pass filter output. The slicer output goes to the low-pass filter. Since the low-pass filter has the same cutoff frequency as the high-pass filter, all the high frequency components left from the 
high-pass filter are gone, and low frequency components associated with the new DC level remain. A new signal with entire spectrums can be reconstructed by adding the output of the high-pass filter and the output of the low-pass filter. It is important that the cutoff frequencies of both filters are higher than the cutoff frequencies of all the AC coupling filters, otherwise the spectrum between the cutoff frequency of the QFB block and the AC coupling filters will not be able to be constructed by the low-pass filter. A typical QFB block was modeled as shown in Figure 2.13.

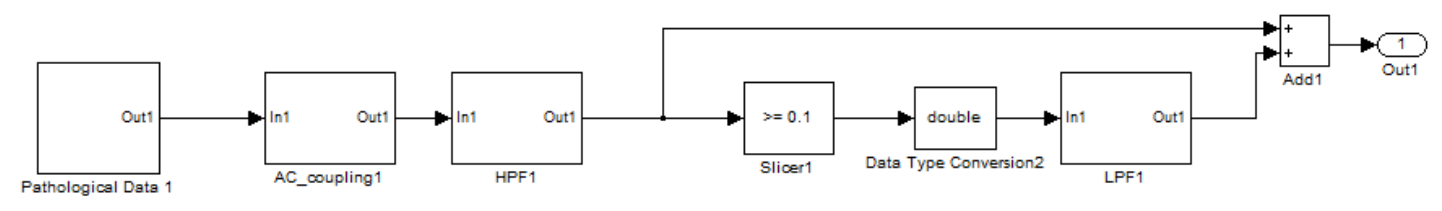

Figure 2.13: Typical QFB Simulink Model

The outputs of every stage in QFB block were illustrated in Figure 2.14. The zero-wander effect could be seen in the output of the AC coupling filter in Figure 2.14(a). Figure 2.14(b) was the output of the high-pass filter in QFB block. Since a higher cutoff frequency was used, more zero-wander effect was observed. Figure 2.14(c) was the output of the low-pass filter in QFB block. All the sharp edges ere removed due to the low-pass response and a new DC level was generated. Figure 2.14(d) was the output of the entire QFB block, showing that all the zero-wander effect was eliminated. 


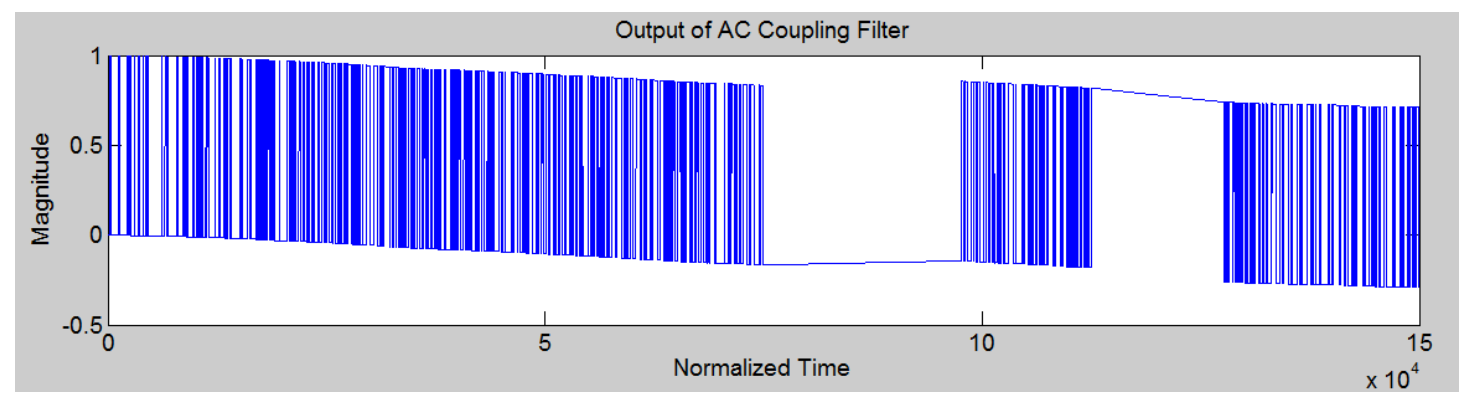

(a)

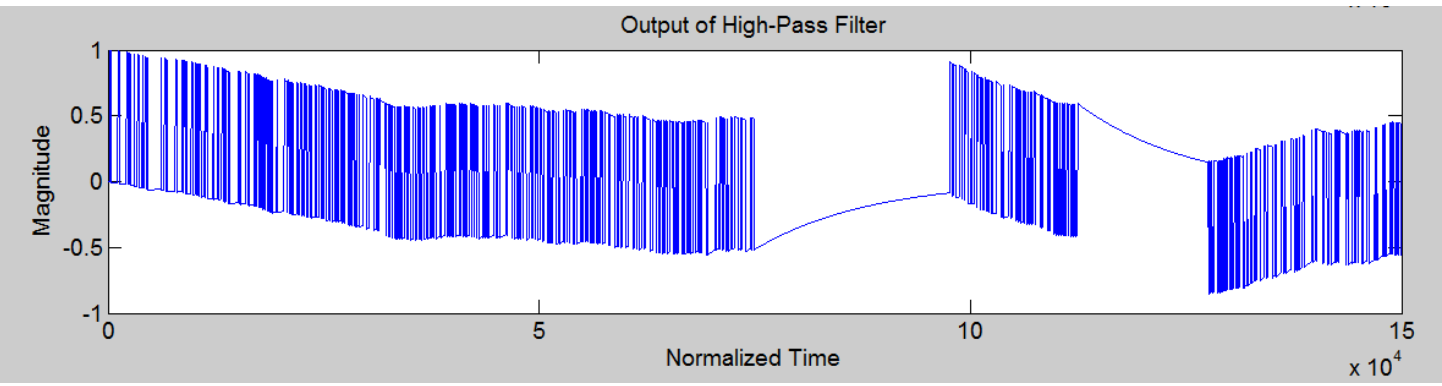

(b)

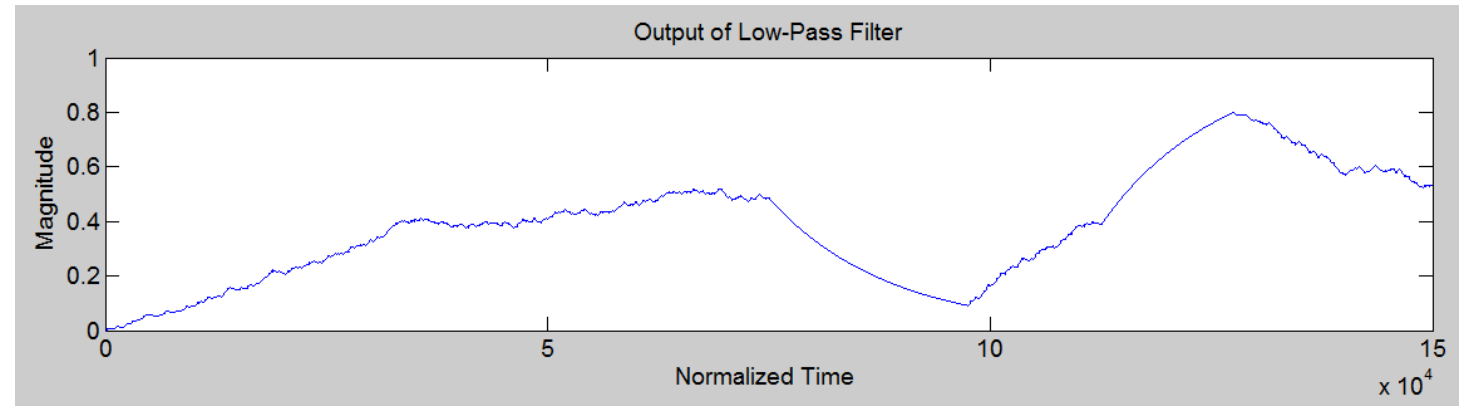

(c)

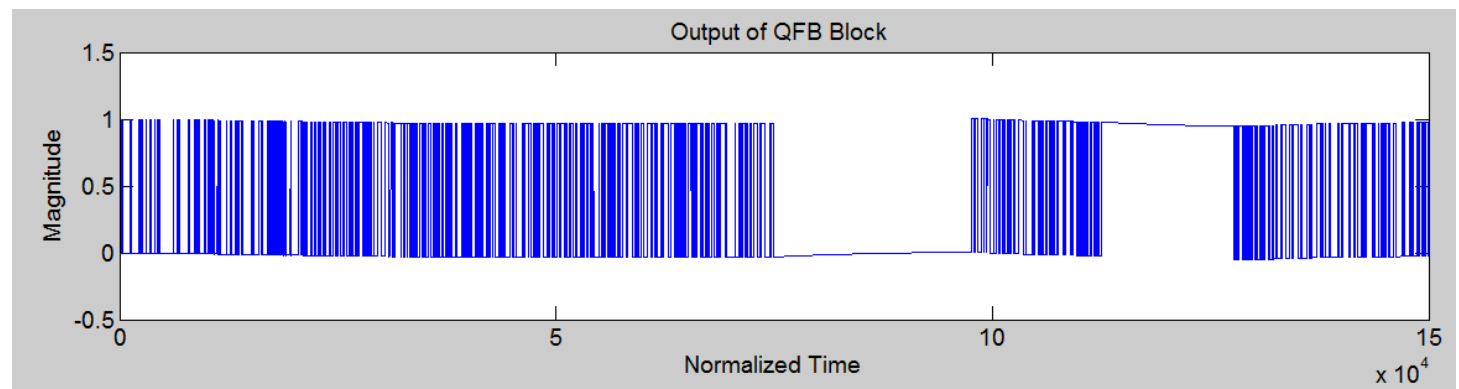

(d)

Figure 2.14: QFB Output Results (a) Output of Coupling Filter (b) Output of High-Pass Filter $\quad$ (c) Output of Low-Pass Filter $\quad$ (d) Output of QFB Block 


\subsection{Adaptive Equalizer Model with QFB Block}

The complete equalizer system model consisted of two main blocks: a cascade of three adaptive equalizer stages and the QFB. The AGC mechanism was embedded in every adaptive equalizer stage. Boosting gain was tuned properly inside each stage before the signal passes to next stage. An alternate way for tuning is to build an extra AGC block controlling all three $\alpha$ values together in all three stages [2]. These two ways had the same time cost in simulation, so in this work the first method was used.

The entire system model was shown in Figure 2.15. Each equalizer stage was able to compensate a maximum of an $80 \mathrm{~m}$ Belden 1694A coaxial cable and adaptively tuned for any shorter cable length. The entire system was fit for $240 \mathrm{~m}$ maximum.
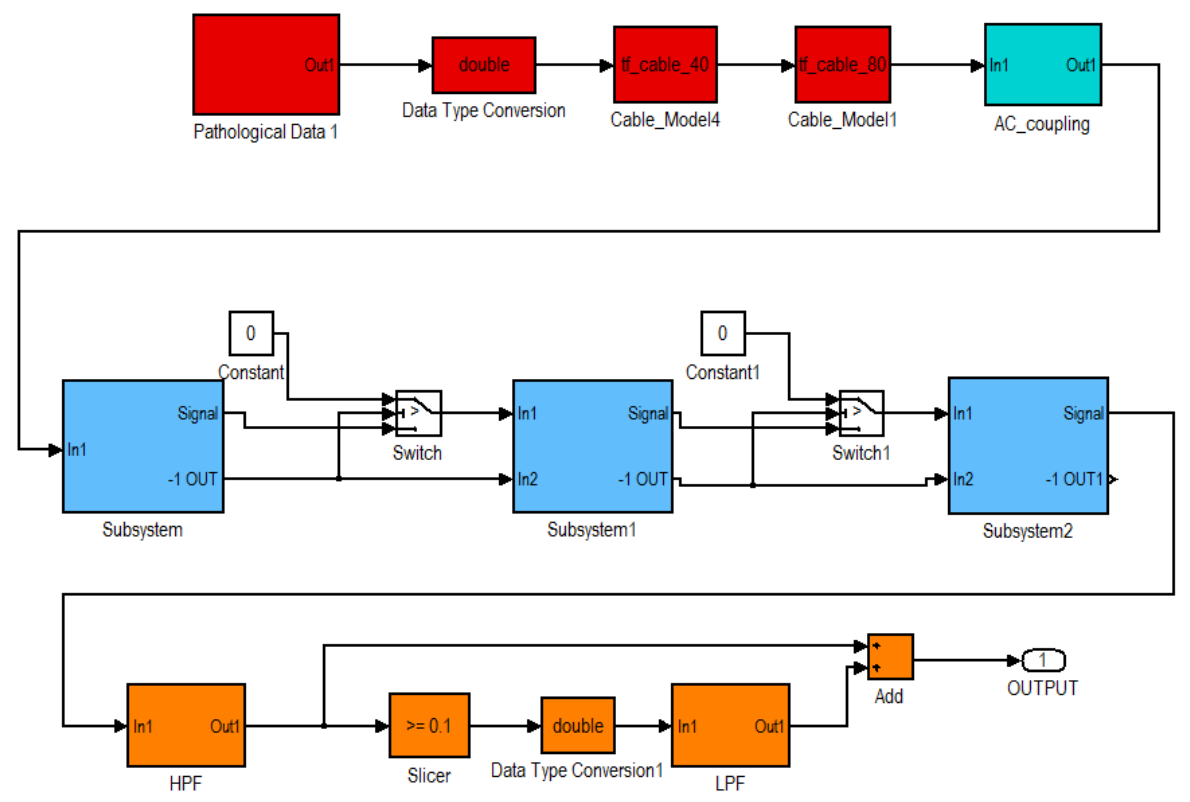

Figure 2.15: Complete Equalizer System Model 
The red blocks were pathological PRBS-23 data generator and cable models, generating PRBS-23 data combined with long sequence of 0 and 1 . It sent the data through the cable models to generate an attenuated signal. The cyan block was the AC coupling filter, the blue blocks were the three adaptive equalizer stages, and the orange blocks were QFB parts.

A 120 m Belden 1694A coaxial cable model was used in the first test. To compensate for this cable length correctly, the three equalizer stages should work in different states: the first stage $\alpha$ should be 1, the second stage $\alpha$ should be between 0 and 1 , and the last stage $\alpha$ should be 0 . Since the three stages were completely identical, $120 \mathrm{~m}$ was good option for debugging. The outputs from every single stage and final output from QFB block were shown below in Figure 2.16.

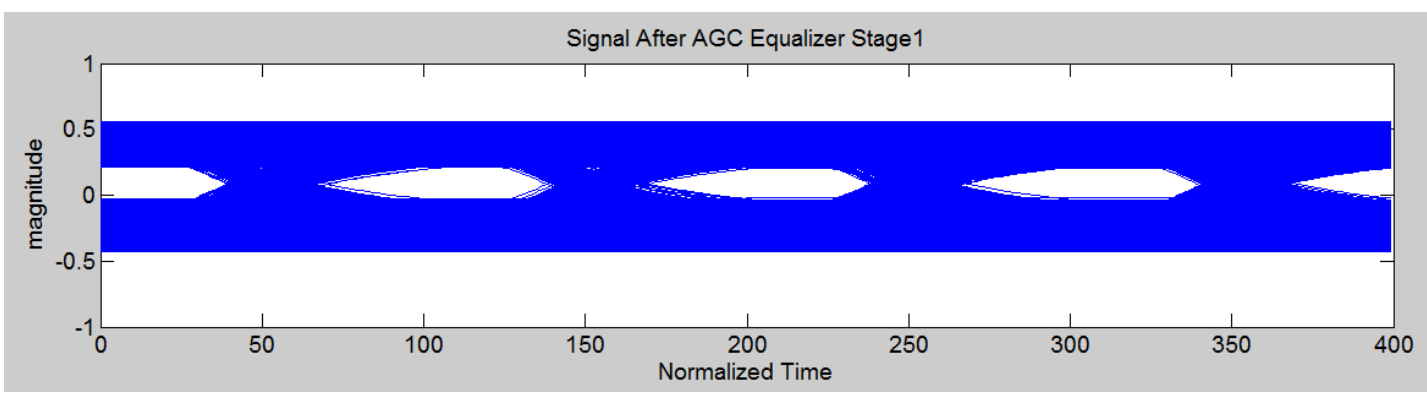

(a)

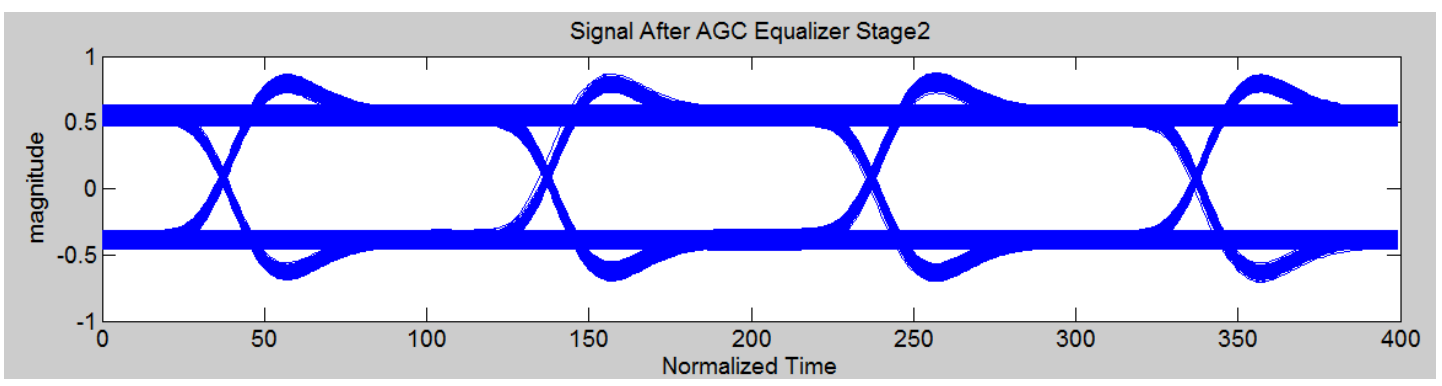

(b) 


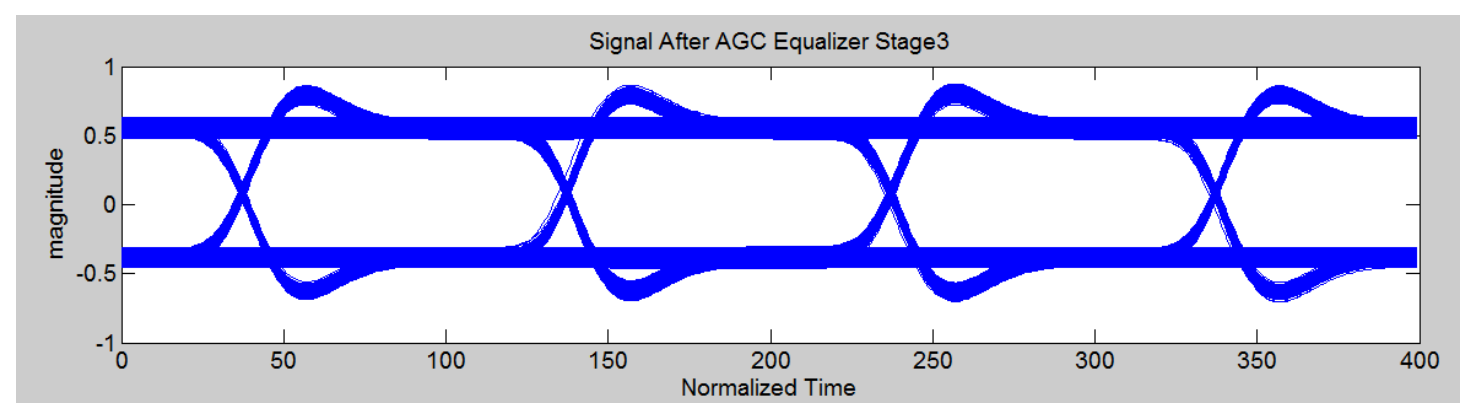

(c)

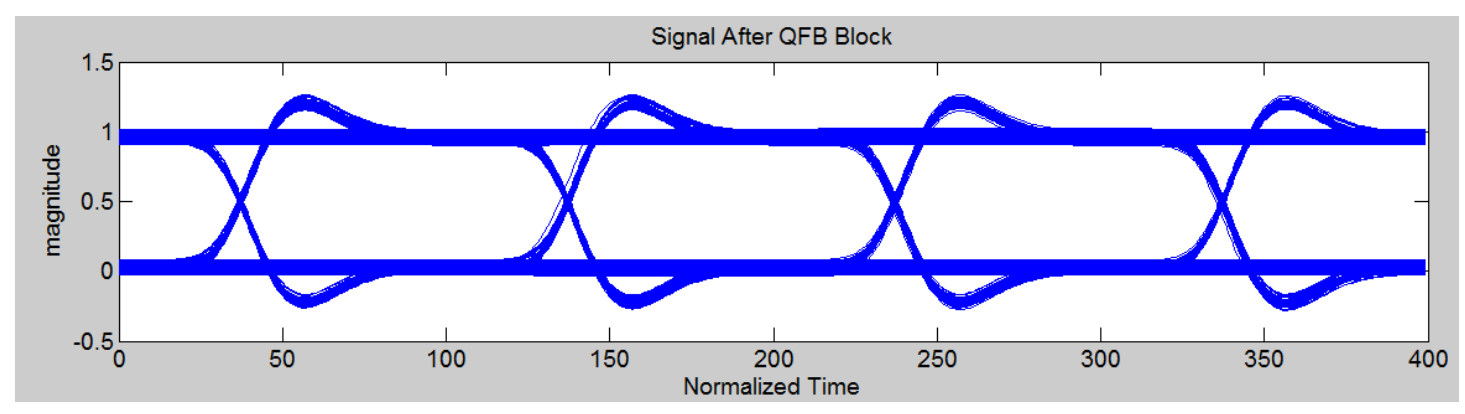

(d)

Figure 2.16: $120 \mathrm{~m}$ Belden 1694A Coaxial Cable Equalization Results

(a)Output of Stage1 (b)Output of Stage2 (b)Output of Stage3 (d)Output of Entire System

The first stage compensated for the $80 \mathrm{~m}$ cable loss completely, so the eye diagram of the output from the first stage showed the original signal with a $40 \mathrm{~m}$ cable loss. The second stage compensated for this $40 \mathrm{~m}$ cable loss and the signal was fully recovered. The third stage did nothing to the signal. The QFB block fixed the zero-wander effect, so the eye height of the final output from QFB block was larger than that in the second and third stage outputs. The $\alpha$ value in the first stage was 1 , in the second stage was 0.41 , in the third stage was 0 , as expected. Different slicer threshold values were used in different simulations to graphically depict the overshoot 
differences caused by them. In this simulation, a large threshold value was used so there was not much overshoot.

Other tests using different cable lengths were also made. $40 \mathrm{~m}$ cable and $200 \mathrm{~m}$ cable were used to check the adaptive function of each stage while $20 \mathrm{~m}$ cable and 240 $\mathrm{m}$ cable were used to check if the equalizer is still functional when a very short or very long cable was used.

The $40 \mathrm{~m}$ cable results were shown in Figure 2.17. A smaller slicer threshold value was used in this simulation so the overshoot increased noticeably. The first stage compensated for all the cable loss so the second and third stages did nothing. The $\alpha$ value of the first stage was still 0.41 , and the $\alpha$ values of second stage and third stage were both 0 .

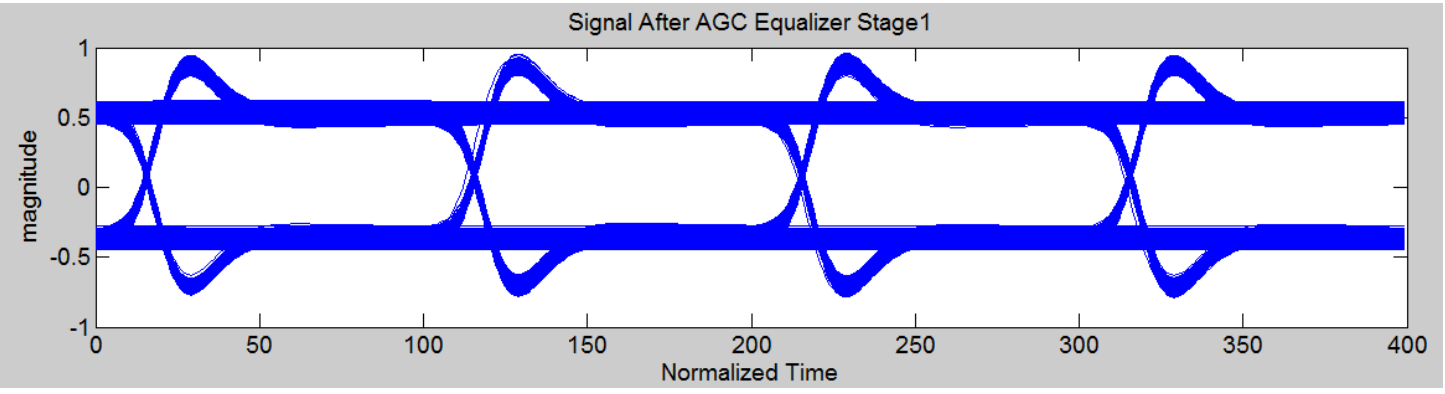

(a)

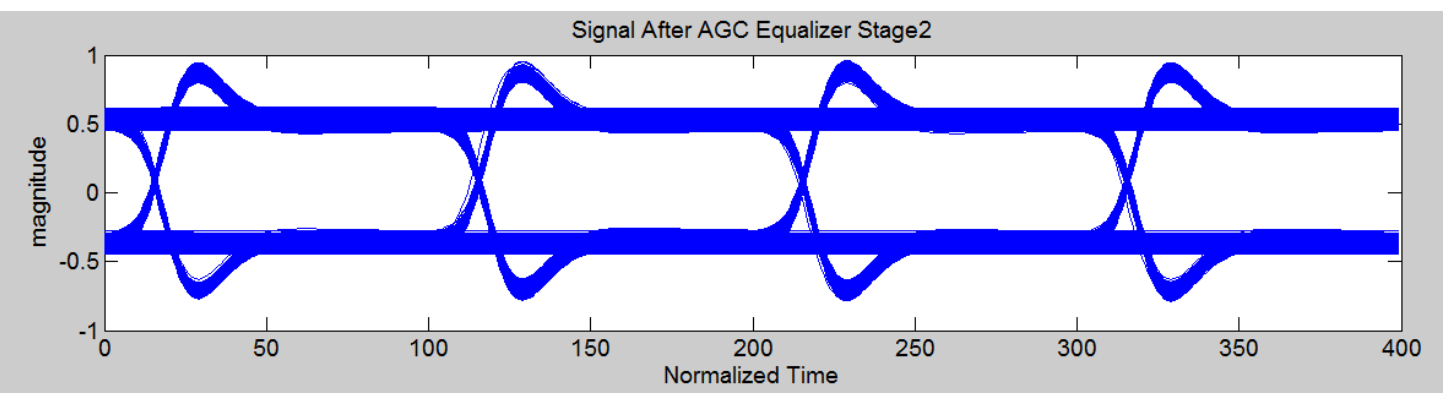

(b) 


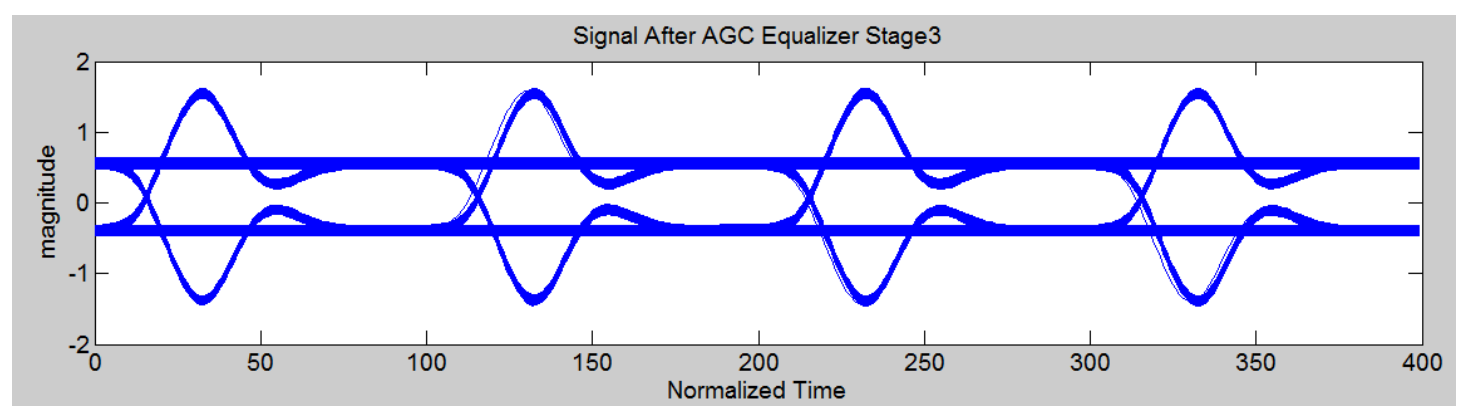

(c)

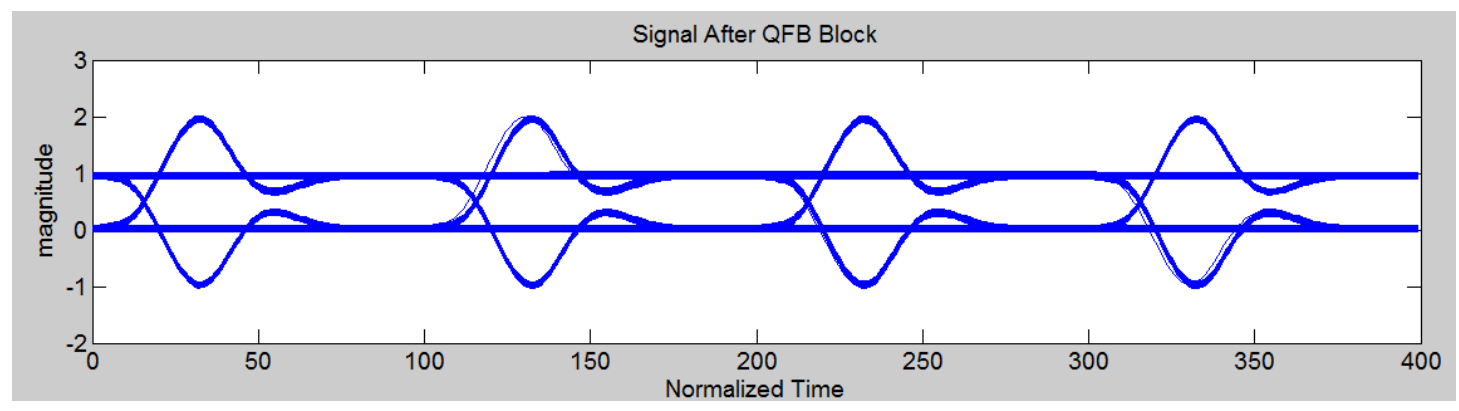

(d)

Figure 2.17: $40 \mathrm{~m}$ Belden 1694A Coaxial Cable Equalization Results

(a)Output of Stage1 (b)Output of Stage2 (b)Output of Stage3 (d)Output of Entire System

The $200 \mathrm{~m}$ cable results were shown in Figure 2.18. A larger slicer threshold value was used in this simulation so the overshoot was smaller compared with last simulation. All three stages were used to compensate cable loss. The first stage and second stage compensated for an $80 \mathrm{~m}$ cable loss each and third stage compensated for a $40 \mathrm{~m}$ cable loss. The $\alpha$ values of the first two stages were 1 , and the $\alpha$ value of third stage was 0.41 now. 


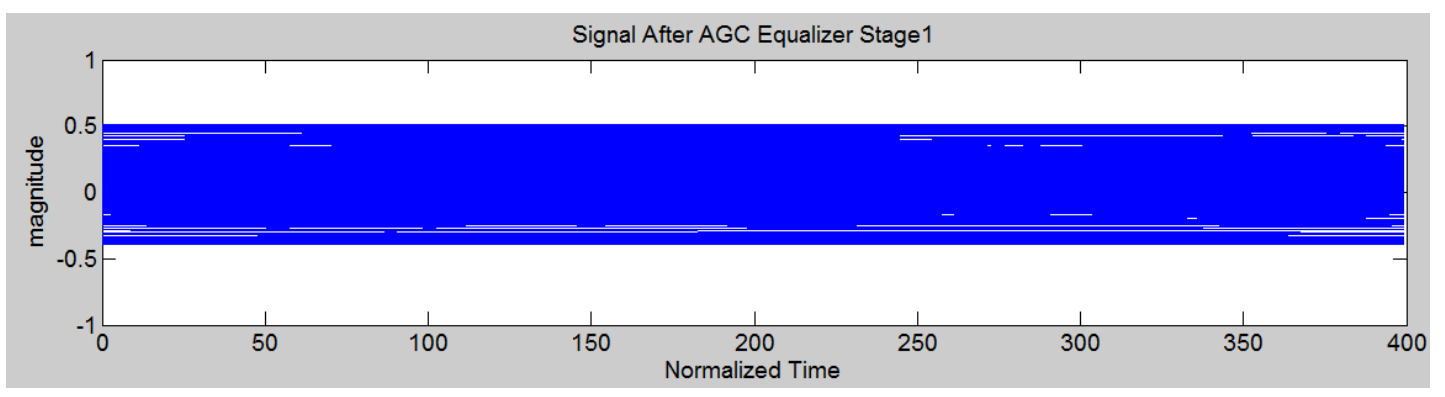

(a)

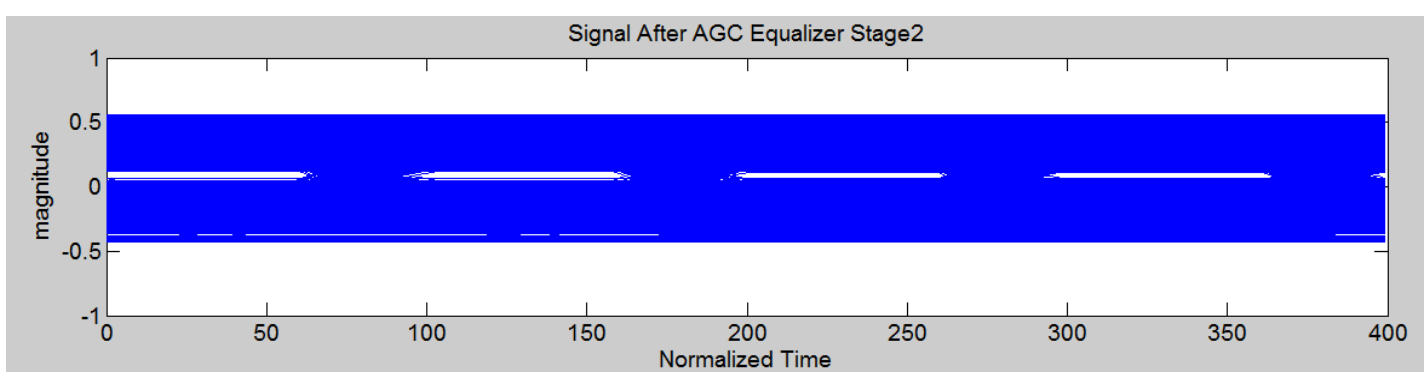

(b)

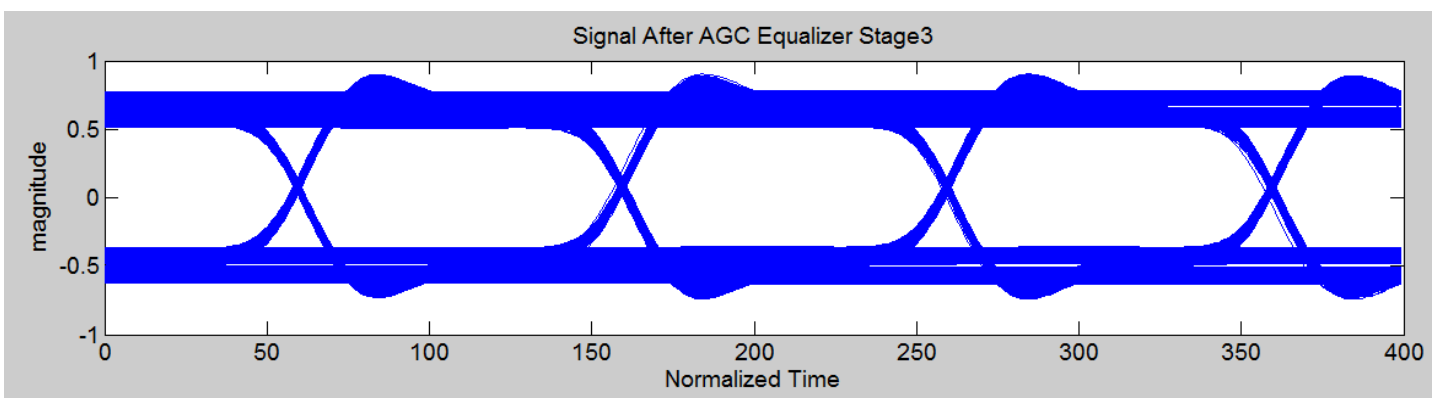

(c)

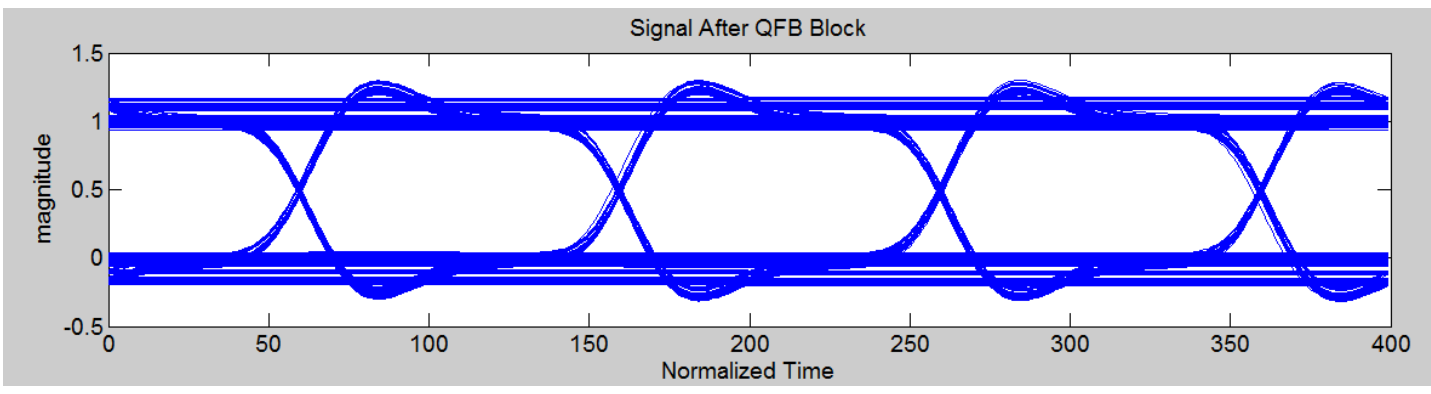

(d)

Figure 2.18: $200 \mathrm{~m}$ Belden 1694A Coaxial Cable Equalization Results (a)Output of Stage1 (b)Output of Stage2 (b)Output of Stage3 (d)Output of Entire System 
The $240 \mathrm{~m}$ cable results were shown in Figure 2.19. There was almost no overshoot since this was the maximum cable length could be handled by this system.

All three stages were used to compensate for cable loss with each stage compensating for an $80 \mathrm{~m}$ cable loss. The $\alpha$ values of all three stages were 1 now.

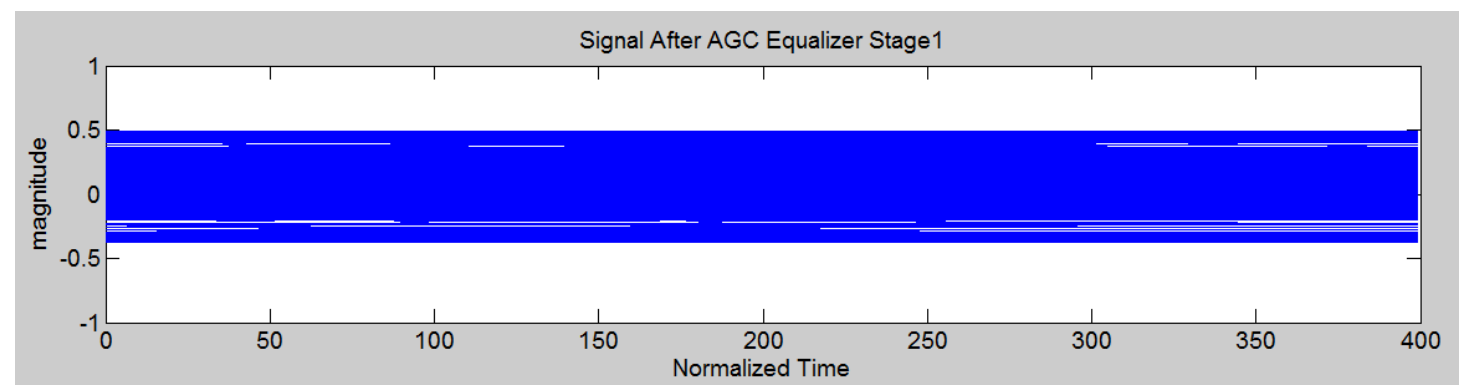

(a)

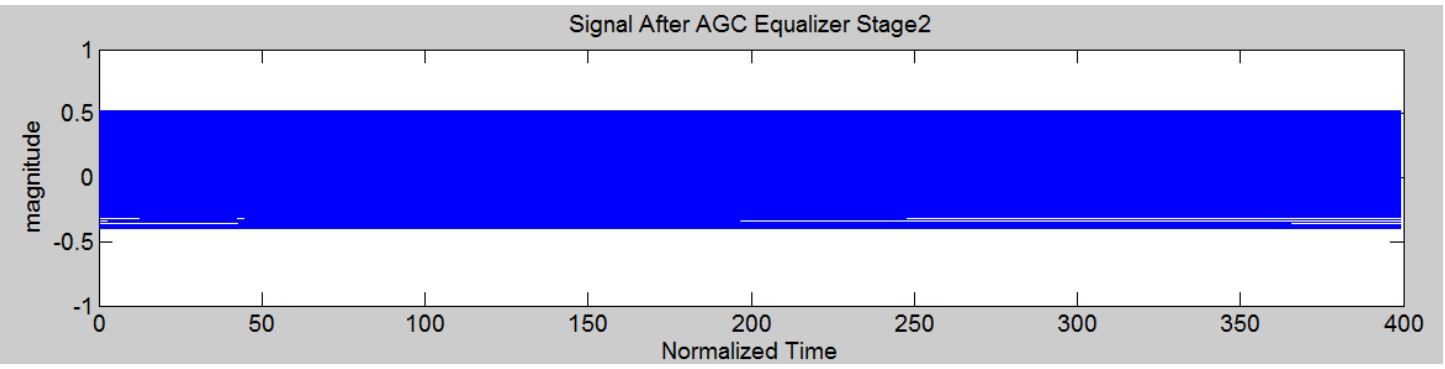

(b)

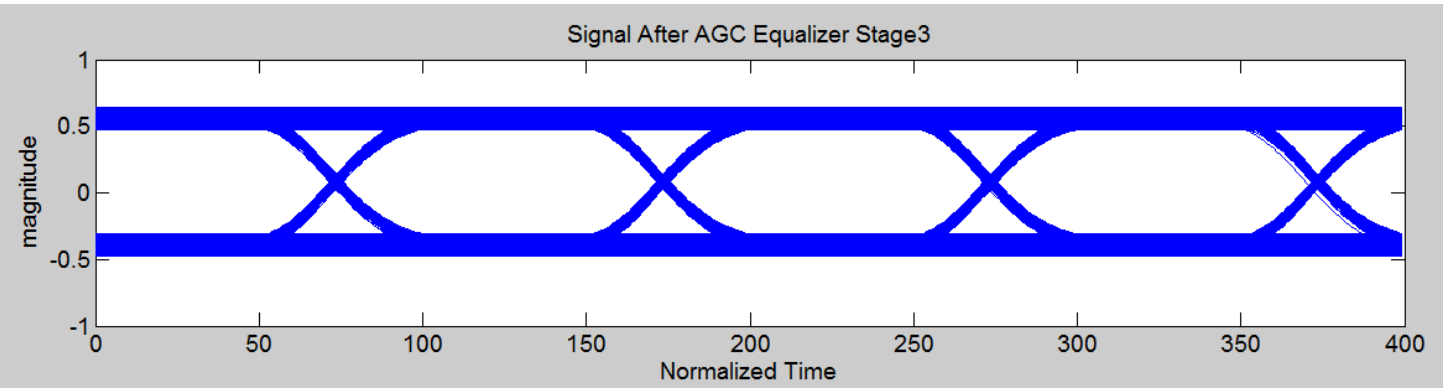

(c) 


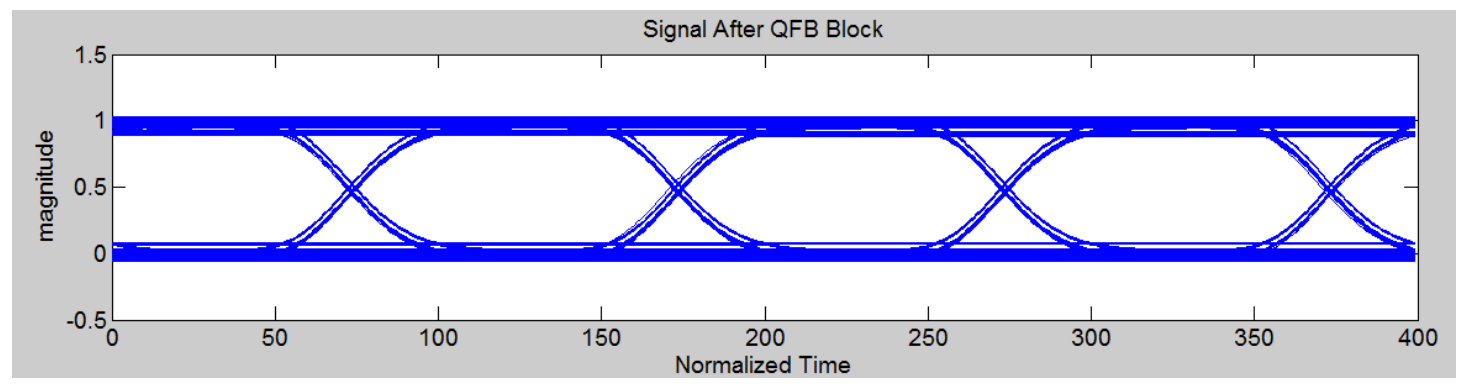

(d)

Figure 2.19: 240 m Belden 1694A Coaxial Cable Equalization Results

(a)Output of Stage1 (b)Output of Stage2 (b)Output of Stage3 (d)Output of Entire System

The $20 \mathrm{~m}$ cable results were shown in Figure 2.20, and they were similar to the 40 $\mathrm{m}$ cable results. The only difference was a larger slicer threshold value which brings down the overshoot effectively. The maximum overshoot value was brought down from 2 to 1.6 now.

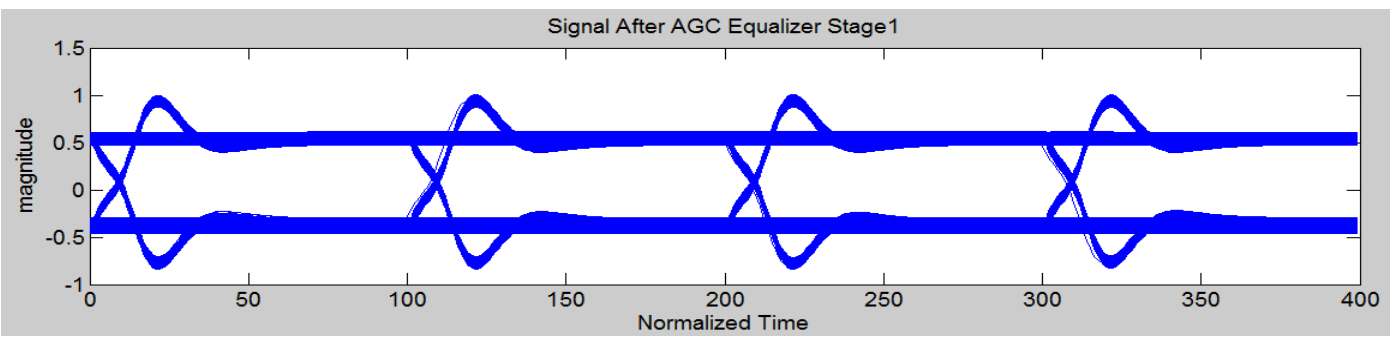

(a)

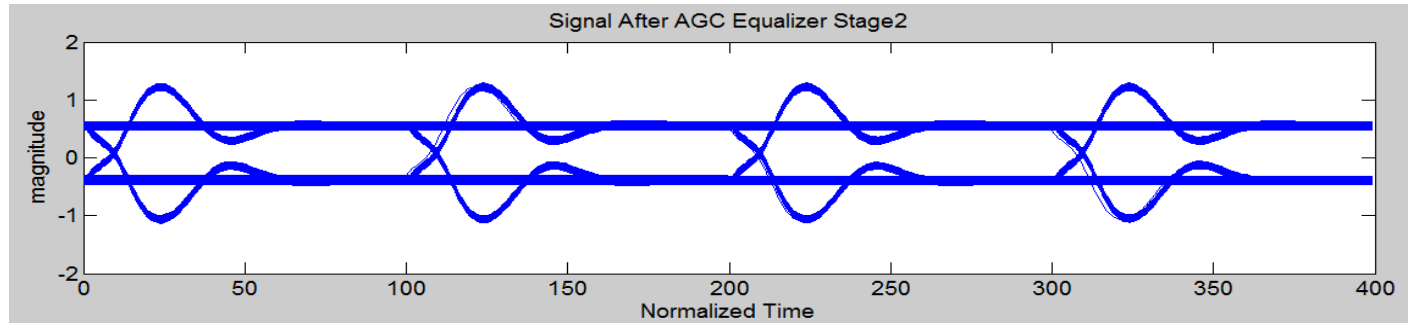

(b) 


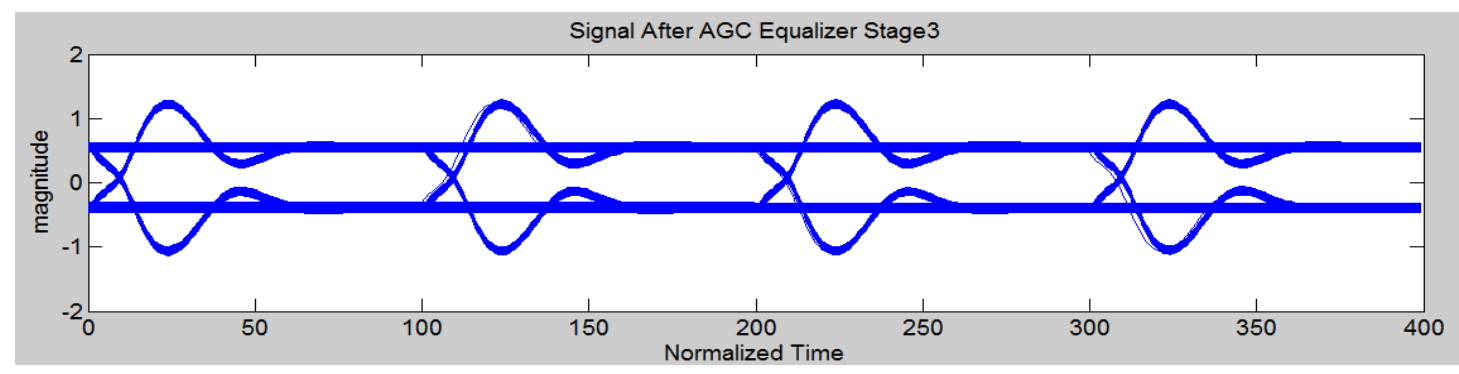

(c)

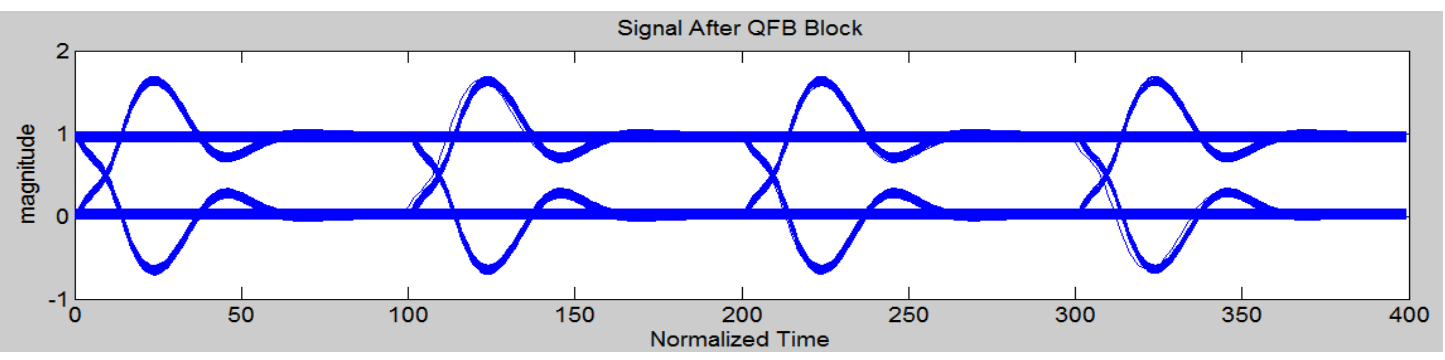

(d)

Figure 2.20: 20 m Belden 1694A Coaxial Cable Equalization Results

(a)Output of

Stage1 (b)Output of Stage2 (b)Output of Stage3 (d)Output of Entire System

From the results presented above, a conclusion can be made that the three stages

adaptive equalizer model with QFB block was adaptively working for maximum $240 \mathrm{~m}$ Belden 1694A coaxial cable. For all the final outputs of the QFB block, the eye heights were around 1 and the peak-to-peak jitters were less than 0.1 UI.

\section{Chapter 3. Circuit Implementation}

\subsection{Methodology}

The key part to transferring the existing design into CMOS circuit is the adaptive filter stage. Following the adaptive equalizer model in the last chapter, a CMOS 
adaptive equalizer stage was designed to adaptively compensate for a maximum $80 \mathrm{~m}$ Belden 1694A coaxial cable.

A typical design flow was illustrated in Figure 3.1. The first step is to build an amplifier with a flat low-pass frequency response. The cutoff frequency of this low-pass response should be slightly larger than the signal frequency, so that the entire spectrum will pass and only noise with higher frequency will be attenuated. The next step is to tune the frequency response to match the reverse cable characteristic. An RC degeneration method is used to reduce the DC gain and extra RC pairs are used to generate additional zero-pole pairs in frequency to make it closer to the target characteristic. The final step is to build a Variable Gain Amplifier(VGA) for gain tuning, which makes the equalizer adaptive for different cable length.

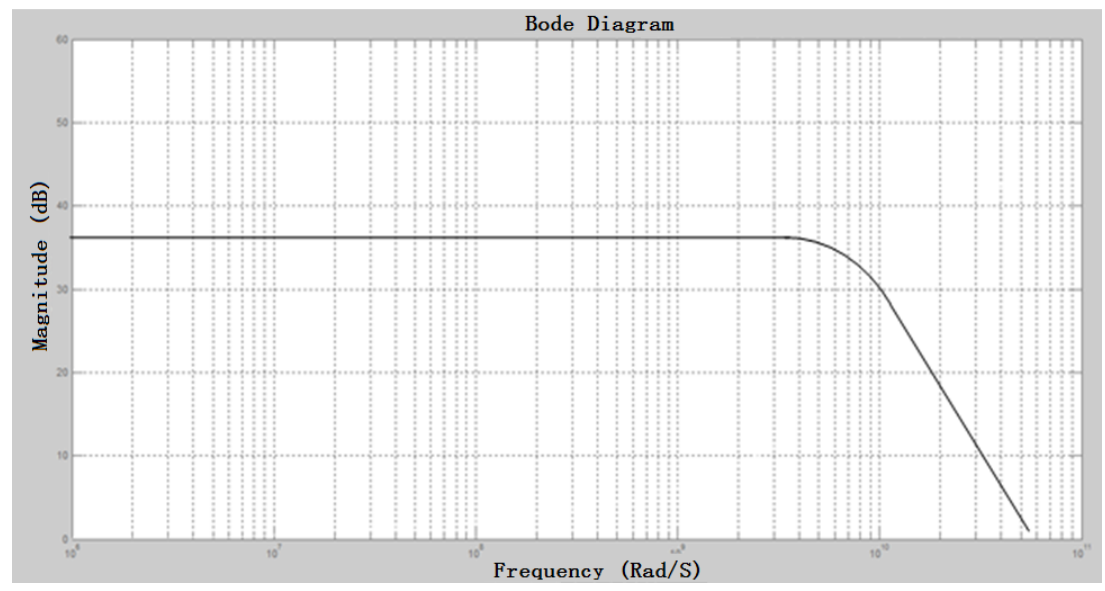

(a) 


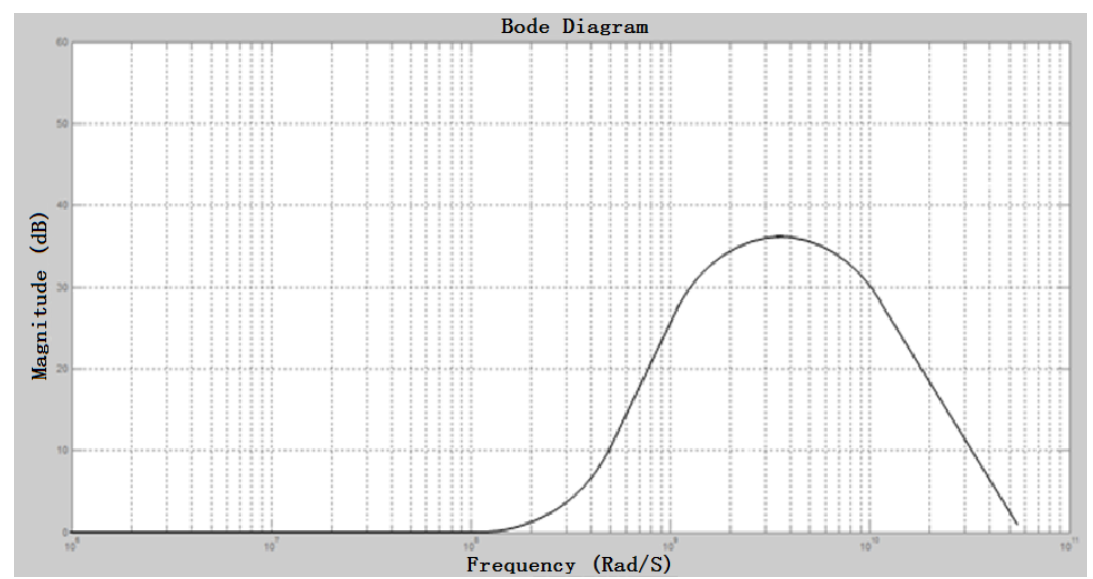

(b)

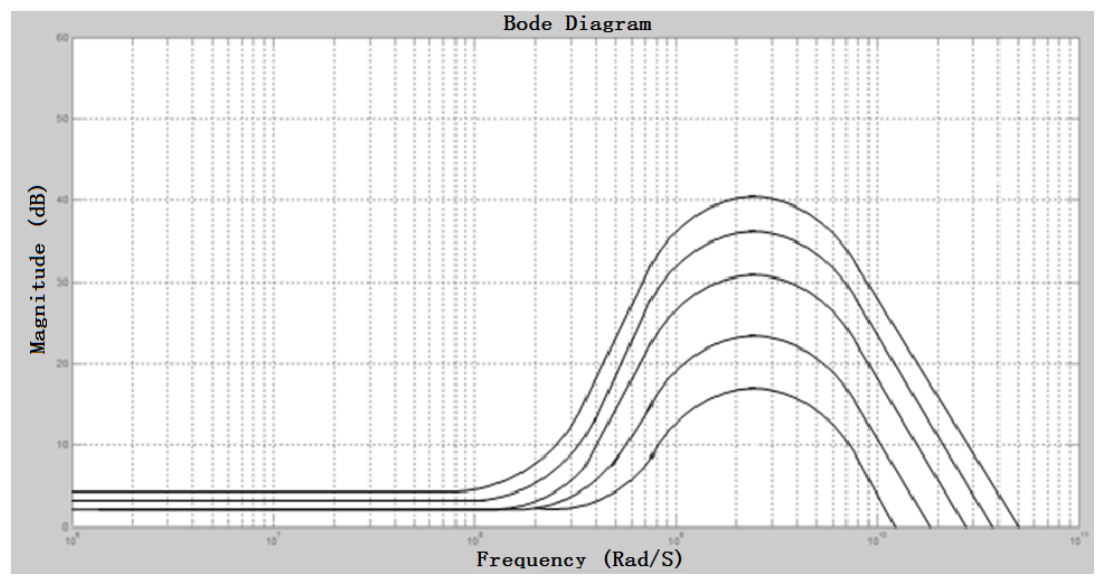

(c)

Figure 3.1: Design Flow of Equalizer $\quad$ (a) Flat Response (b) RC Degeneration and Tuning (c) Variable Gain Control

The circuit was implemented in GPDK $45 \mathrm{~nm}$ CMOS technology and simulated in

Cadence environment. For an $80 \mathrm{~m}$ Belden 1694A coaxial cable, the cable loss at 1.5 $\mathrm{GHz}$ was $21 \mathrm{~dB}$. Two methods were used to realize the steps in Figure 3.1. The first one was to design a pre-amplifier stage offering enough gain and bandwidth with a VGA stage used as an attenuator for adaptive consideration. $\mathrm{RC}$ degeneration was 
added to both stages for tuning the frequency response close to the reverse cable characteristic. A folded cascode amplifier and a folded Gilbert cell were used in this method as the pre-amplifier and the VGA, respectively. The second method used an RC degenerated pre-amplifier and VGA together to generate the required gain. In the second method, a single differential amplifier was used as the pre-amplifier stage since the gain requirement was not as strict as in the first method. A folded Gilbert cell was still used as the VGA stage.

\subsection{Differential Amplifier}

A CMOS differential amplifier implemented with GPDK $45 \mathrm{~nm}$ technology was shown in Figure 3.2. Since this amplifier was used to drive another CMOS circuit in $45 \mathrm{~nm}$ technology and currently $C_{g g}$ of NM0 and NM1 were $47 \mathrm{fF}$, the load capacitor value was set to $60 \mathrm{fF}$ to match the future design. The $\mathrm{DC}$ gain of the amplifier was [9]:

$$
\left|A_{v}\right|=g_{m(N M))} \cdot\left(R_{D S(P M 0)} \| R_{D S(N M 0)}\right)
$$

and we also knew:

$$
g_{m(N M 0)}=\sqrt{\frac{\mu_{n} C_{o x} W_{(N M 0)} I_{D S(N M 2)}}{L_{(N M 0)}}}
$$

and the bandwidth of the amplifier was [9]:

$$
\omega \approx \frac{1}{\left(R_{D S(P M 0)} \| R_{D S(N M 0)}\right) C_{\text {load }}}
$$



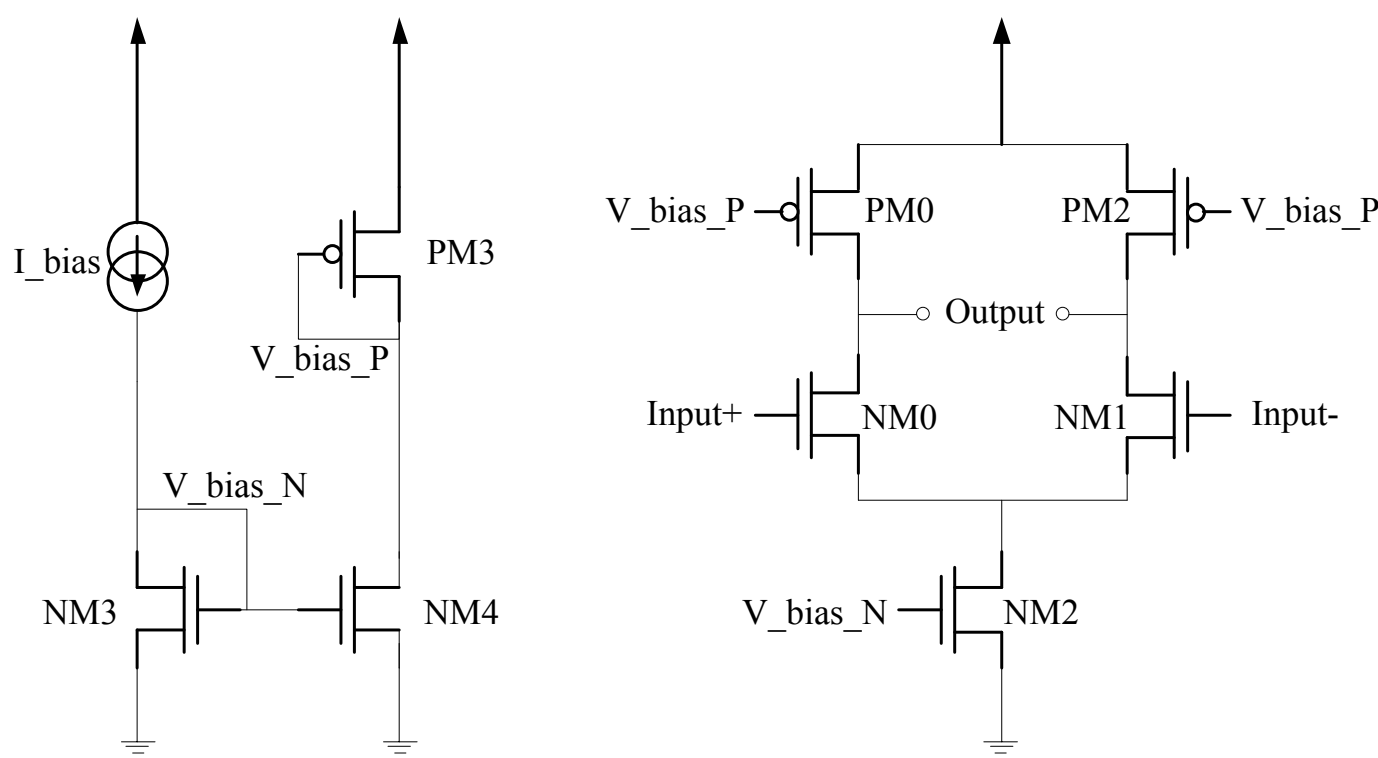

Figure 3.2: CMOS Differential Amplifier in GPDK $45 \mathrm{~nm}$ Technology

According to Eq. (3.1), Eq. (3.2), and Eq. (3.3), there was a tradeoff between the DC gain and the bandwidth. Without changing load capacitance, the only way to improve the bandwidth was to decrease $R_{D S(P M 0)} \| R_{D S(N M 0)}$, which caused a reduction in $\left|A_{v}\right|$ according to Eq. (3.1). Increasing $g_{m(N M 0)}$ was achieved by increasing $W_{(N M 0)}$ or $I_{D S(N M 2)}$. If $W_{(N M 0)}$ was increased, $R_{D S(P M 0)} \| R_{D S(N M 0)}$ was decreased and bandwidth went down; if $I_{D S(N M 2)}$ was increased, to maintain all the transistors working in saturation mode, $W_{(N M 0)}$ and $W_{(P M 0)}$ should be increased, $R_{D S(P M 0)} \| R_{D S(N M 0)}$ was then decreased and bandwidth was also decreased. The bias current I_bias was selected based on the output slew rate. The data rate of the signal 
was 1.5 Gbps. One bit period was $666.7 \mathrm{ps}$, assuming the rising and falling edges take no more than $60 \mathrm{ps}$ each and the output signal swing was $400 \mathrm{mV}$ based on current data transmission standard. For each differential output branch, the swing should be 200 $\mathrm{mV}$ and the slew rate as $3.33 \mathrm{mV} / \mathrm{ps}$, since the slew rate was defined as:

$$
S R=\frac{I_{D S}}{C_{\text {load }}}
$$

and minimum $I_{D S}$ was calculated by:

$$
I_{D S}=S R \times C_{\text {load }}=\frac{200 \times 10^{-3}}{60 \times 10^{-12}} \times 60 \times 10^{-15}=2 \times 10^{-4} \mathrm{~A}
$$

The tail current of the differential amplifier should be at least $0.4 \mathrm{~mA}$. Giving design margins for the corner conditions, I_bias was set to $4 \mathrm{~mA}$ in this thesis.

All the transistor sizes and devices parameters were listed in table 2.

Table 2. Transistor Sizes and Devices Parameters of $45 \mathrm{~nm}$ Differential Amplifier

\begin{tabular}{|c|c|c|c|c|c|}
\hline Element & W/L & Element & W/L & Element & Value \\
\hline PM0 & $45 \mathrm{~nm} / 48 \mathrm{um}$ & NM0 & $45 \mathrm{~nm} / 68 \mathrm{um}$ & I_bias & $4 \mathrm{~mA}$ \\
\hline PM2 & $45 \mathrm{~nm} / 48 \mathrm{um}$ & $\mathrm{NM} 1$ & $45 \mathrm{~nm} / 68 \mathrm{um}$ & Vgs & $0.8 \mathrm{~V}$ \\
\hline PM3 & $45 \mathrm{~nm} / 48 \mathrm{um}$ & $\mathrm{NM} 2$ & $45 \mathrm{~nm} / 120 \mathrm{um}$ & C_load & $60 \mathrm{fF}$ \\
\hline NM3 & $45 \mathrm{~nm} / 82 \mathrm{um}$ & NM4 & $45 \mathrm{~nm} / 48 \mathrm{um}$ & VDD & $1 \mathrm{~V}$ \\
\hline
\end{tabular}

The frequency response of the differential amplifier was shown in Figure 3.3. 


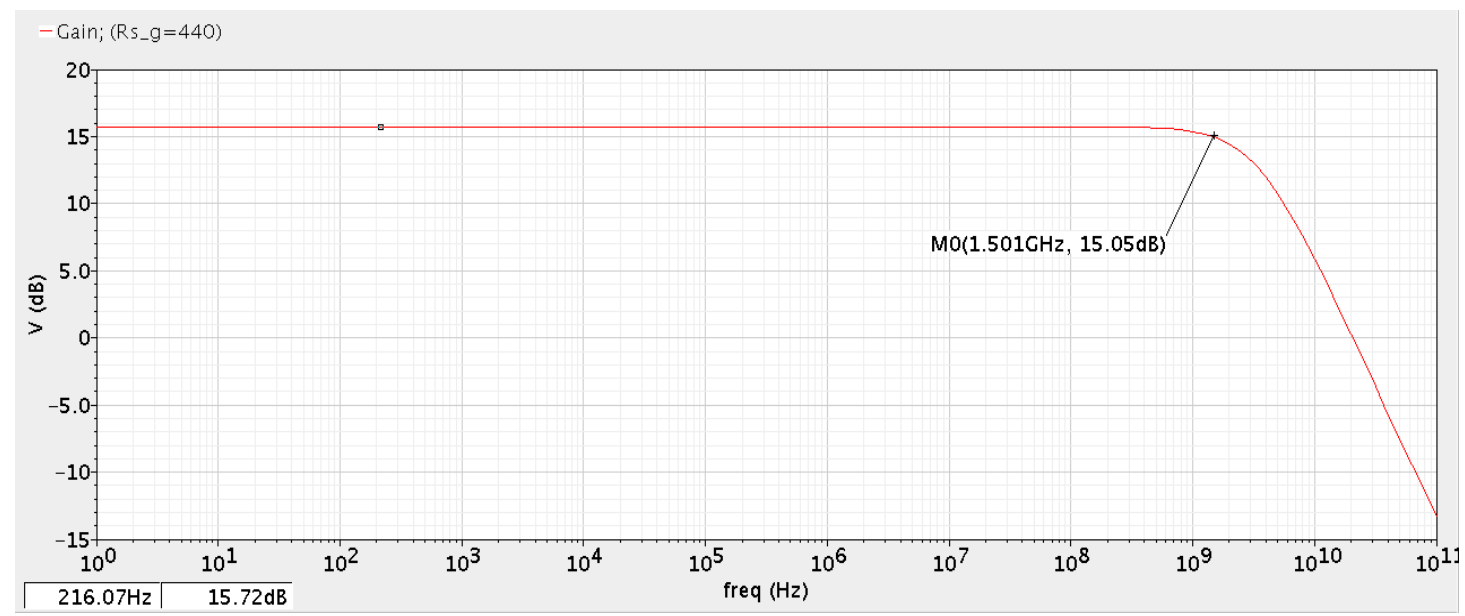

Figure 3.3: Frequency Response of the Differential Amplifier

The DC gain of the differential amplifier was $15.8 \mathrm{~dB}$ and gain at $1.5 \mathrm{GHz}$ was $15.05 \mathrm{~dB}$. It suggested that if a single stage differential amplifier was used as a pre-amplifier, the VGA stage should also be able to offer around $10 \mathrm{~dB}$ gain to fully compensate for the $80 \mathrm{~m}$ Belden 1694A coaxial cable at $1.5 \mathrm{GHz}$.

\subsection{Wide Swing Current Mirror and Folded Cascode}

The wide swing current mirror [10], also known as the low-voltage cascode mirror [9], is used to increase signal swing in cascode mirror.

A typical wide swing current mirror was shown in Figure 3.4. The transistors sizes were set as $\frac{W_{1} / L_{1}}{n^{2}}=\frac{W_{4} / L_{4}}{n^{2}}=W_{3} / L_{3}=W_{2} / L_{2}$ and $\frac{W_{3} / L_{3}}{n^{2}}=W_{5} / L_{5}$. 


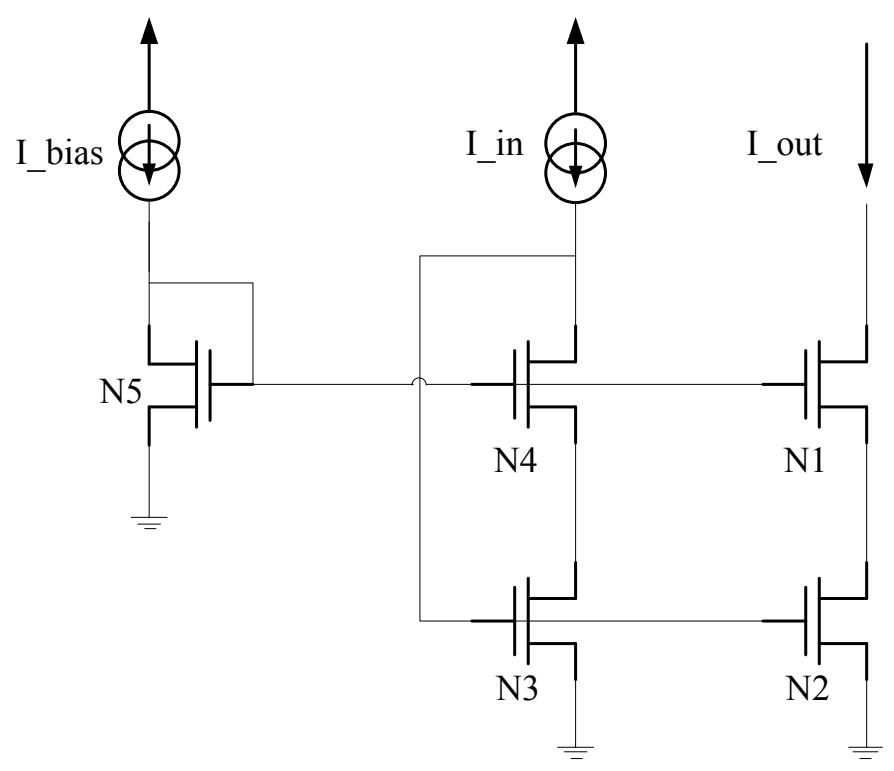

Figure 3.4: Wide Swing Current Mirror

According to the transistors sizes, assume I_bias = I_in = I_out, then it is known

$$
\text { that } V_{\text {eff }}=V_{\text {eff } 2}=V_{e f f 3}=\sqrt{\frac{2 \times I_{-} \text {bias }}{\mu_{n} C_{o x}\left(W_{2} / L_{2}\right)}}
$$

since N5 has the same $I_{D S}$ but is $(n+1)^{2}$ times smaller,

$$
\begin{aligned}
& \text { then } \quad V_{e f \delta}=(n+1) V_{e j} \\
& \text { and } \quad V_{\text {eff } 1}=V_{\text {eff } 4}=n V_{e f f}
\end{aligned}
$$

thus it is known that

$$
V_{G 5}=V_{G 4}=V_{G 1}=(n+1) V_{e f f}+V_{t h}
$$

furthermore, since $V_{G S 1}=V_{G S 4}$,

$$
\text { so } \quad V_{D S 2}=V_{D S 3}=V_{G 5}-V_{G S 1}=V_{G 5}-\left(n V_{e f f}+V_{t h}\right)=V_{e f f}
$$

This $V_{D S}$ puts $\mathrm{N} 2$ and $\mathrm{N} 3$ at the edge of linear region. Thus the minimum allowable output voltage is 


$$
V_{\text {out }}>V_{\text {eff } 1}+V_{\text {eff } 2}=(n+1) V_{\text {eff }}
$$

if $n=1$,

$$
\text { then } V_{\text {out }}>2 V_{\text {eff }}
$$

also it is required that

$$
V_{D S 4}>V_{e f f 4}=n V_{e f f}
$$

since

$$
V_{D S 4}=V_{G 3}-V_{D S 3}=\left(V_{e f f}+V_{t h}\right)-V_{e f f}=V_{t h}
$$

it is not hard to achieve.

A typical folded cascode amplifier was shown in Figure 3.5.

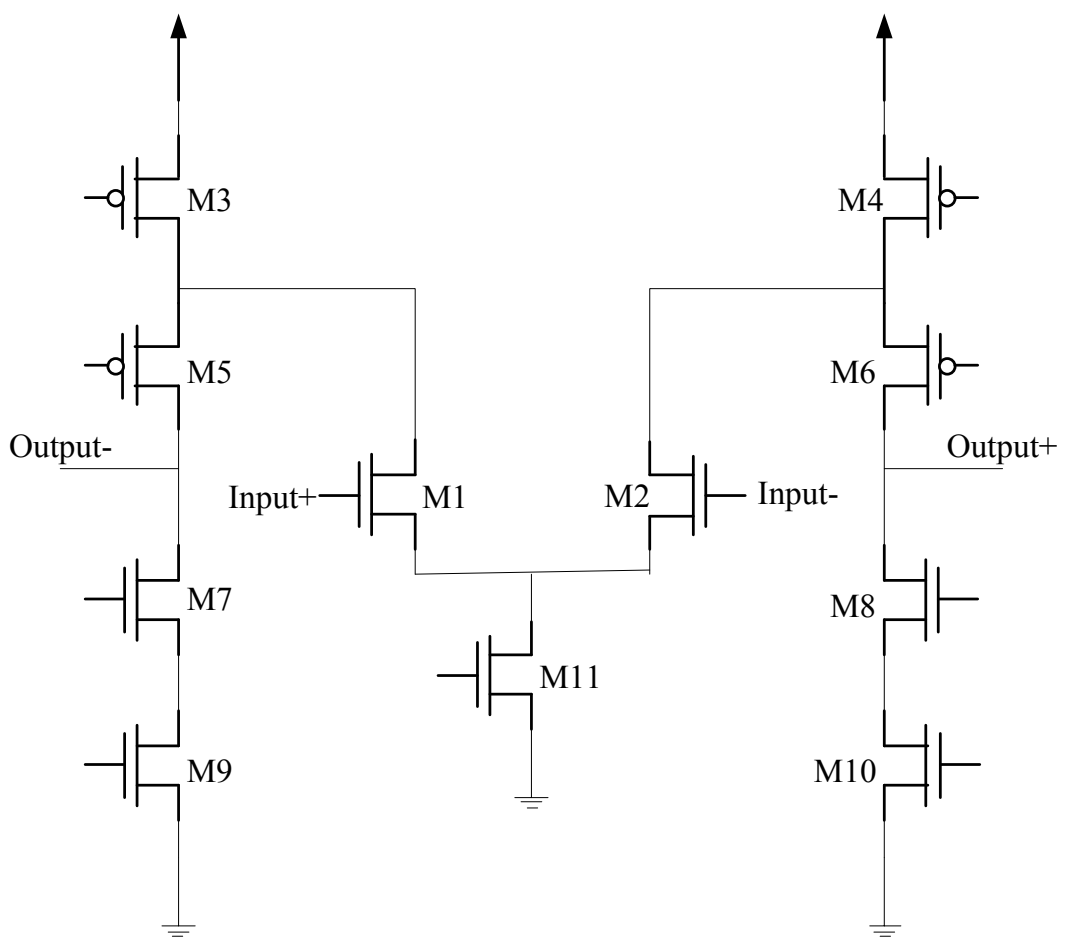

Figure 3.5: Folded Cascode Amplifier

The advantage of folded cascode amplifier is higher DC gain compared with a 
single stage differential amplifier, but output swing is limited due to the four stacks of transistors between VDD and GND. The wide swing current mirror is introduced for properly biasing the folded cascode amplifier at a lower voltage.

DC gain of the folded cascode is:

$$
\left|A_{v}\right|=g_{m 1}\left[\left(g_{m 5}+g_{m b 5}\right) R_{D S 5}\left(R_{D S 3} \| R_{D S 1}\right) \|\left(g_{m 7}+g_{m b 7}\right) R_{D S 7} R_{D S 9}\right]
$$

and the bandwidth is:

$$
\omega=\frac{1}{\left[\left(g_{m 5}+g_{m b 5}\right) R_{D S 5}\left(R_{D S 3} \| R_{D S 1}\right) \|\left(g_{m 7}+g_{m b 7}\right) R_{D S 7} R_{D S 9}\right]\left(C_{G D 7}+C_{G D 5}+C_{\text {load }}\right)}
$$

A folded cascode biased with wide swing current mirror was shown in Figure 3.6.

A larger version of Figure 3.6(a) was in Appendix 2.
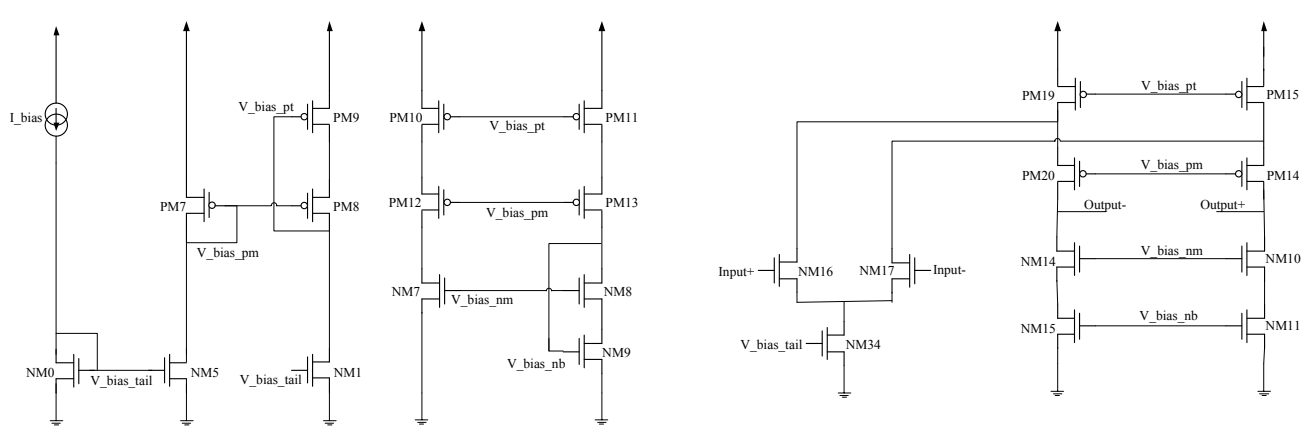

(a)
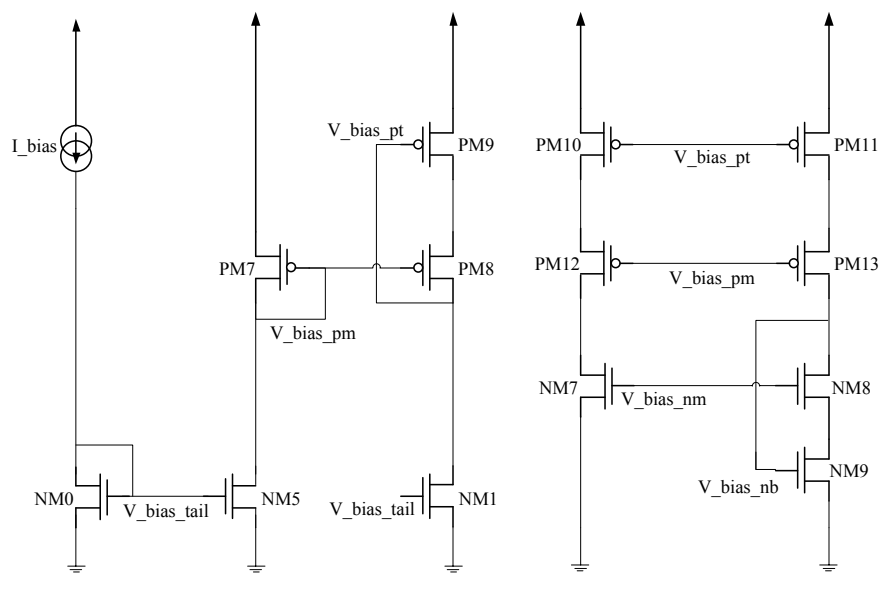

(b) 


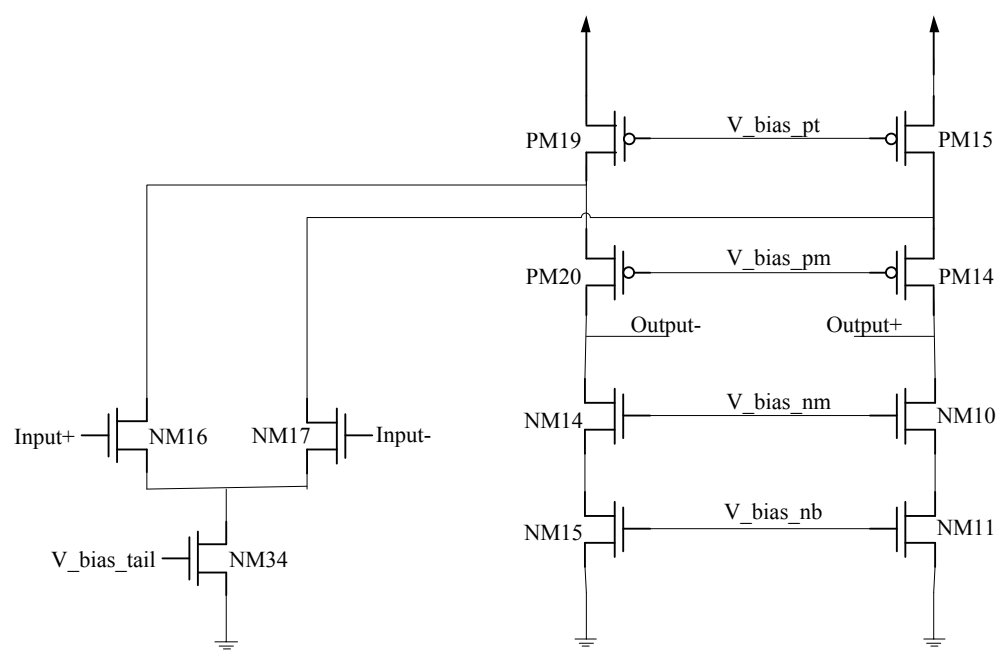

(c)

Figure 3.6: CMOS Folded Cascode Amplifier in GPDK $45 \mathrm{~nm}$ Technology (a) Biasing Circuit and Folded Cascode (b)Biasing Wide Swing Current Mirror (c) Folded Cascode

I_bias was set to $4 \mathrm{~mA}$, same as the differential amplifier. VDD was $1 \mathrm{~V}$. All the transistors sizes were listed in table 3.

Table 3. Transistor Sizes in Folded Cascode and Wide Swing Current Mirror

\begin{tabular}{|c|c|c|c|}
\hline Transistor & W/L & Transistor & W/L \\
\hline NM0 & $45 \mathrm{~nm} / 84 \mathrm{um}$ & PM7 & $45 \mathrm{~nm} / 16 \mathrm{um}$ \\
\hline NM5 & $45 \mathrm{~nm} / 84 \mathrm{um}$ & PM8 & $45 \mathrm{~nm} / 140 \mathrm{um}$ \\
\hline NM1 & $45 \mathrm{~nm} / 112 \mathrm{um}$ & PM9 & $45 \mathrm{~nm} / 100 \mathrm{um}$ \\
\hline NM7 & $45 \mathrm{~nm} / 12 \mathrm{um}$ & PM10 & $45 \mathrm{~nm} / 50 \mathrm{um}$ \\
\hline NM8 & $45 \mathrm{~nm} / 56 \mathrm{um}$ & PM11 & $45 \mathrm{~nm} / 50 \mathrm{um}$ \\
\hline
\end{tabular}




\begin{tabular}{|c|c|c|c|}
\hline NM9 & $45 \mathrm{~nm} / 64 \mathrm{um}$ & PM12 & $45 \mathrm{~nm} / 70 \mathrm{um}$ \\
\hline NM16 & $45 \mathrm{~nm} / 88 \mathrm{um}$ & PM13 & $45 \mathrm{~nm} / 72 \mathrm{um}$ \\
\hline NM17 & $45 \mathrm{~nm} / 88 \mathrm{um}$ & PM14 & $45 \mathrm{~nm} / 72 \mathrm{um}$ \\
\hline NM34 & $45 \mathrm{~nm} / 144 \mathrm{um}$ & PM15 & $45 \mathrm{~nm} / 96 \mathrm{um}$ \\
\hline NM10 & $45 \mathrm{~nm} / 56 \mathrm{um}$ & PM19 & $45 \mathrm{~nm} / 96 \mathrm{um}$ \\
\hline NM11 & $45 \mathrm{~nm} / 64 \mathrm{um}$ & PM20 & $45 \mathrm{~nm} / 72 \mathrm{um}$ \\
\hline NM14 & $45 \mathrm{~nm} / 56 \mathrm{um}$ & NM15 & $45 \mathrm{~nm} / 64 \mathrm{um}$ \\
\hline
\end{tabular}

The frequency response of this folded cascode amplifier was shown in Figure 3.7. The DC gain was $26.16 \mathrm{~dB}$, although the bandwidth was smaller than $1.5 \mathrm{GHz}$, the gain at $1.5 \mathrm{GHz}$ was $20.8 \mathrm{~dB}$, which was enough to compensate for $80 \mathrm{~m}$ Belden 1694A coaxial cable.

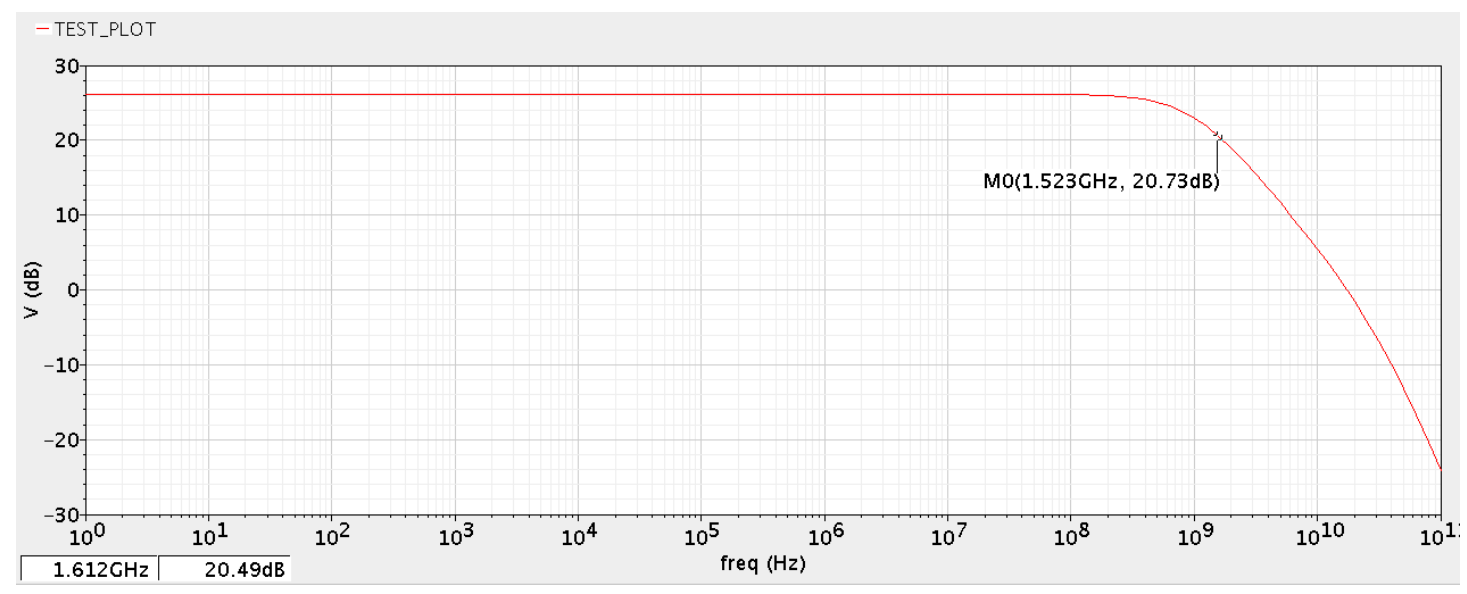

Figure 3.7: Frequency Response of the Folded Cascode Amplifier 
Since this amplifier was already able to offer enough gain, I used this folded cascode amplifier as pre-amplifier stage and used a VGA as attenuator only.

\subsection{Gilbert Cell and Folded Gilbert Cell}

A Gilbert cell consists of two differential amplifiers, as shown in Figure 3.8.

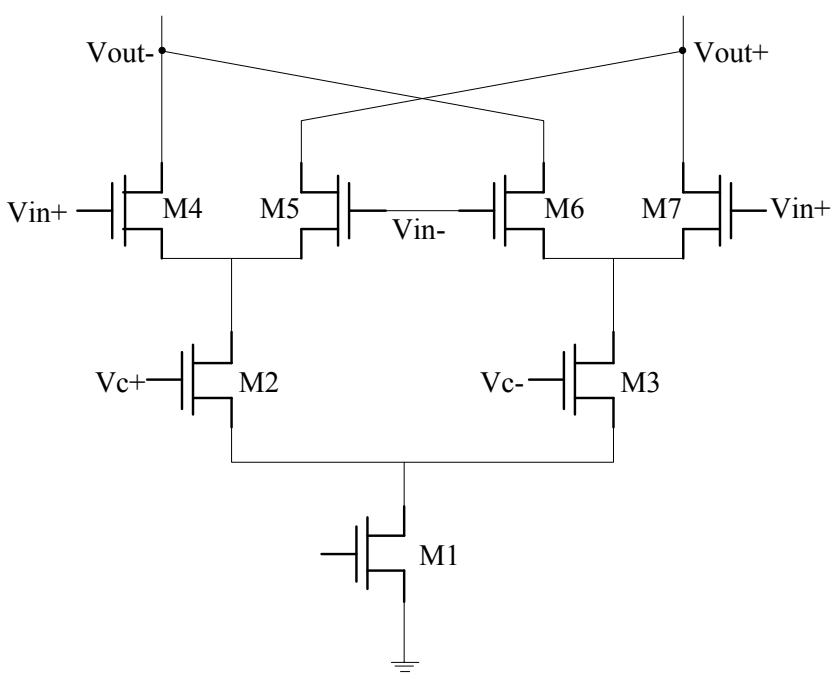

Figure 3.8: Gilbert Cell

Tail current from M1 splits into M2 and M3 and controlled by voltage pair Vc+ and Vc-. When Vc+ equals Vc- with same tail current, the two differential amplifiers will have equivalent performance, thus both of the outputs are 0 since M5-M6 and M4-M7 pairs will have fully differential outputs and cancel each other when coupled as shown. When $\mathrm{Vc}+$ and $\mathrm{Vc}$ - are not equal, $I_{D S 2}$ is not equal to $I_{D S 3}$, and 
$I_{D S 2}+I_{D S 3}=I_{D S 1}$. The current at Vout- is $\frac{I_{D S 2}-I_{D S 3}}{2}$ and current at Vout + is $\frac{I_{D S 3}-I_{D S 2}}{2}$, a fully differential output is generated, and the gain is tuned by $I_{D S 2}$ and $I_{D S 3}$. These currents are controlled by $\mathrm{Vc}-$ and $\mathrm{Vc}+$.

The maximum gain of the Gilbert cell appears when M2 or M3 is turned off and all tail current flows through the other transistor. The maximum gain of the Gilbert cell is roughly equal to sum of the two differential amplifier gains.

Considering the active load, there are four total stacked transistors in the Gilbert cell from VDD to GND. A folded version of Gilbert cell is presented in [11], [12], and [13], with three stacks only allowing for more headroom.

A folded Gilbert cell implemented in GPDK $45 \mathrm{~nm}$ technology was depicted in Figure 3.9. Transistors sizes were decided in the same way as the differential amplifier. An important fact was for best linearity performance, $\left(\frac{W}{L}\right)_{3 / 4} \approx \frac{1}{7}\left(\frac{W}{L}\right)_{1 / 2}$ should be used [14].

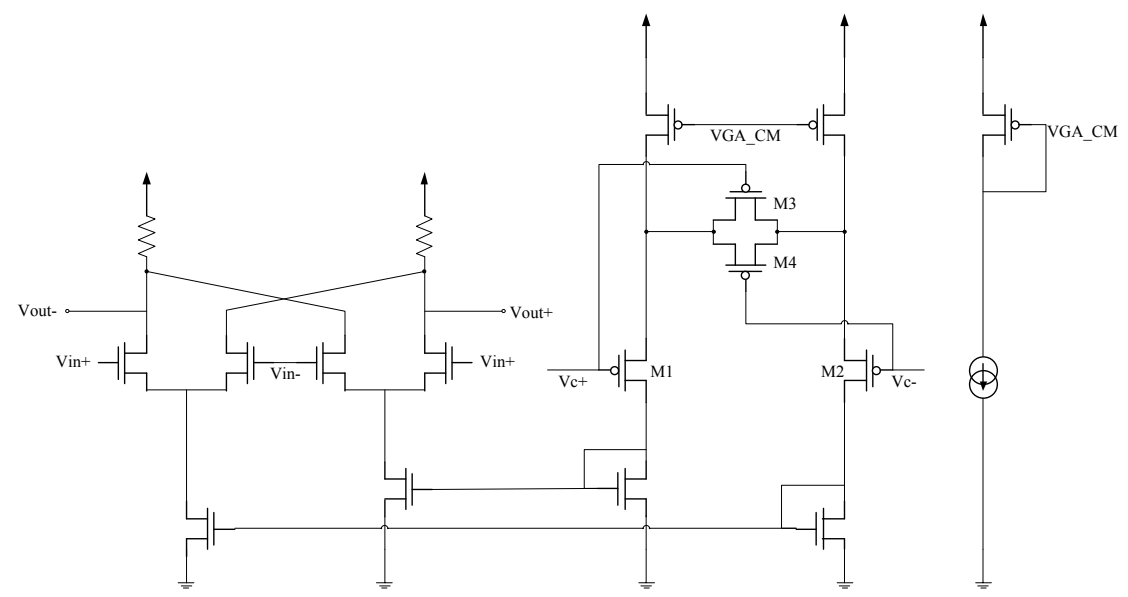

Figure 3.9: CMOS Folded Gilbert Cell in GPDK 45 nm Technology 
The result of the Gilbert cell was shown in Figure 3.10. Different V+ and V-pairs were used. Although the gain attenuation versus control voltage relationship was not linear, it was adequately controlled by properly selecting the control voltage pair.

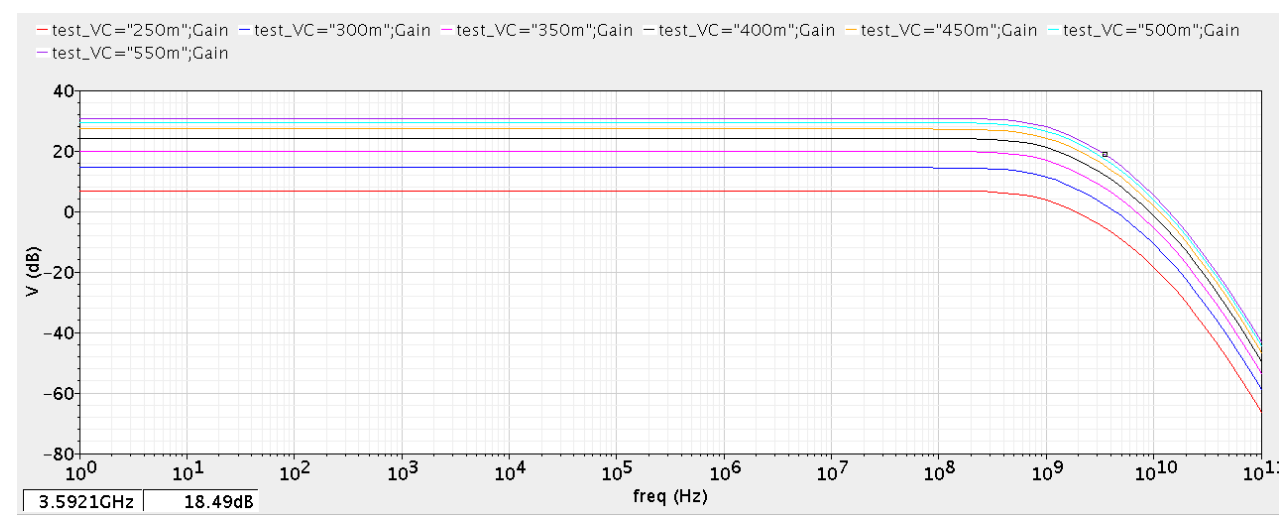

Figure 3.10: Folded Gilbert Tuning Results

\subsection{RC Degeneration}

$\mathrm{RC}$ degeneration is an effective method for tuning the frequency response curve close to the reverse cable characteristic. A schematic and frequency response was shown in Figure 3.11.

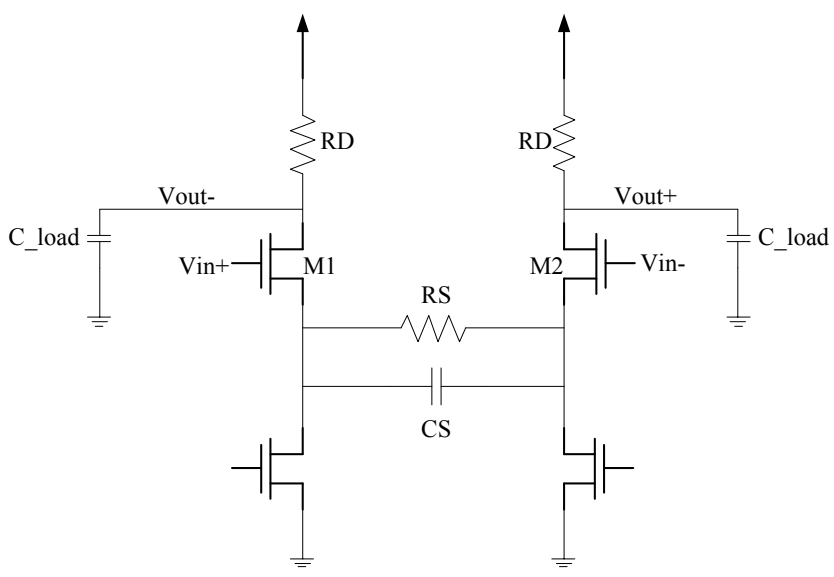

(a) 


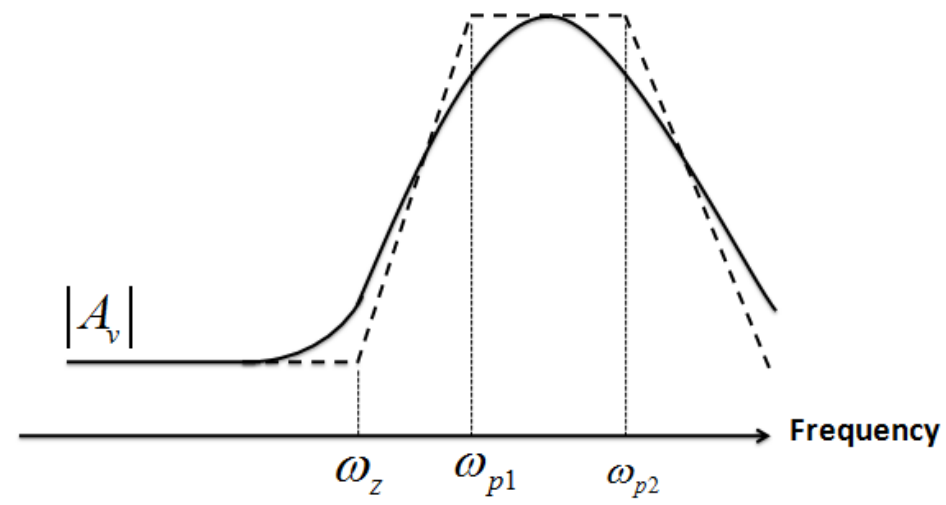

(b)

Figure 3.11: RC Degeneration (a) Schematic (b) Frequency Response

The zero-pole positions and DC gain are decided by:

$$
\begin{gathered}
\left|\omega_{z}\right|=\frac{1}{R_{S} C_{S}} \\
\left|\omega_{p 1}\right|=\frac{1}{R_{D} C_{L o a}} \\
\left|\omega_{p 2}\right|=\frac{1+\frac{\left(g_{m}+g_{m b}\right) R_{S}}{2}}{R_{S} C_{S}} \\
\left|A_{v}\right|=\frac{g_{m} R_{D}}{1+\frac{\left(g_{m}+g_{m b}\right) R_{S}}{2}}
\end{gathered}
$$

Extra zero and pole pairs can be generated by adding a resistor in series with a capacitor in parallel to Rs and Cs. This allows the tuning the frequency response more close to the reverse cable characteristic. Calculation about the extra zero and pole pair is complex, it is easier to tune them empirically through simulation. 
A target frequency response values at specific frequency points for $80 \mathrm{~m}$ Belden 1694A coaxial cable were listed in table 4.

Table 4. Target Frequency Response for $80 \mathrm{~m}$ Belden 1694A Coaxial Cable

\begin{tabular}{|c|c|c|c|c|c|}
\hline Frequency & $1 \mathrm{MHz}$ & $10 \mathrm{MHz}$ & $100 \mathrm{MHz}$ & $1 \mathrm{GHz}$ & $1.5 \mathrm{GHz}$ \\
\hline Boosting & Almost & & & & \\
Value & $0 \mathrm{~dB}$ & $1.7 \mathrm{~dB}$ & $4.9 \mathrm{~dB}$ & $17.1 \mathrm{~dB}$ & $21 \mathrm{~dB}$ \\
\hline
\end{tabular}

\subsection{Folded Cascode Amplifier Type Equalizer Stage}

Combining the folded cascode amplifier implemented before with the folded Gilbert cell, an equalizer stage was generated, then the frequency response was tuned following the values from table 4 .

The schematic and the simulation results were shown in Figure 3.12. A larger version of Figure 3.12(a) was in Appendix 3.

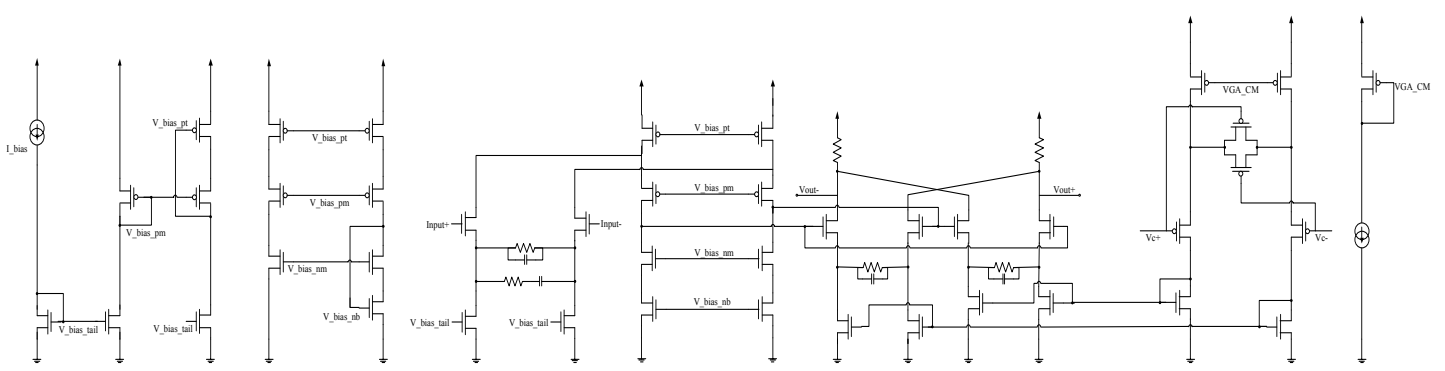

(a) 


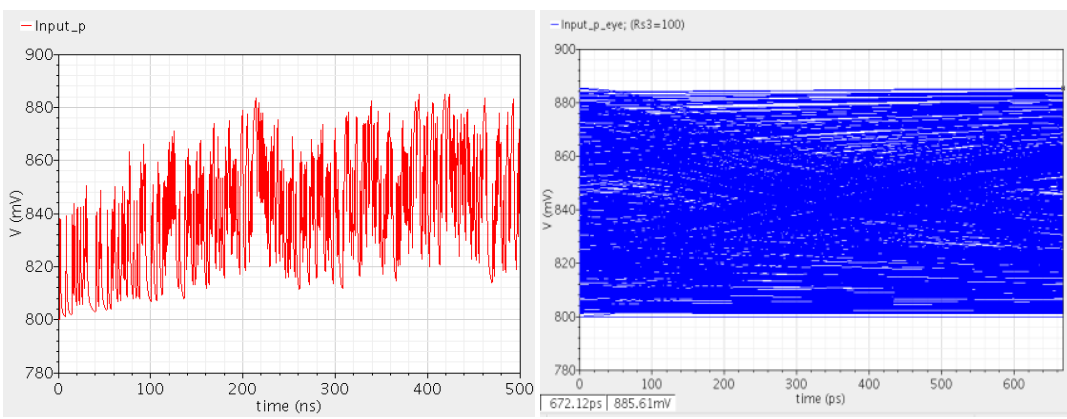

(b)

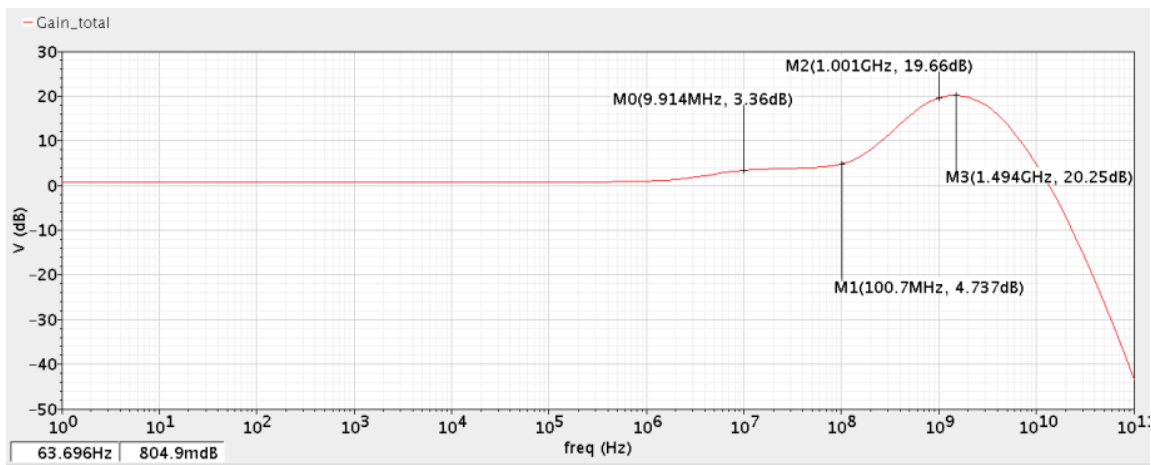

(c)

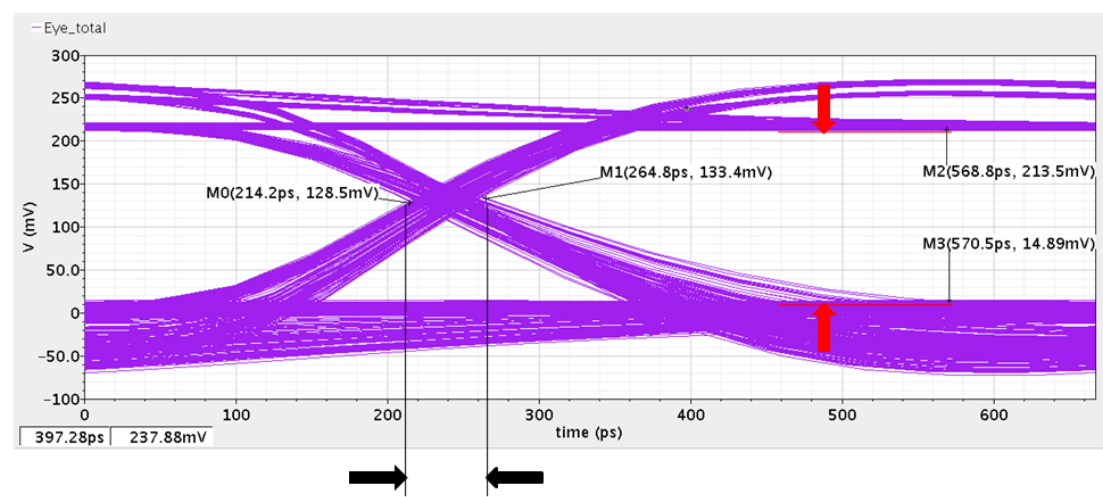

\section{Peak-to-Peak Jitter}

$\frac{264.8 p s-214.2 p s}{666.7 p s}=0.076 U I$

\section{Eye Height}

$213.5 m V-14.89 m V$

$=198.61 \mathrm{mV}$

(d)

Figure 3.12: Folded Cascode Amplifier Type Equalizer Stage (for $80 \mathrm{~m}$ Belden 1694A Coaxial Cable) (a) Schematic (b) Input Signal and Eye Diagram $\quad$ (c) Frequency Response of the Stage (d) Output Eye Diagram 
A $200 \mathrm{mV}$ PRBS-23 input signal was processed by a $80 \mathrm{~m}$ cable model in Matlab environment, output signal of the cable model was imported to Cadence as simulation input as shown in Figure 3.12(b). The equalizer stage frequency response was shown in Figure 3.12(c). Mismatch was not able to be eliminated completely, which caused the unstable DC level and overshoot shown in Figure 3.12(d). However, the eye height was almost $200 \mathrm{mV}$ and the peak-to-peak jitter was only $0.077 \mathrm{UI}$.

\subsection{Differential Amplifier Type Equalizer Stage}

Another equalizer stage was implemented by using both a single stage differential amplifier and the VGA as preamplifier stage. The equalizer frequency response was tuned in same way as the folded cascode amplifier type equalizer stage.

The schematic and the simulation results were shown in Figure 3.13. A larger version of Figure 3.13(a) was in Appendix 4.

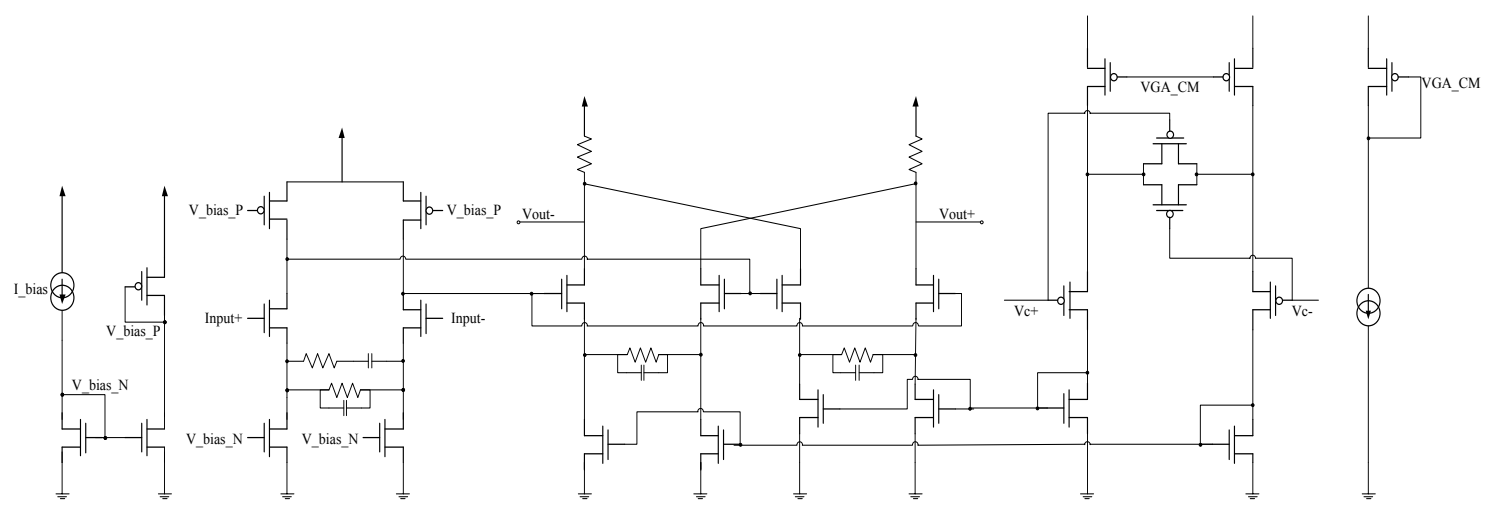

(a) 


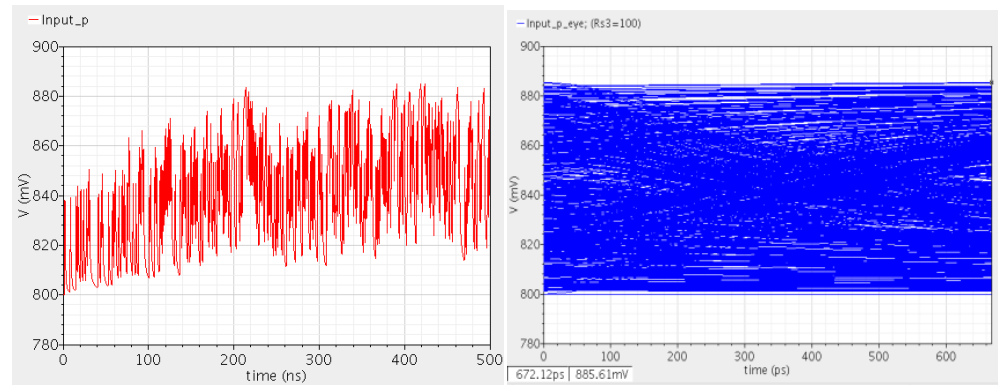

(b)

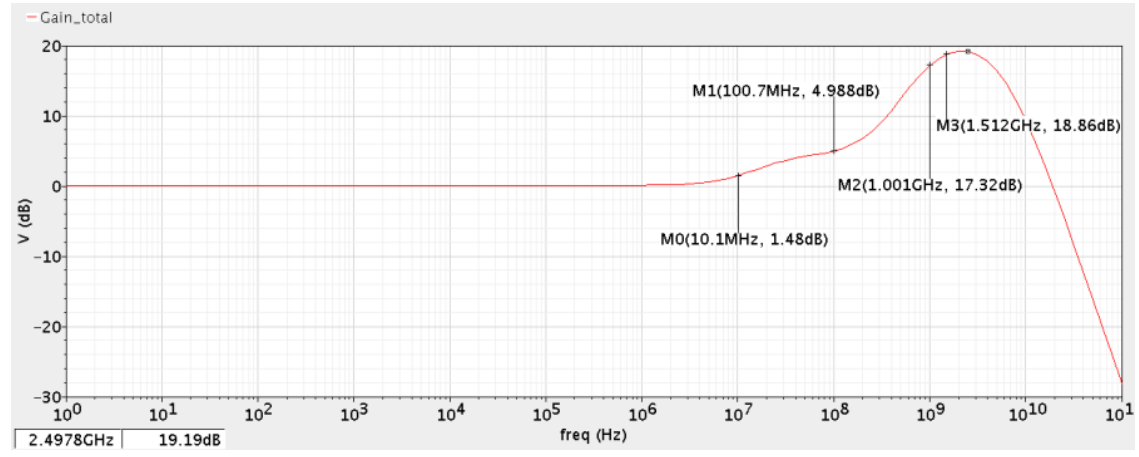

(c)

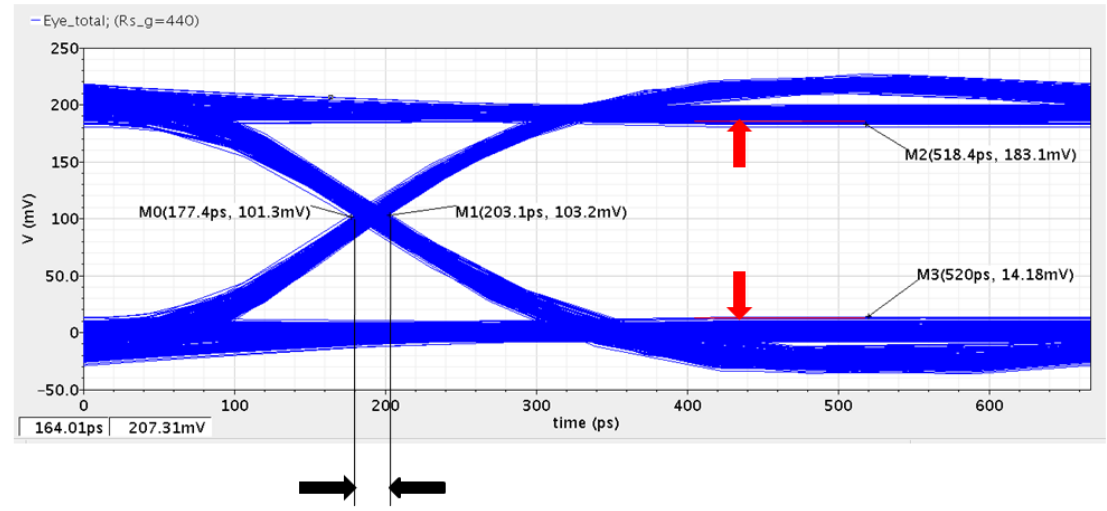

Peak-to-Peak Jitter

$\frac{203.1 \mathrm{ps}-177.4 \mathrm{ps}}{666.7 \mathrm{ps}}=0.039 \mathrm{UI}$
Eye Height

$183.1 \mathrm{~m} V-14.18 \mathrm{mV}$

$=168.92 \mathrm{mV}$

(d)

Figure 3.13: Differential Amplifier Type Equalizer Stage (for $80 \mathrm{~m}$ Belden 1694A Coaxial Cable) (a) Schematic (b) Input Signal and Eye Diagram (c) Frequency Response of the Stage (d) Output Eye Diagram 
The equalizer frequency response was tuned differently in this stage so the peak-to-peak jitter reduced by half whereas the eye height dropped slightly.

Peak-to-peak jitter and eye height in this case cannot be optimized together, since in order to fully compensate for an 80 m Belden 1694A coaxial cable attenuation, the equalizer frequency response should boost up $17 \mathrm{~dB}$ at $1 \mathrm{GHz}$ and $21 \mathrm{~dB}$ at $1.5 \mathrm{GHz}$, a first order zero in frequency response cannot afford such a high slope. If $21 \mathrm{~dB}$ at 1.5 $\mathrm{GHz}$ is matched, there will be a mismatch at $1 \mathrm{GHz}$, causing a peak-to-peak jitter increment, otherwise if $17 \mathrm{~dB}$ at $1 \mathrm{GHz}$ is matched, the equalizer can offer only 18.86 $\mathrm{dB}$ gain at $1.5 \mathrm{GHz}$, which causes an eye height decrease.

\subsection{Adaptive Simulation Results and Cascade Simulation Results}

The adaptive ability was also tested in chapter 2.4 of this thesis. The $\alpha$ value should be 0.41 when the cable length was $40 \mathrm{~m}$. Following same way, a PRBS-23 data was processed in Matlab environment with $40 \mathrm{~m}$ cable model, the output was imported to Cadence as input of the simulation. Since $20 \times \log _{10}(0.41)=-7.7 d B$, and also:

$$
E_{q}(s)=1+\alpha H(s)=1+\alpha\left(\frac{1}{C_{\max }(s)}-1\right)=(1-\alpha)+\alpha \cdot \frac{1}{C_{\max }(s)}
$$

By properly tuning the control voltage of the VGA, the frequency response dropped by $7.7 \mathrm{~dB}$, then add 0.4 times of the input signal to the output signal. 
The final output was shown in Figure 3.14. It matched the results in Figure 2.17 very well.

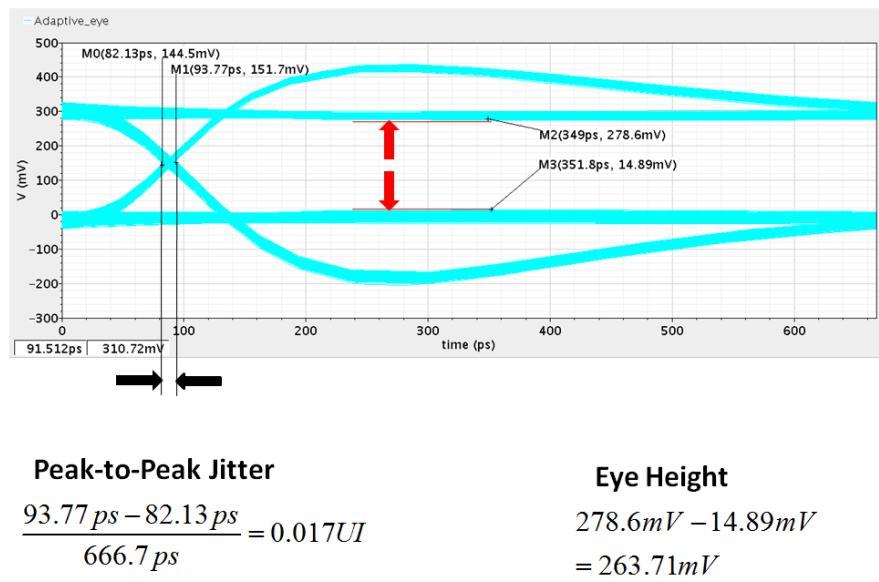

Figure 3.14: Differential Amplifier Type Equalizer Stage Adaptive Output

PRBS-23 data was process with 240 m cable model in Matlab environment and imported to Cadence as the input of three cascade equalizer stages. The input and output of every stage was illustrated in Figure 3.15. Differential amplifier equalizer stages were used, the targeting frequency response and the circuit frequency response were listed in Table 5.

Table 5. Targeting Frequency Response and Circuit Frequency Response of Differential Amplifier Equalizer Stages

\begin{tabular}{|c|c|c|c|c|c|}
\hline Frequency & $1 \mathrm{MHz}$ & $10 \mathrm{MHz}$ & $100 \mathrm{MHz}$ & $1 \mathrm{GHz}$ & $1.5 \mathrm{GHz}$ \\
\hline $\begin{array}{c}\text { Targeting } \\
\text { Frequency } \\
\text { Response }\end{array}$ & $\begin{array}{c}\text { Almost } \\
0 \mathrm{~dB}\end{array}$ & $1.7 \mathrm{~dB}$ & $4.9 \mathrm{~dB}$ & $17.1 \mathrm{~dB}$ & $21 \mathrm{~dB}$ \\
\hline $\begin{array}{c}\text { Circuit } \\
\text { Frequency } \\
\text { Response }\end{array}$ & $\begin{array}{c}\text { Almost } \\
0 \mathrm{~dB}\end{array}$ & $1.4 \mathrm{~dB}$ & $4.98 \mathrm{~dB}$ & $17.32 \mathrm{~dB}$ & $18.86 \mathrm{~dB}$ \\
\hline
\end{tabular}




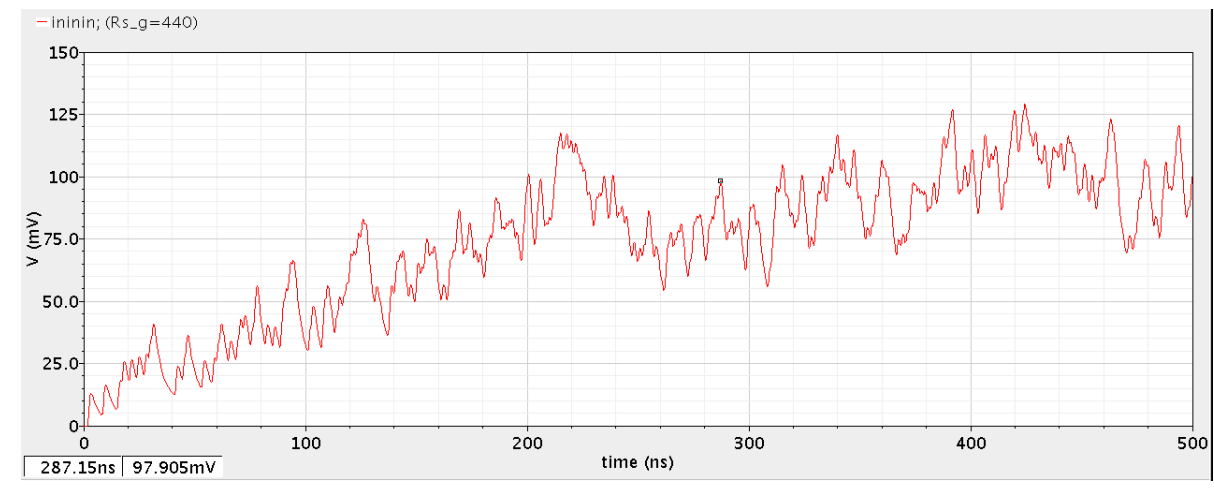

(a)

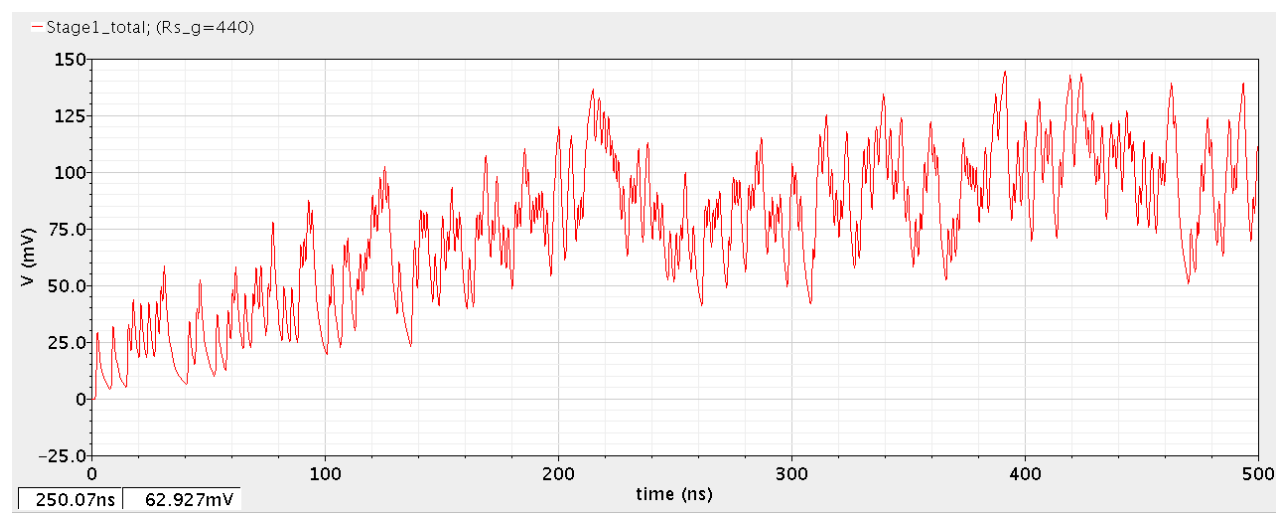

(b)

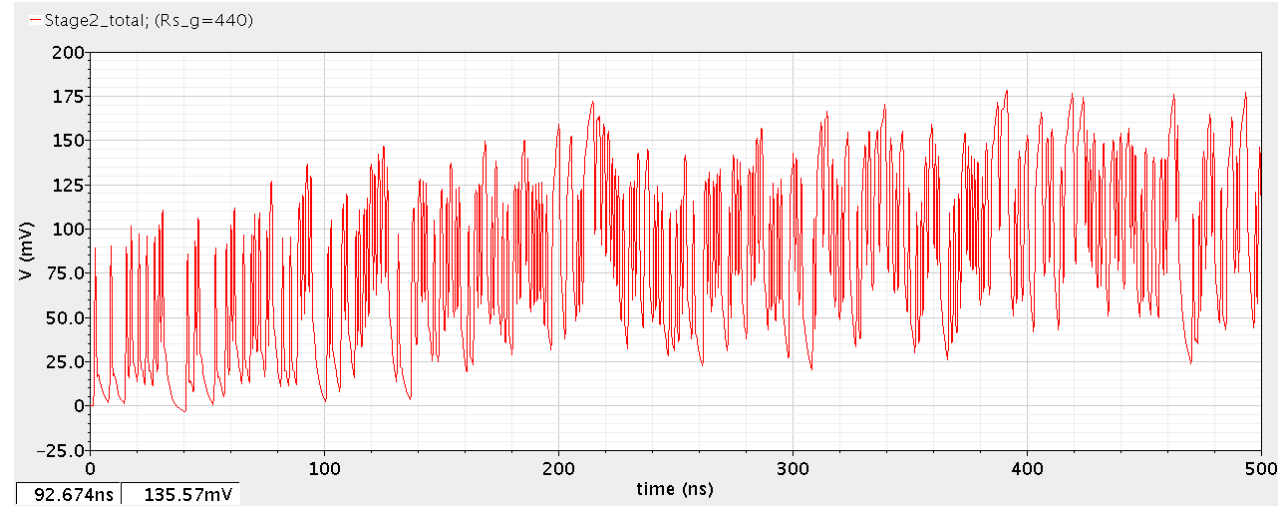

(c) 


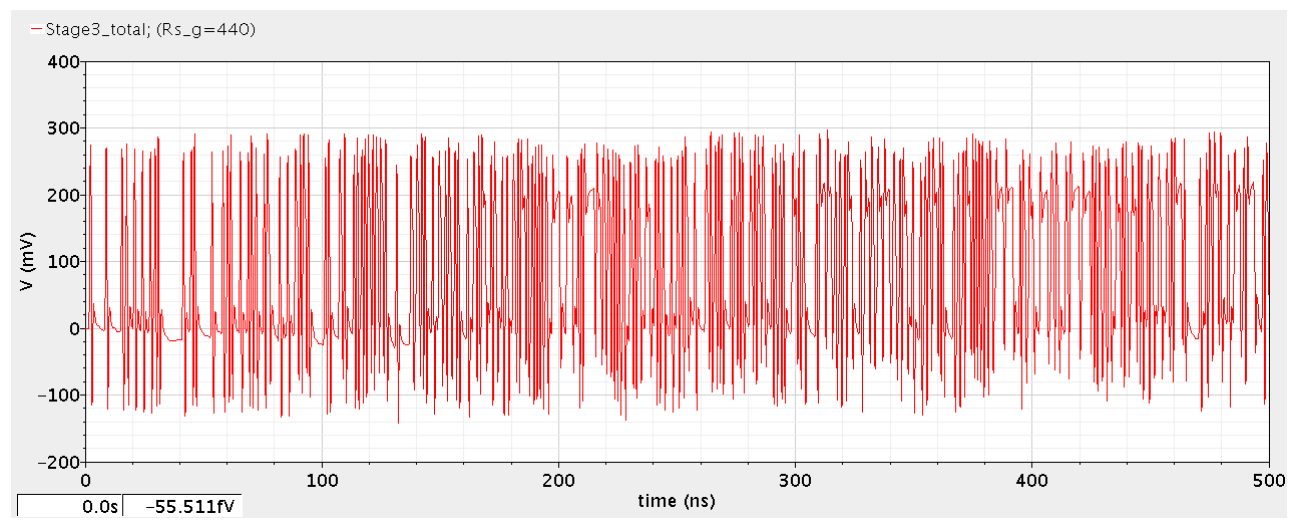

(d)

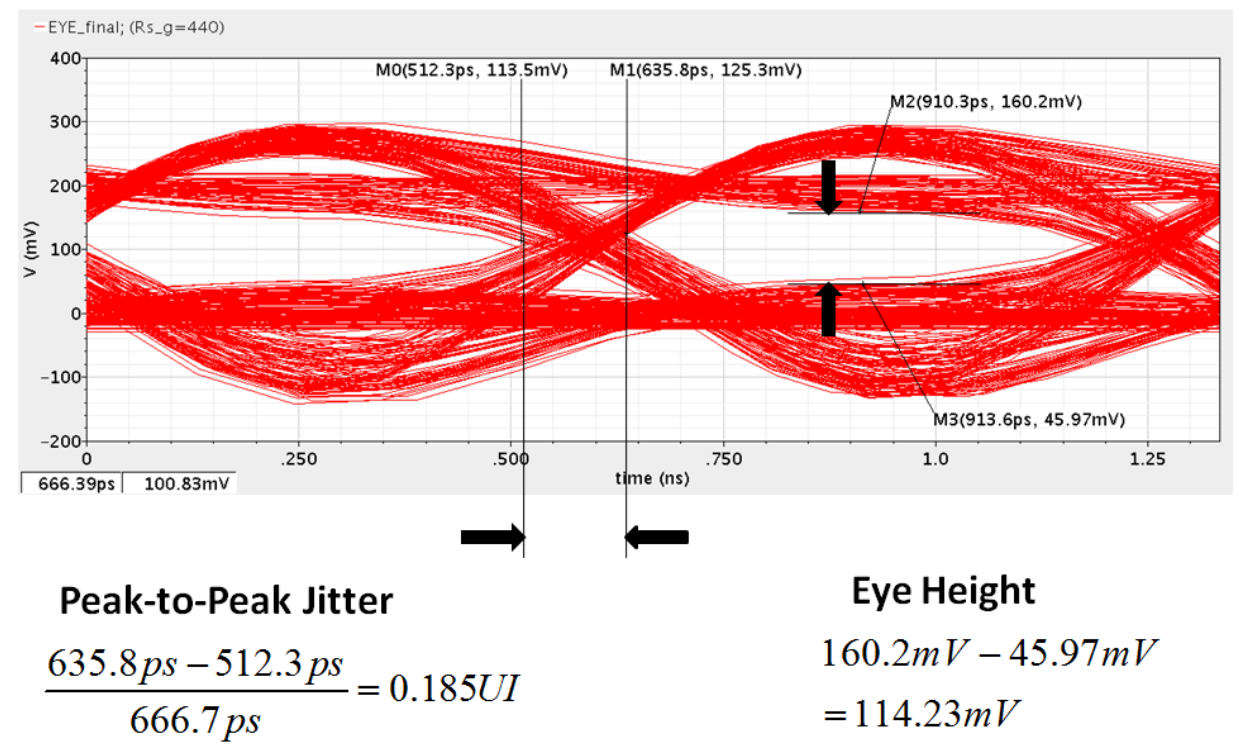

(e)

Figure 3.15: Differential Amplifier Type Equalizer Stage Cascade Results

Input (b) Output of the First Equalizer Stage $\quad$ (c) Output of the Second Equalizer Stage (d) Output of the Third Equalizer Stage (e) Final Output Eye Diagram

Replacing all the differential amplifier equalizer stages by folded cascode amplifier equalizer stages, using the same input signal as above, the input and output of every stage was illustrated in Figure 3.16 and the targeting frequency response and the circuit frequency response were listed in Table 6. 
Table 6. Targeting Frequency Response and Circuit Frequency Response of Folded Cascode Amplifier Equalizer Stages

\begin{tabular}{|c|c|c|c|c|c|}
\hline Frequency & $1 \mathrm{MHz}$ & $10 \mathrm{MHz}$ & $100 \mathrm{MHz}$ & $1 \mathrm{GHz}$ & $1.5 \mathrm{GHz}$ \\
\hline $\begin{array}{c}\text { Targeting } \\
\text { Frequency } \\
\text { Response }\end{array}$ & $\begin{array}{c}\text { Almost } \\
0 \mathrm{~dB}\end{array}$ & $1.7 \mathrm{~dB}$ & $4.9 \mathrm{~dB}$ & $17.1 \mathrm{~dB}$ & $21 \mathrm{~dB}$ \\
\hline $\begin{array}{c}\text { Circuit } \\
\text { Frequency } \\
\text { Response }\end{array}$ & $\begin{array}{c}\text { Almost } \\
0 \mathrm{~dB}\end{array}$ & $3.36 \mathrm{~dB}$ & $4.74 \mathrm{~dB}$ & $19.66 \mathrm{~dB}$ & $20.25 \mathrm{~dB}$ \\
\hline
\end{tabular}

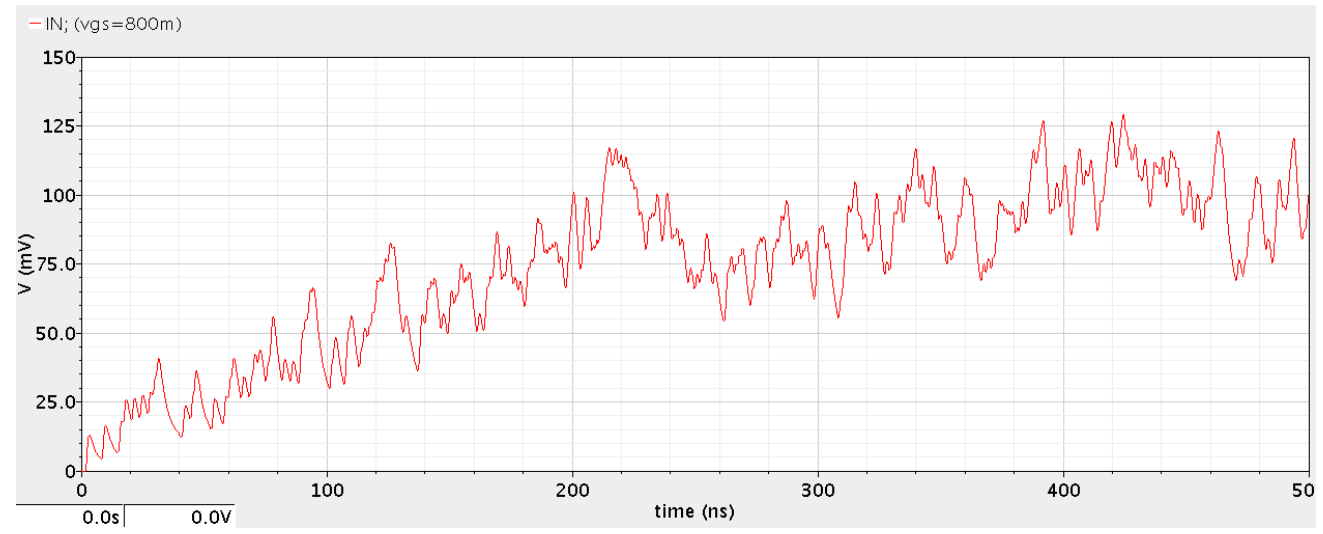

(a)

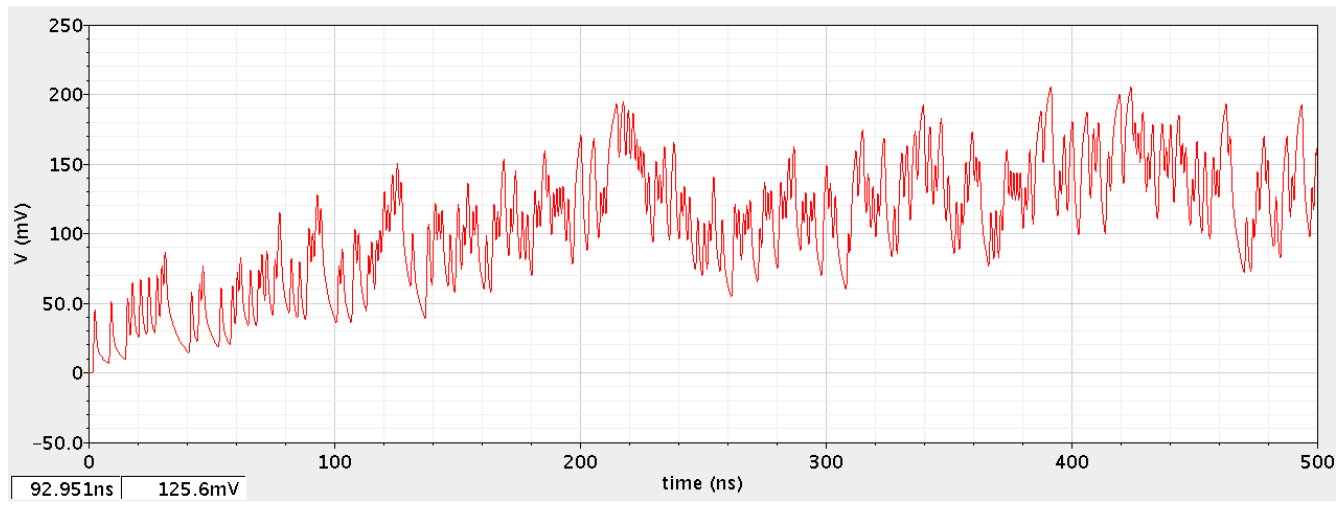

(b) 


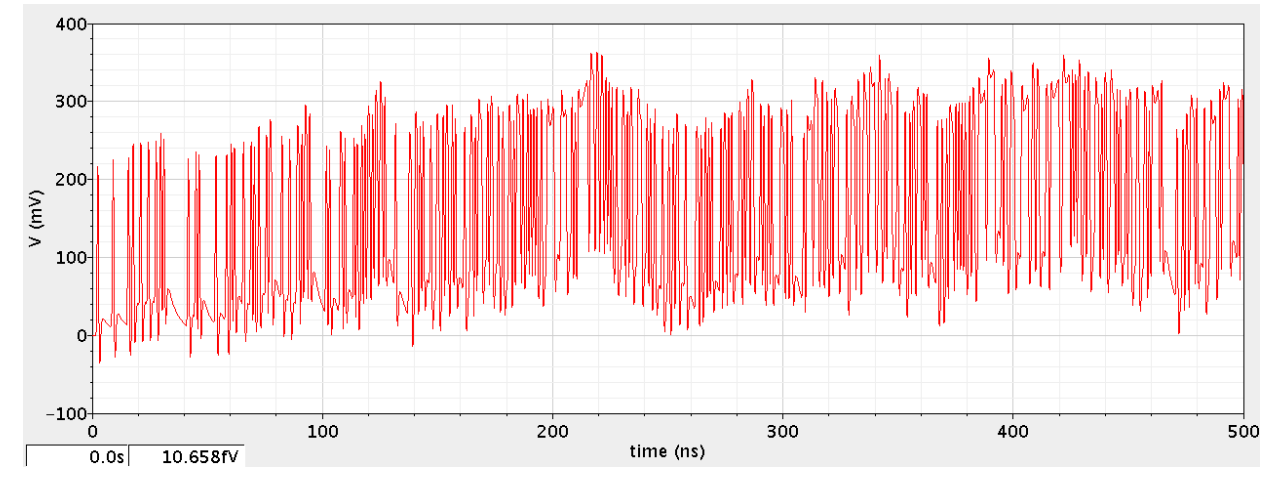

(c)

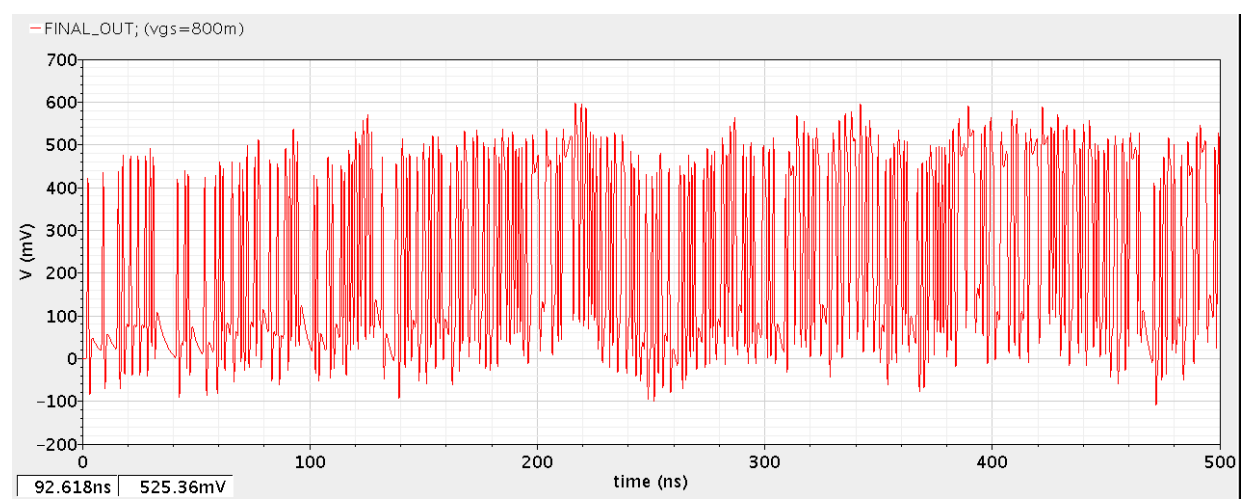

(d)

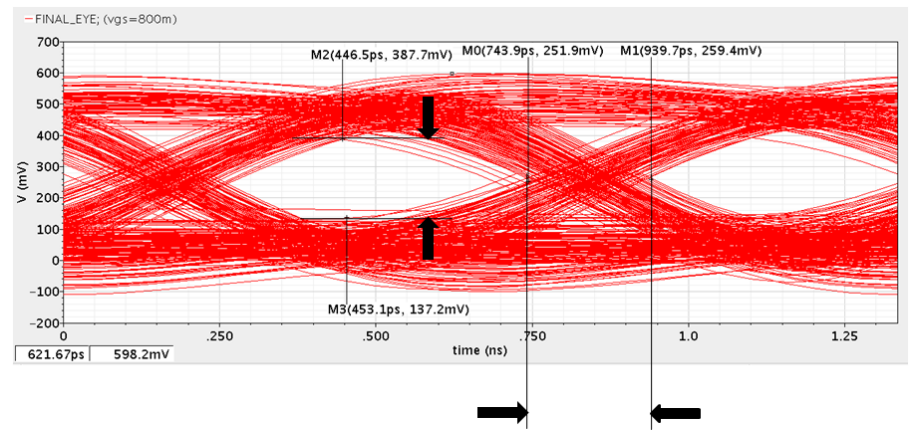

Peak-to-Peak Jitter

$\frac{939.7 p s-743.9 p s}{666.7 p s}=0.294 U I$
Eye Height

$387.7 \mathrm{mV}-137.2 \mathrm{mV}$

$=250.5 \mathrm{mV}$

(e)

Figure 3.16: Folded Cascode Amplifier Type Equalizer Stage Cascade Results $\begin{array}{lll}\text { (a) Input (b) Output of the First Equalizer Stage } & \text { (c) Output of the Second }\end{array}$ Equalizer Stage (d) Output of the Third Equalizer Stage (e) Final Output Eye Diagram 
The frequency response at $1 \mathrm{GHz}$ and $1.5 \mathrm{GHz}$ can not be satisfied together due to the first order filter frequency response slope. The results shown in Figure 3.15 and Figure 3.16 illustrated the tradeoff between the two scenarios. If the frequency response at $1 \mathrm{GHz}$ was satisfied, the response at $1.5 \mathrm{GHz}$ had roughly a $2 \mathrm{~dB}$ error and caused a $6 \mathrm{~dB}$ attenuation on eye height at the final output. This could be seen in the simulation result. If the frequency response at $1.5 \mathrm{GHz}$ was satisfied, the frequency response at $1 \mathrm{GHz}$ was $2 \mathrm{~dB}$ higher than needed. This increased the final jitter from 0.2 UI to $0.3 \mathrm{UI}$, also shown in the simulation result.

\section{Chapter 4. Conclusion and Future Work}

In this thesis, a genetic algorithm was used for modeling the coaxial cable frequency response characteristics, the maximum error was limited within $0.25 \mathrm{~dB}$. Aiming at a 1080P full HD video signal with $1.5 \mathrm{Gbps}$ data rate, an adaptive equalizer system-level model with QFB block was built and tested by cable models with different cable lengths. Two circuits based on different amplifiers are implemented in GPDK $45 \mathrm{~nm}$ technology, both circuits are working as single adaptive equalizer stages. Two tuning methods are used and corresponding results are compared. Adaptive ability are tested and the results are compared with model simulation results. A cascade of three equalizer stages was tested in the end, two different structures are used and the results are compared. 
This work aims to transfer existing BJT and BiCMOS design into CMOS implementation. Adaptive control mechanism and QFB block is not implemented in circuit level. Frequency response tuning is still an open problem since jitter and eye height cannot be optimized together unless decrease the cable length. It will be a valuable work if an mathematic model about frequency response tuning can be found. QFB and control block also need to be designed and the complete circuit will be fabricated and tested. 


\section{References}

[1] Martin J. Van Der Burgt, "Coaxial Cable and Applications,", Belden Electronics Division.

[2] Shakiba, M.H., "A 2.5 Gb/s Adaptive Cable Equalizer," Solid-State Circuits Conference, 1999. Digest of Technical Papers. ISSCC. 1999 IEEE International, pp.396-397, 1999.

[3] Andreea Balteanu, "Coaxial Cable Equalization Techniques at 50-110 Gbps," M.S. Thesis, Dept. Elect. Eng., Univ. of Toronto, 2010.

[4] Hao Liu, "Analog Equalizers for High-Speed Wire-Line Data Communications," Ph.D. dissertation, Dept. Elect. Eng., Univ. of Texas at Dallas, 2010.

[5] Wiki-pedia, "Jitter," [online]. Available: http://en.wikipedia.org/wiki/Jitter

[6] Wiki-pedia, "Genetic Algorithm," [online]. Available: http://en.wikipedia.org/wiki/Genetic_algorithm

[7] Narges, S.H.,"An automated design flow for cable equalizer in data communication systems," M.S. Thesis, Dept. Elect. Eng., Univ. of Toronto, 1999.

[8] Wiki-pedia, "Capacitive Coupling," [online]. Available: http://en.wikipedia.org/wiki/Capacitive_coupling

[9] B. Razavi, Design of Analog CMOS Integrated Circuits, 1st ed. New York: McGraw-Hill, 2003.

[10] D.A.Johns,K.Martin.(1997). Advanced Current Mirrors and Opamps [online]. Available: http://ee.sharif.edu/ elec3/06_advanced_opamps.pdf

[11] I.Kim et al. " CMOS Ultrasound Transceiver Chip for High-Resolution Ultrasonic Imaging Systems," IEEE Transactions on Biomedical and Systems, vol. 3, no. 5, pp.293-303, October, 2009.

[12] C.F.Liao, S.L.Liu, "A 10Gb/s CMOS Amplifier with 35dB Dynamic Range for 10Gb Ethernet," ISSCC Dig. Tech. Paper, Feb., 2006 
[13] C.H.Wu, C.S.Liu and S.L.Liu, "A 2GHz CMOS Variable-Gain Amplifier with 50dB Linear-in-Magnitude Controlled Gain Range for 10Gbase-LX4 Ethernet," ISSCC Dig. Tech. Paper, pp.484-485, Feb., 2004

[14] F.Krummenacher, N.Joehl, "A 4-MHz CMOS Continuous-Time Filter with On-Chip Automatic Tuning," IEEE J. Solid-State Circuits, vol. 23, pp.750-758, June, 1988. 


\section{Appendix}

1. Model of A Single Adaptive Equalizer Stage

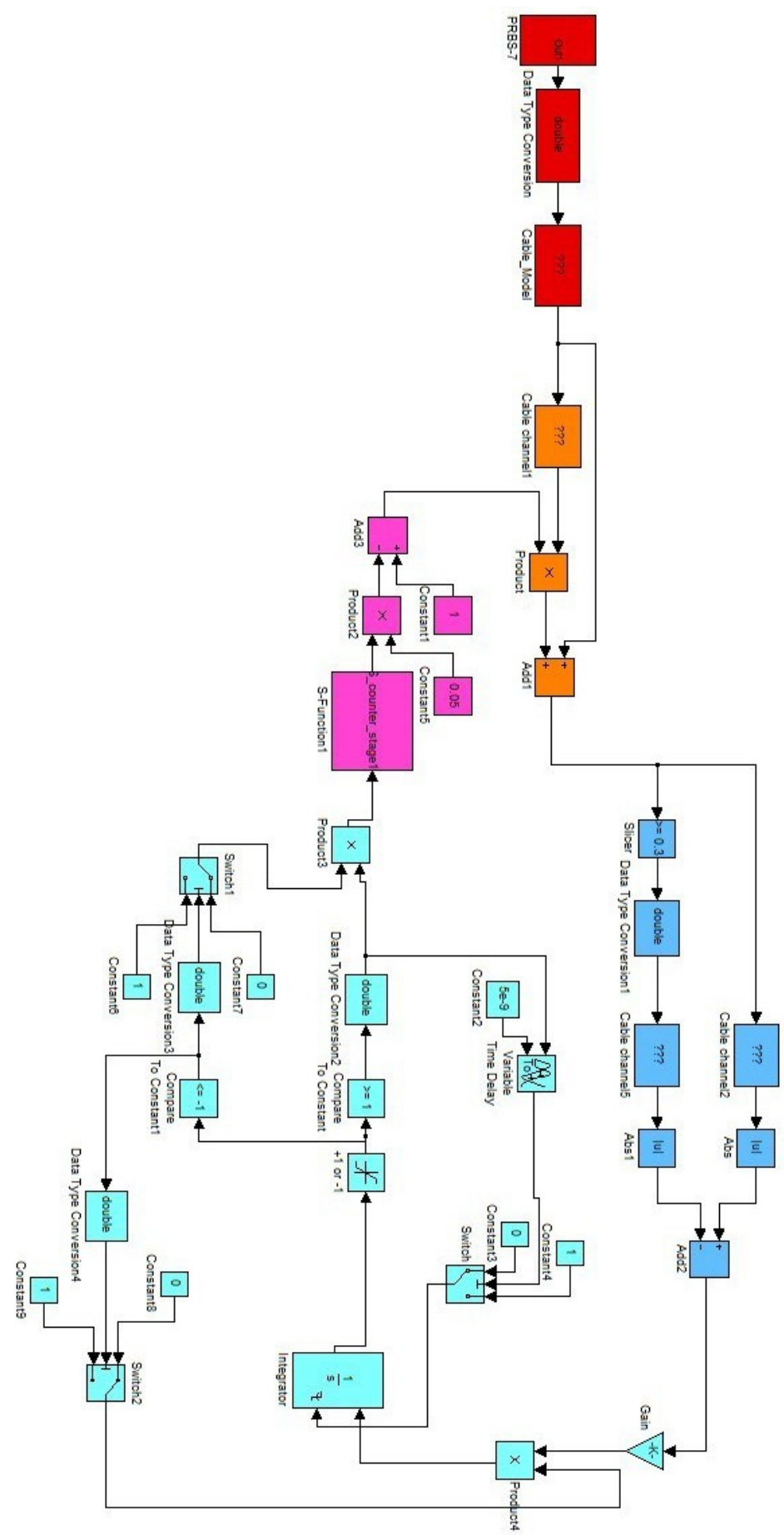


2. CMOS Folded Cascode Amplifier in GPDK $45 \mathrm{~nm}$ Technology
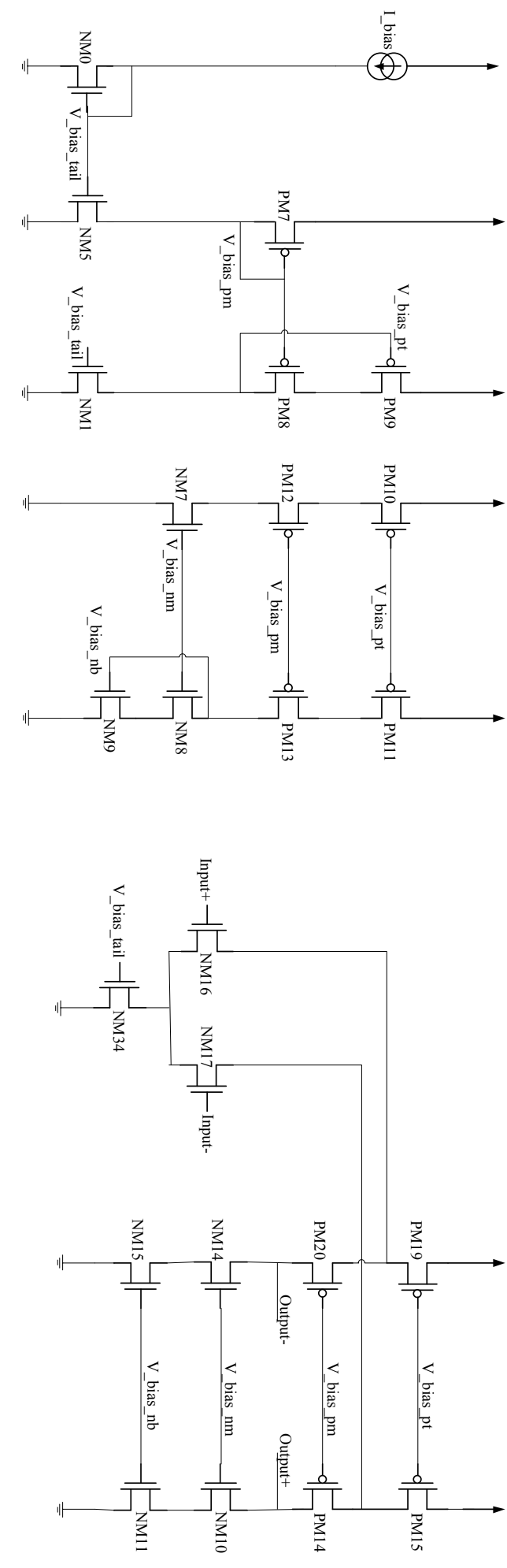
3. Folded Cascode Amplifier Type Equalizer Stage
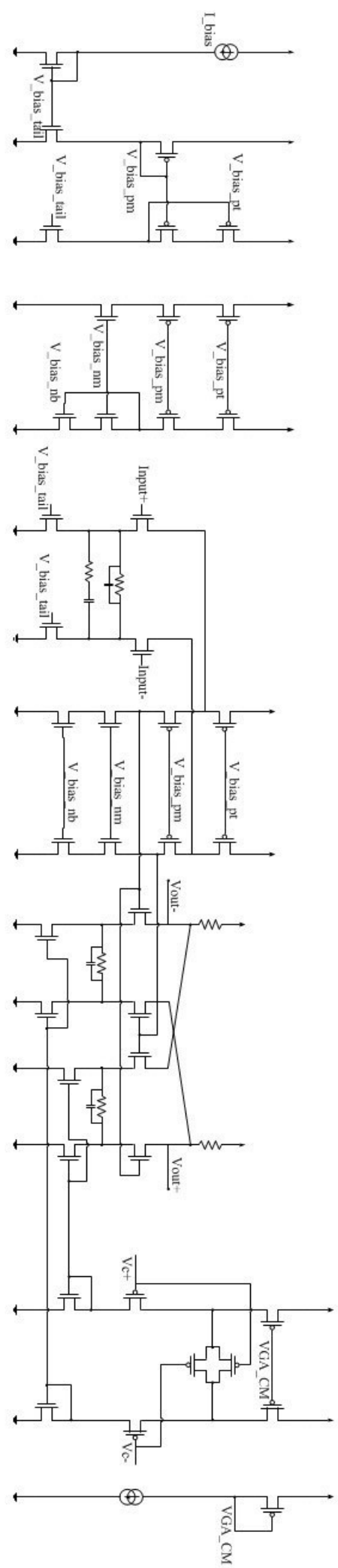


\section{Differential Amplifier Type Equalizer Stage}

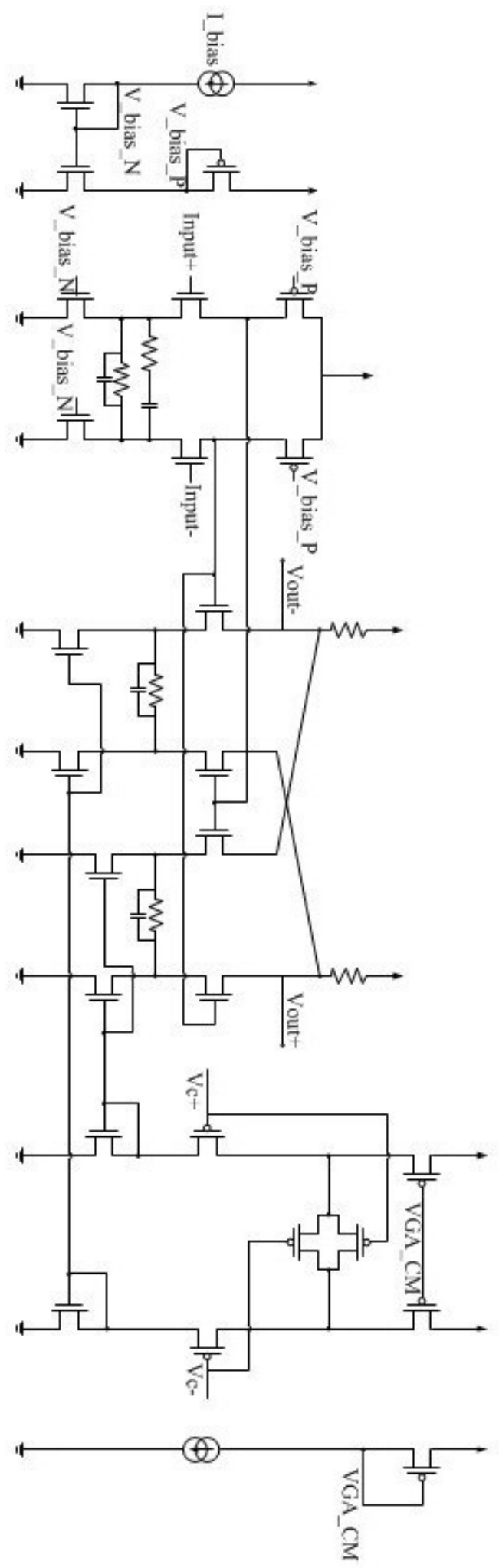

